
(1) tof

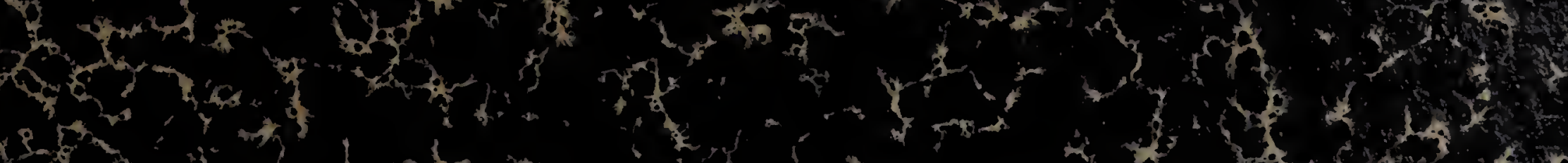

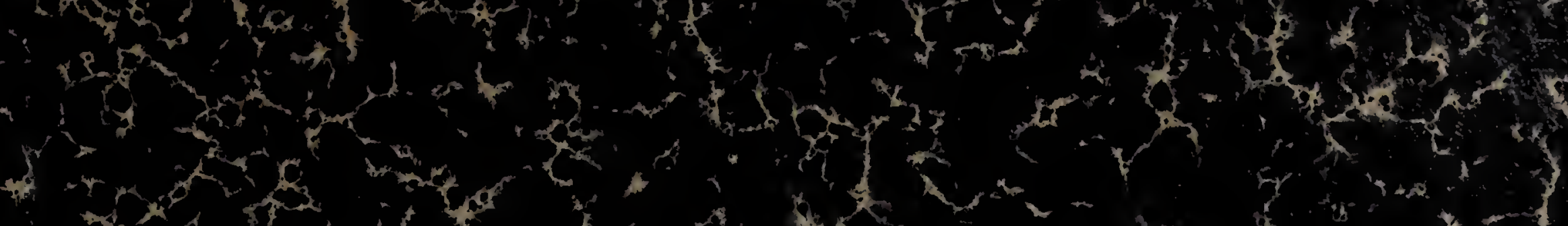

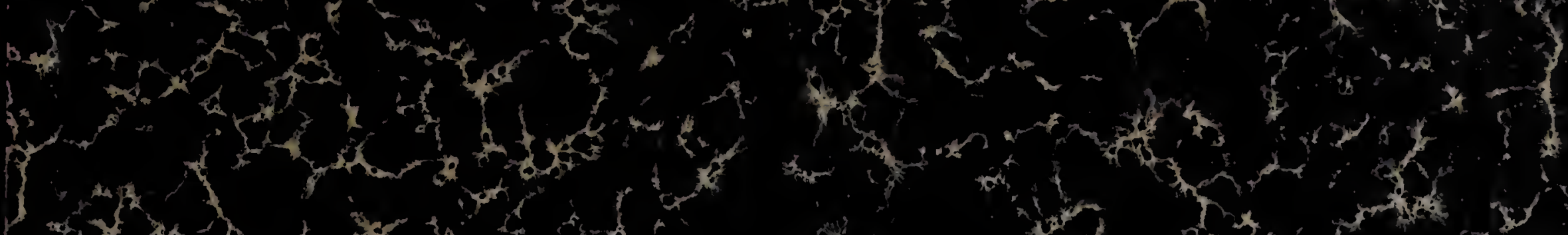

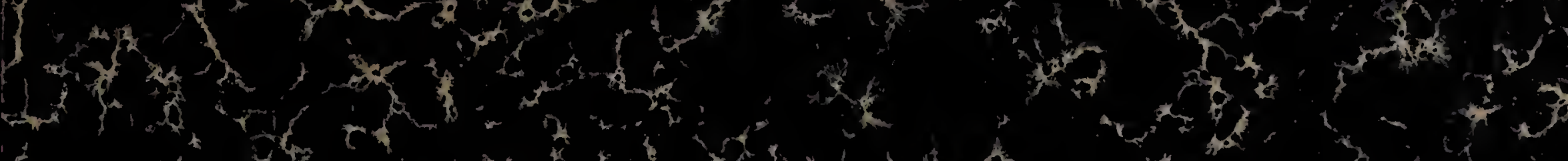
int

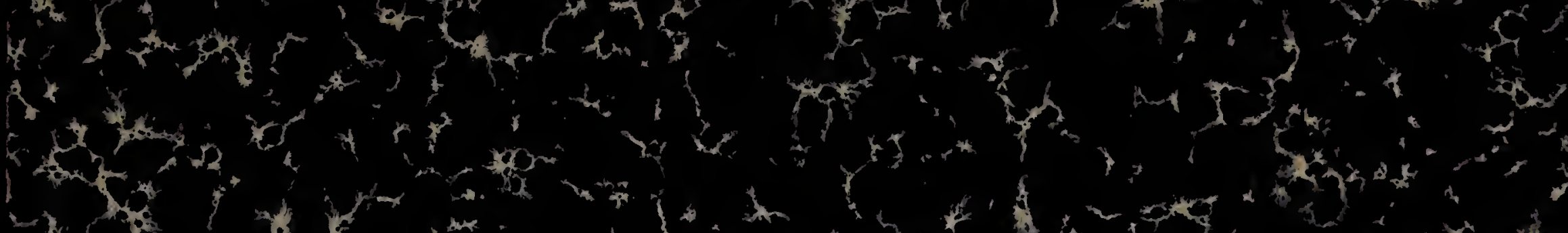
L 4t

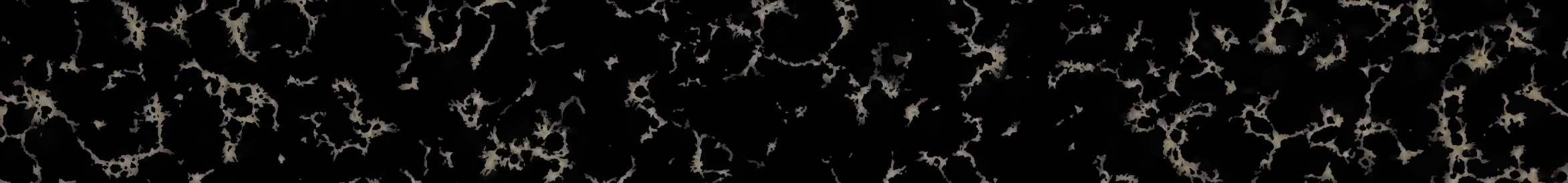
(5) (n)

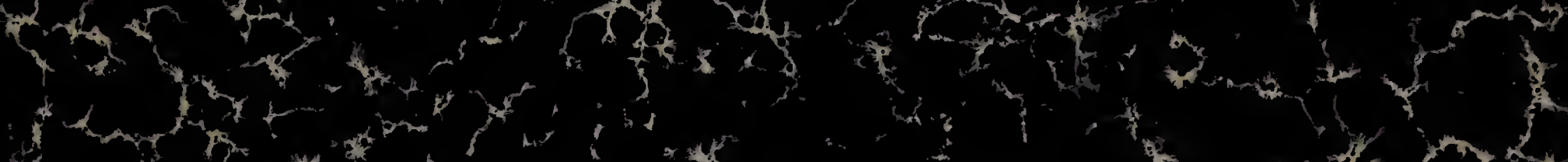

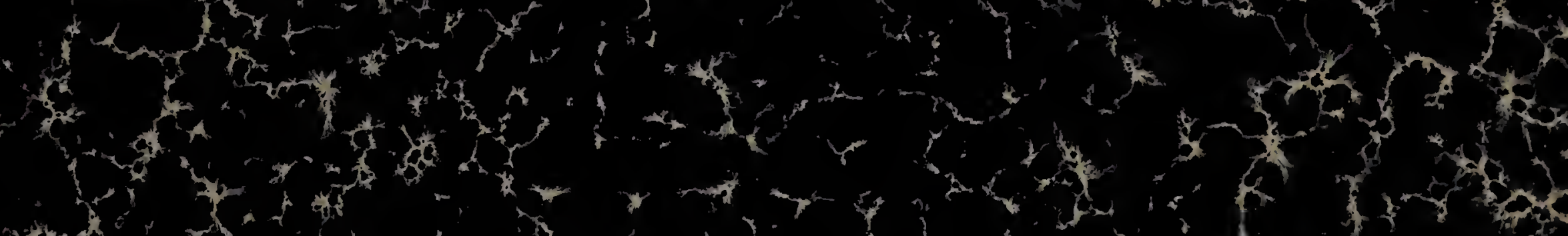

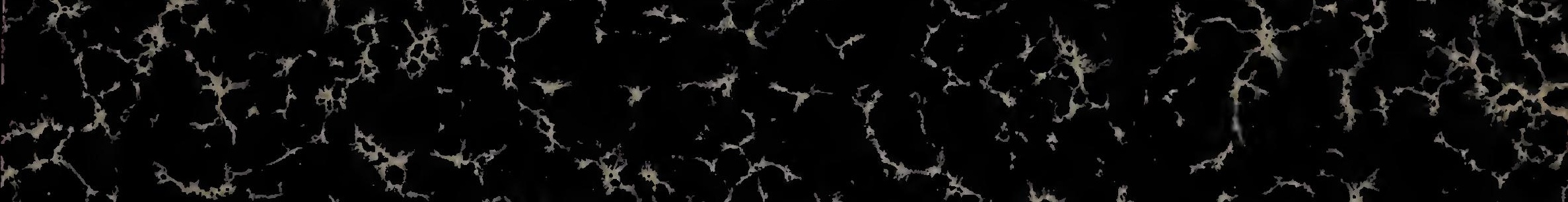

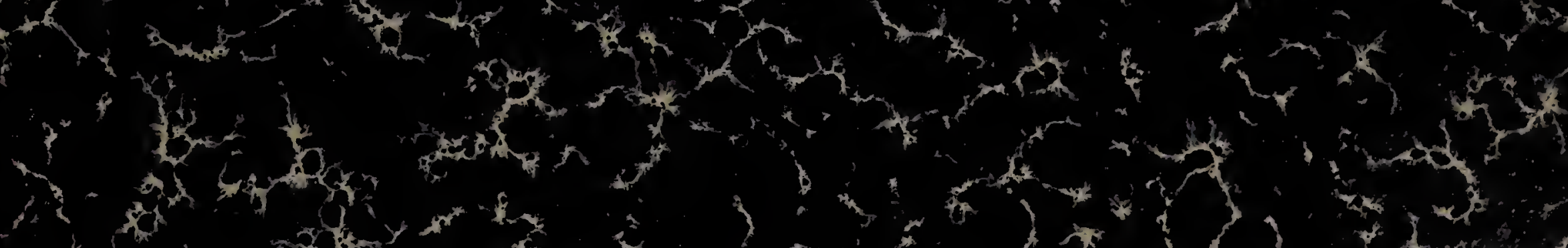

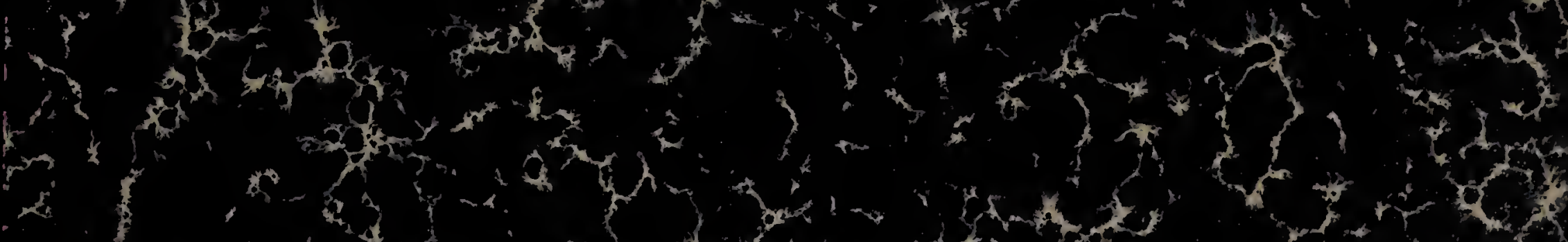
(1)

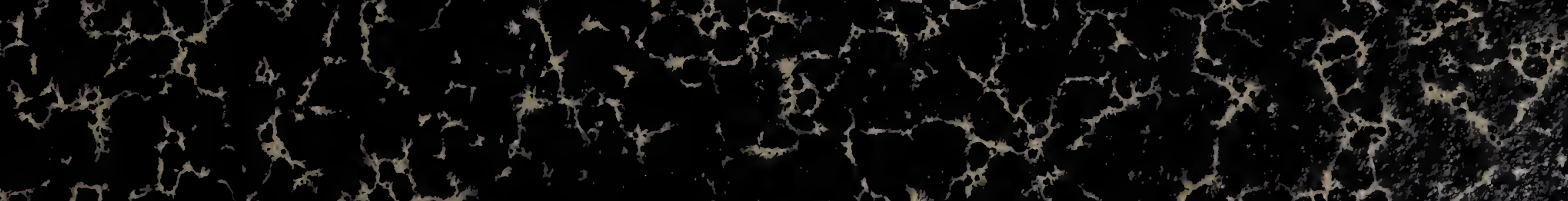
舟 $x^{2}+x^{2}$

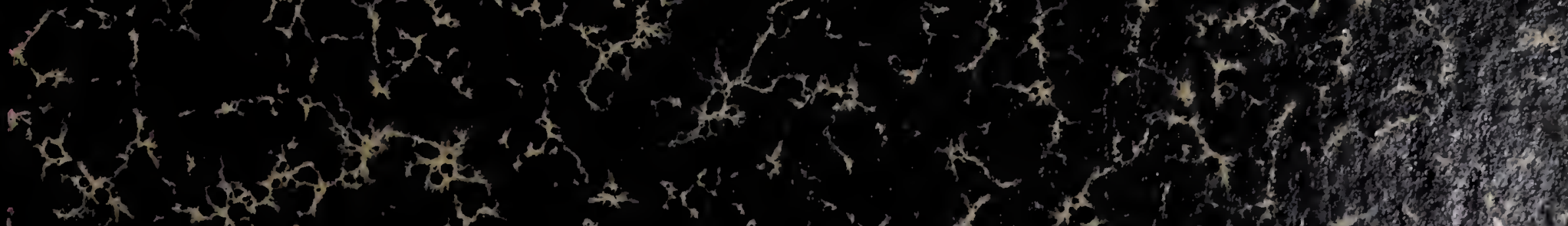

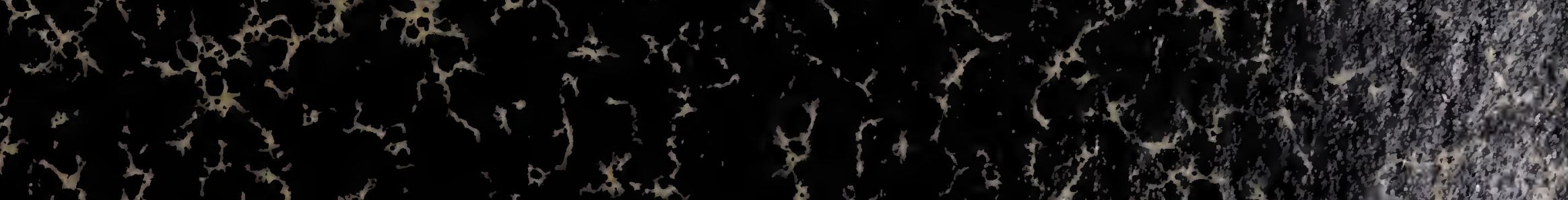

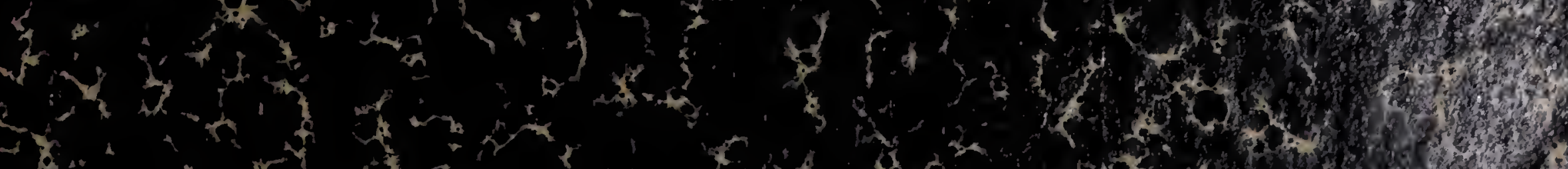
* a

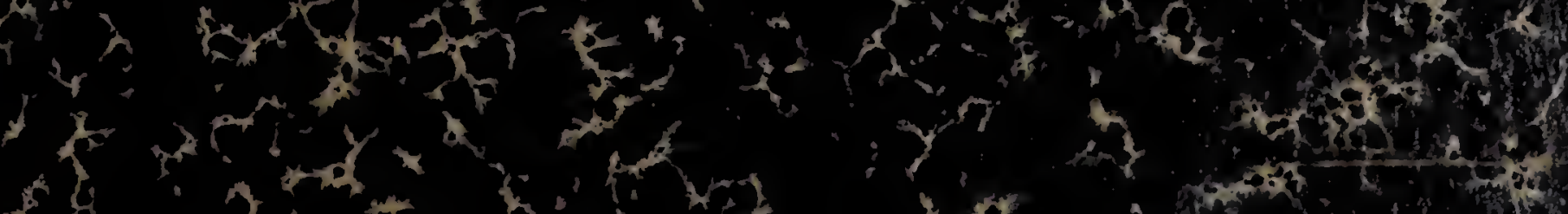

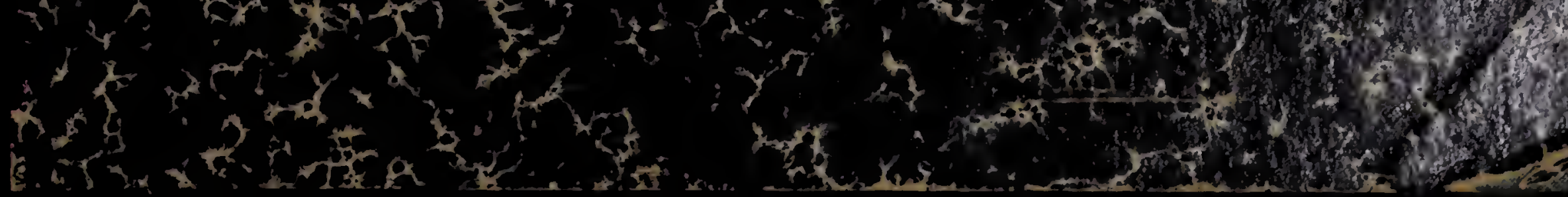




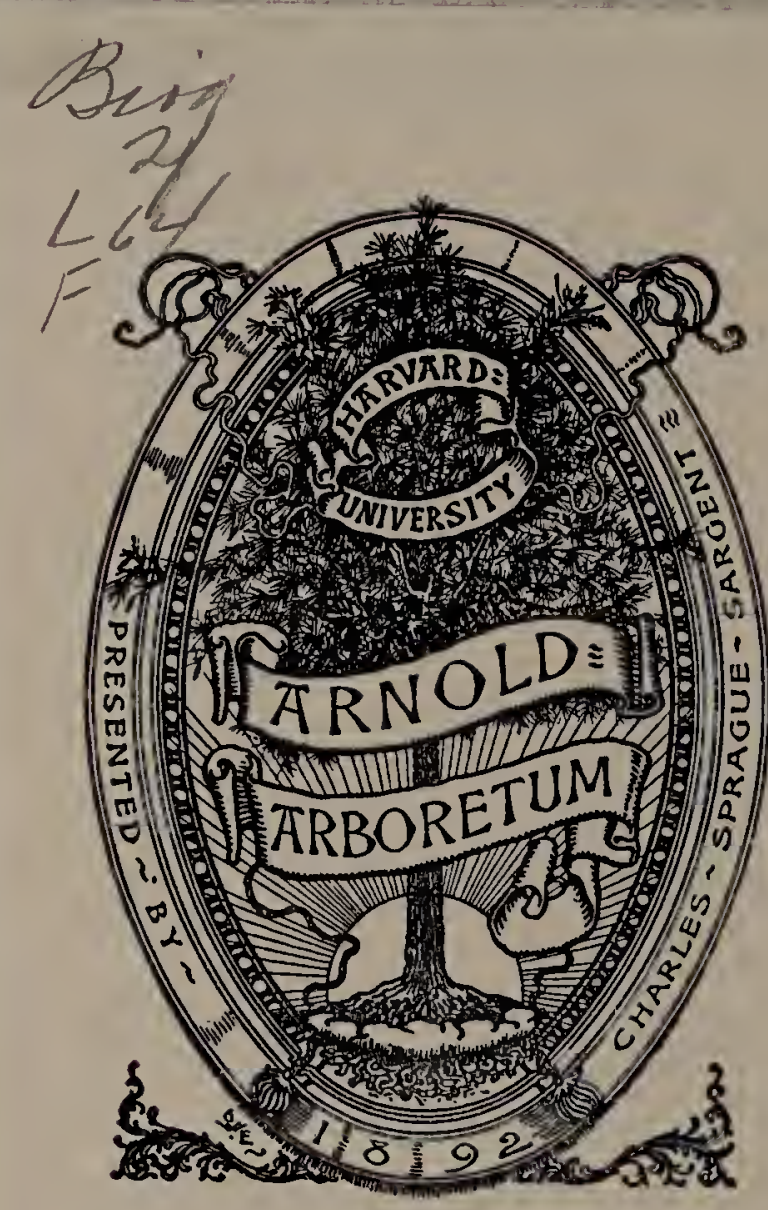






\section{FELIX BRYK}

\section{LINNEUS IM AUSLANDE}

NACHTRAG

M.CM.XXI 



\section{I N N $Æ U S$}

IM AUSLANDE

NA C H TR A G 
Es wurden zweihundert numerierte Exemplare abgezogen, davon die zehn ersten auf Bütten. Von den zweihundert ist dies No. 182. 


\section{LINNÆUS}

IM AUSLANDE

LINNÉS GESAMMELTE JUGENDSCHRIFTEN AUTOBIOGRAPHISCHEN INHALTES

AUS DEN JAHREN

$1732-1738$

\section{NACHTRAG}

HERAUSGEGEBEN VON

FELIX B R YK

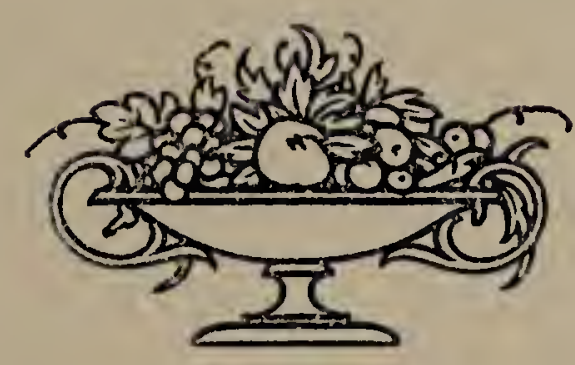

STOCKHOL M

IM EIGENEN VERLAGE 


\section{VORWORT DES HERAUSGEBERS.}

E in Faksimile wiedergegebenen kleinen Hamburgischen Berichte mit Linnés von uns wiederaufgefundenen Jugendschriften waren für Größe und Format des ersten Teil es von „Linnæus im Auslande“ (1919) bestimmend. Infolgedessen konnten Dokumente von weit größerem Fläch enumfange nicht gerne oder leicht in das kleine Mustermaß eingeengt werden. Wie diese nun zum Teile die Veröffentlichung eines Nachtrages anregten, so waren sie jedenfalls für ein folioähnliches Format „,maßgebend“. Bei dieser Gelegenheit erwies es sich angemessen, gleichzeitig Ehrets Briefe an Linsé mitzuteilen, schon wegen des sehr wichtigen Hinweises darin auf die durch das Stammbuch ans Licht gezogenen Icones methodi sexualis. Auch wird dadurch jedem das von uns vorher kaum gestreifte Verhältnis von Lins aus zum ausgezeichneten Illustrator EHRET nunmehr ganz greifbar und lebendig. Kleine Ergänzungen oder noch kleinere Berichtigungen konnten ferner mitgenommen werden. Eine bibliographische Zusammenstellung der angesammelten, bisher im Ganzen noch nicht behandelten Jugendschriften ergab sich als Abschlußthema von selbst. Auch hier begünstigte das Format die Veröfentlichung eines sehr merkwürdigen Linséschen Manuskriptes von einer bisher ganz unbekannten Originalschrift. Dieser Umstand, sowie die jüngste Flut von veröffentlichten Linnéschriften gaben schließlich den Anstoß dazu, die ins Auge gefaßte bibliographische Zusammenstellung zu einem abgeschlossenen Ganzen abzurunden. - In dieser Frage überließen wir das Wort ganz und gar LinNé selbst.

Ohne die überaus entgegenkommende Gefälligkeit seitens einiger Herren wäre es mir überhaupt unmöglich gewesen, diese Schrift in diesem reichen Gewande zu veröffentlichen; es sei daher auch hier nochmals jenen guten Herren, die mich mit Material freundlichst unterstützten, mein herzlicher Dank ausgesprochen: Herrn Oberbibliothekar Dr. J. M. HuLru für die zeitweise Ueberlassung zu Studienzwecken der Abschriften von Linnés Briefwechsel aus der Universitätsbibliothek zu Uppsala, Herrn Professor Chr. Aurivillius wie Bibliothekar Dr. J. Bergstedt und Herrn Reichsantiquar O. Janse für die Erlaubnis zur Vervielfältigung einiger Dokumente aus ihren Archiven. 



\section{EHRETS BRIEFWECHSEL MIT LINN\&US.}

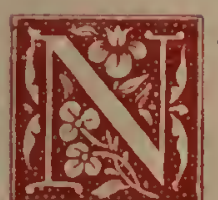

OCH bIS ZUM heUtigen Tage Schmücken DIChT WIE KachelN aneinander gereihte wundervoll kolorierte Kupfer die beredten Wände von Linnés Schlafzimmer in Hammarby; so wie sie Linné vor etwa 150 Jahren dort um sein Himmelbett herum aufgehängt haben mochte. Nicht genug satt konnte er sich an diesen herrlichen exotischen Blumenbildern ergötzen, nicht wenig stolz war er auf die Tapeten, ,wie sie selbst kein König besitzt". Der Künstler, der diese Bilder geschaffen hat, heißt Georg Dionysius Ehret, ein Badenser von Geburt; das Werk, dem diese Foliotafeln entnommen sind - es sei dabei dahingestellt, ob sie Linné aus den Lieferungen herausgerissen hat, oder ob sie nur eine Sammlung von Probedrucken darstellen, die Linné stets erhielt - trägt den Titel: Plantæ Selectæ . . . Norimb., 1750-73, von Chr. JAc. Trew herausgegeben.

Die Paradiesfeige mit dem üppigen sattgelben Bananenbüschel mußte besondere Jugenderinnerungen beim Greise hervorrufen. Ehret hat sie im selben Jahre, als die berühmte Musa Linné hold war, nach einem anderen gleichzeitig blühenden Exemplare des Londoner Gartens abgemalt. Linnæus war damals beim reichen CLIFFord und beschäftigte einen anderen deutschen Künstler Hofmans. Aber während der Fertigstellung seines Hortus Cliffortianus wurde es Linnæus klar, daß der wirkliche Mann für seinen Hortus nur Ehret sein konnte. Hoffman, VandelaAR waren zu wenig oder gar keine Botaniker. Man lese nur in den paar Briefen nach, mit welcher Liebe zur Wissenschaft, mit welchem Hange zu Floras Kindern dieser gelehrte Maler sich ans Werk machte. Kein Wunder, war er ja als Sohn eines Hofgärtners in Baden-Durlachschen Diensten von Hause aus Botaniker ${ }^{\mathbf{1}}$ ).

I.

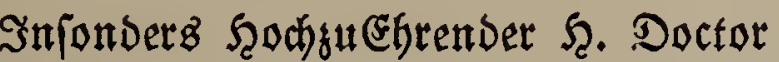

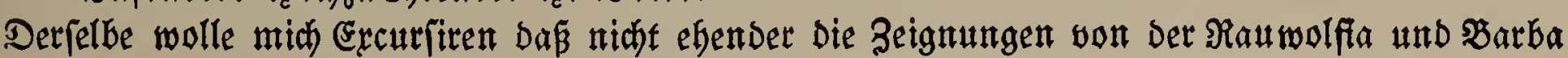

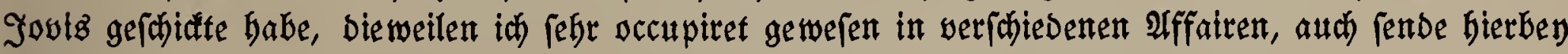

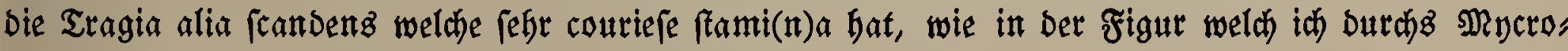
fcopium gemacht gut fehen ift und hab ro ftamina barinen gefunden. und now eine andere Pflante melche gants ein neu SSenuz ift wie Sie in Der figur leben werben.

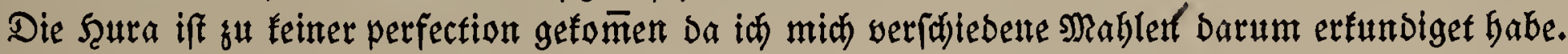

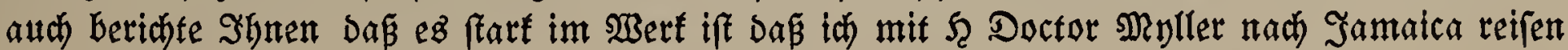

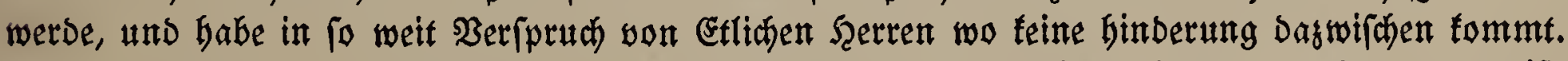

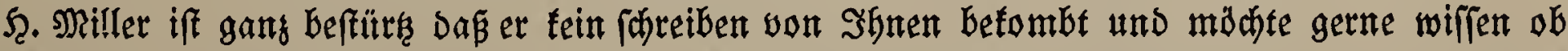

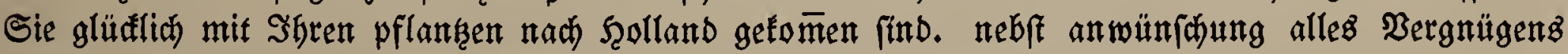

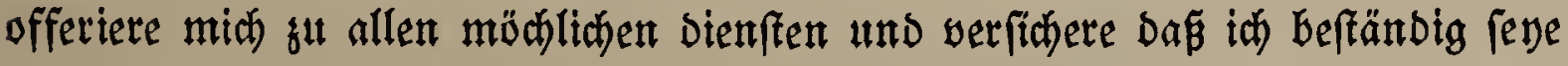

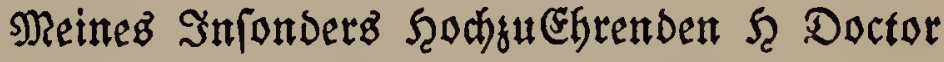

Ergebenfter Diener

Ehelfea

ESearg Dionyfing Ėgret

Detobre D. 3. 1736

(Eine gemalte Zeichnung liegl dem Originalbricfe bei.)

Linnés sämtliche Briefe an Ehret sind durch Veröffentlichung bekannt $\left.{ }^{2}\right)$. Es kann aber zur Verdeutlichung des Briefwechsels dienen, wenn hie und da einzelne Stichworte, aus Linnés 
Briefen herausgegriffen, den Monolog beleben. In seiner Antwort vom 29. Nov. 1736 beeilt sich u. a. Linné mitzuteilen, daß er von der Academia Imperialis Leopoldino Carolinæ Naturæ Curiosorum zum Dioscorides, den II, ernannt wurde ${ }^{3}$ ). „Du kanntest doch Alle in Nürnberg, wo ich keinen Bekannten hatte; bitte, sag' mir wer ist der Dr. Widmann? er ist der erste der mich berief." Der „Hortus Cliffortianus ist bereits bis Seite $310^{4}$ ) abgeschlossen.“

\section{II.}

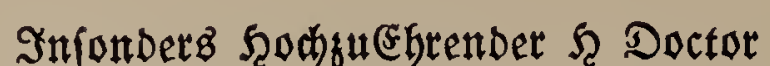

Dáp th) auf Dero webrtes Schreiben bie antwort fhulbig geblieben biffe meinen vielen ver; ritbtungen fugufdreiben.

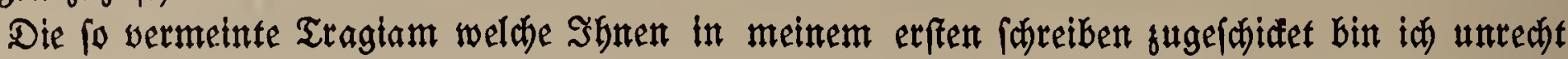

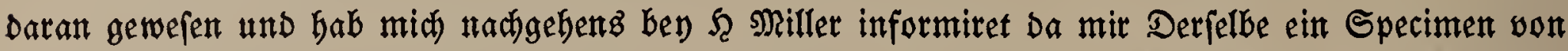

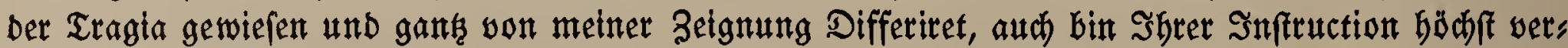

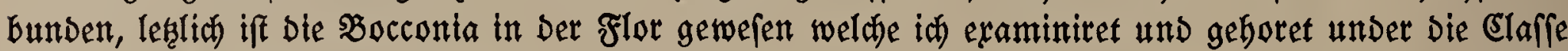
Sexandria Calix nulluz, Petala Duo, Stamina fex, aud babe under andere fpecies Phylliteae examiniret und ntajt mebr als 2 ftamina baben und in \$hrer fiftema నaturae im einer andere Slaffe gefunden,

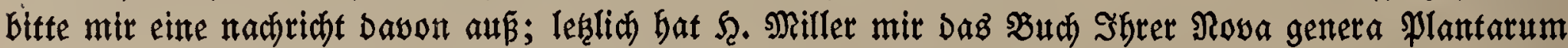
weldhe Sie thm fugefdidet gelehnet. Dariñen viele neue Genera erfehen, idh wünjhe ein Dergleidjes vertrefflidjes $\mathfrak{B}$ ud Dariñen ftudiere;

Diefen bevorftebenden Sō̄er werde viele neue pflanken weder zu feben befōmen, Da mir

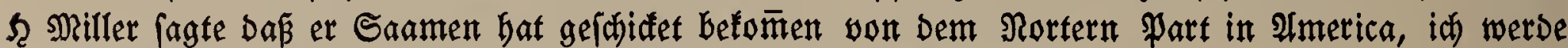

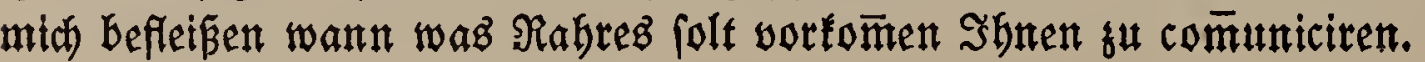

verbleibe in allem sefpect

\section{Dez $\mathfrak{T}$ Doctora}

Beborfantfer Diener

Eseorg Dionifüz Ébret

EGerlea $\mathfrak{D} 3$ Iprill

Ilo 1737

[Adresse:] A Monsieur

Monsieur Linnæus Docteur en

Medecin et de la Soc. Imperiel

chez Monsieur Cliffort Man(!)chand

Banquier tres renommé

Amsterdam

In seiner Antwort vom 16. I. 1738 berichtet Linnæus, daß der Gärtner vom Cliffordschen Garten, der früher am Amsterdamer angestellt war, „Dein Freund wie ich hoffe“, starb.

Darauf folgt erst der Brief ${ }^{5}$ ) von Ehret, der direkten Anlaß zur Veröffentlichung seiner Briefe gab. Darin beklagt er sich, daß Gronovius seine Icones nachdrucken ließ. Es ist leicht möglich, daß Linnæus eine entsprechende bibliographische Notiz im Stammbuche (p. 294) just diesem Brief entnommen hat; in diesem Falle wäre es als gegeben anzunehmen, daß wenigstens jene Notiz nicht vor Juli 1738 dort eingetragen wurde.

III.

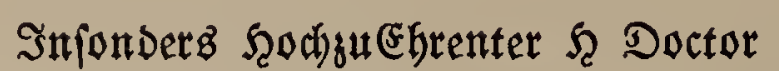

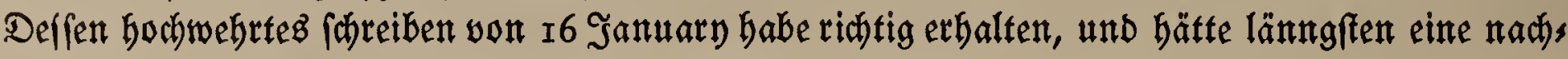
rtat Darauff etheilen follen bieweilen aber mit to vielen Gefhafften äberlaben als bitte mein bodwebr: tefter h. Doctor wird mid fu excuftren wiffen, Gierbey fende Die Earacteres Der Banhinia und Petiveria

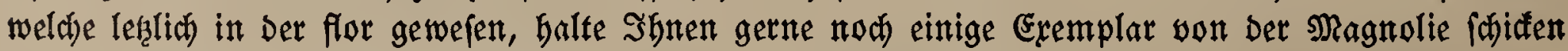

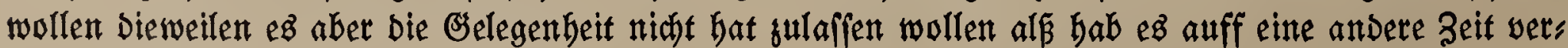
fpabren wollen.

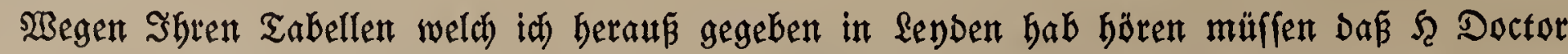

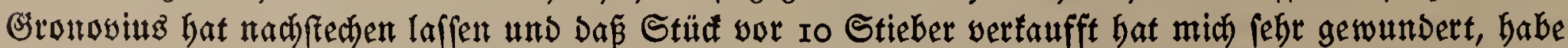

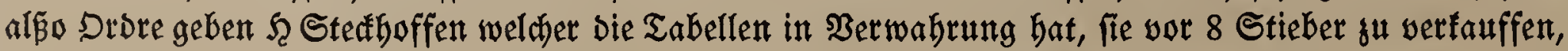
in la la es an feinent Drt geftellet fein etc. 


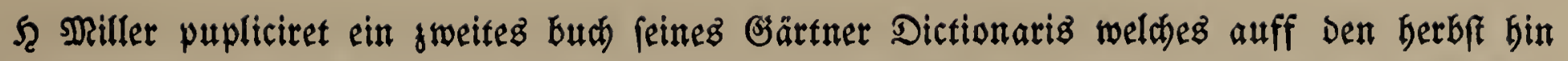
beraustomen wird, Item Eatesbei sweiter Bolume von Fif

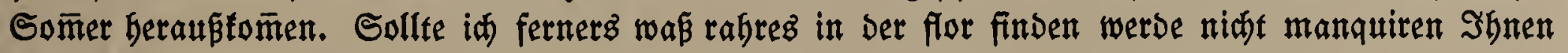
Eatacteres gutufdicen,

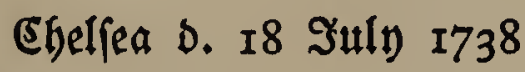

[Adresse:] Monsieur

Monsieur C. Linnæus

Docteur en Medicin \&

chez Monsieur Cliffort

Banquier très renommé

a

Amsterdam
Berbleibe meines God webrteften $\mathfrak{S}$ Doctors Dienftwilligfter und ergebenfter Diener

હ). D. Efret

(Als Beilage folgte eine Zeichnung von Blütenteilen der Bauhinia mit.)

\section{ZUSÄTZE.}

In Ergänzung zum mitgeteilten Promotionsakte wird hier in Faksimile das pergamentene Doktordiplom mitgeteilt; dadurch werden auch Namen verdeutlicht, die dort nur abgekürzt veröffentlicht oder ganz ausgelassen wurden, wie J. Chr. Struchtmeyer, van Holthe. Das Diplomsiegel ist auf dem Umschlage wiedergegeben.

ARTEDis tödliche Verunglückung in Holland wurde später einmal von Linné transzendental-kausal als ein Racheakt der Nemesis divina aufgefaßt: „ARTEDi zeigte einen tötlichen $\mathrm{Haß}$ gegen die Holländer, weshalb er in Amsterdam ertrank." Fürwahr eine eigentümliche Gottheit, diese Nemesis, die so drakonisch einen so harmlosen $\mathrm{Haß}$ bestraft. Bei Anwendung desselben Strafverfahrens müßte sie heute mit mehr Fug über einen ganzen Ozean für Ertrunkene verfügen! -

Daß Linnæus so ohne weiteres von CLIFFord angesprochen wurde, bezeichneten wir als eine Anekdote ${ }^{6}$ ), der ein ähnlicher Präzedenzfall voranging. Daß jedoch dem ersten Klischee hierzu, einem ähnlichen Zusammentreffen mit einem seiner ersten Gönner, mit O. CELsıus d. ä. in Upsala, keine Naturaufnahme zugrunde liegt, hierfür gibt es einen Haltpunkt in der Gedenkrede von Linnés Freunde Bäck über O. Celsius (p. 15, 1758). Dort wird ausdrücklich erwähnt, daß es der bekannte Astronom A. Celsius war, der ihm damals Eintritt in das Haus des erwähnten Gönners verschaffte. Wie derselbe Freund ihn dann in Deutschland protegierte, darüber ist im ersten Teile (p. 11) nachzulesen. (Vgl. auch hier p. 16, 17.)

\section{BERICHTIGUNGEN.}

Die Mitteilung p. 23, daß Clifford keine Tafelwidmung in Flor. Lapp. erhalten hätte, beruht auf einem Irrtume: das Frontispiz ist doch Clifford gewidmet.

p. 54 (Note 44): 1741 (non 1731). - p. 56 (Note 56): p. 287 (non p. 28).

ANMERKUNGEN.

1) Von seiner Gartenkunst schien jedoch LiNNé keine hohe Meinung zu haben. „Sibthorp in Oxford", schreibt Linné an Bäck den 2. II. 1751, ,hat Ehret zum Gärtner; also einen Herren zum Stallknecht genommen. So gerne ich ihn zum Zeichner will, so wenig zum Gärtner. Obwohl dies seine Profession ist. Nun wird mein Bruder sehen, daß der Teufel den Garten holt." „Georg Dionysius EHREт Pictor plantarum Eximius", diese eigenhändige Aufschrift von LiNsé findet sich auf dem kleinen Konvolut mit Ehrets Briefen.

2) Vgl. Proceding of the Linnæan Society of London 1883-1884, p. 45-46; der gegenseitige Briefwechsel wird in der Linnégesellschaft zu London aufbewahrt.

3) Das Diplom der Akademie, die damals vorübergehend ihren Sitz in Erfurt hatte, bringen wir als Beilage.

4) Die Angabe just dieser Seitenzahl ist sehr interessant. Im H. Cliff. macht nämlich die Paginierung einen ganz unerklärlichen Sprung von 231 auf 301. Diese Fehlpaginierung, die wohl in der nach träglichen Einziehung von mehreren Textbogen ihren Grund haben dürfte, war also nichts Zufälliges, sobald Linné in der Mitte der Arbeit eine Seite nicht viel hinter 301 erwähnen konnte.

Bryk, Linnaus im Auslande. 
5) Mit jenem Bricfe schließt EHrETs Briefwechsel mit Linnæus in Holland ab, - er wird nach einem Zeitintervalle später auf schwedischem Boden von ihm wieder aufgenommen; davon interessicrt besonders, daß sich LinNé ganz ernst bemühte, EHRET als Universitätszeichner anstelle des senilen unbrauchbaren ,,der weder sieht noch hört, dem Alle sein fatum wünschen“ für Upsala zu gewinnen. Ehret dankt ablehnend 26. III. 1748, daß L. "for mid fo treulid forget, mid in bie Stelle bes

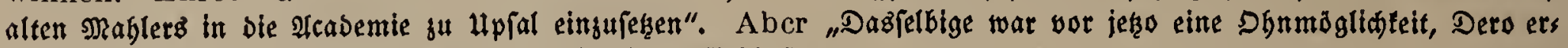

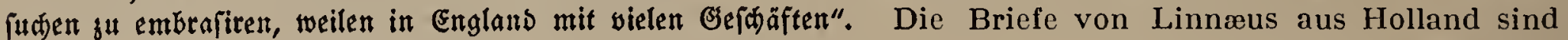
stets nach Chelsea, wo damals Ehret angestellt war, adrcssiert, und es muß wohl auf einem Mißverständnisse beruhen, wenn die Quellen (zuletzt U. Thiense in: Allgem. Lex. d. bild. Künstl, Vol. X, p. 396, 1914) angeben, daß „Ehret in Holland mit Linné bei Clifford bekannt“ . . „war“, ,ging 1740 zum zweitenmal nach England."

6) Eine weitere negative Mitteilung könnte man auf Linn \&us angebliches Geschenk an BERNIARD Jussieu beziehen. Laut einer Adresse des Direktors am Pittsburger Carnegie Museum, W. J. Holland, von 1907 an die New-Yorker Akademie befindet sich im dortigen Museum ein Mikroskop mit folgender Inschrift auf einem vom Alter vergilbten Papierzettel:

„Zur ewigen Erinnerung an die Bekanntschaft, in der er mit dem liebenswürdigsten Kollegen Kart Linné in Paris stand, erhielt diesc Freundschaftsgabe im August 1738 Bernhard Jussieu." (Original lateinisch)

Für eine Mystifikation sprechen folgende Umstănde:

Als sich Linnæus in Frankreich aufhielt, befand er sich in einer großen Geldklemme, daß er wohl kaum Mittel zum Ankaufe eines so kostspieligen Geschenkes hatte.

Einen Linné gab es damals nicht!

Im Auguste 1738 hatte Linnæus bereits seit langem Frankreich verlassen; er befand sich zu jener Zeit im Hause seiner künftigen Schwiegereltern in Falun.

„Der grobe Preusse" LieberküHN konnte freilich ein selbstverfertigtes Mikroskop an Jussieu auf Bestellung durch Linnæus Vermittelung geliefert haben.

\section{LINNÉ ALS SEIN EIGENER BIBLIOGRAPH.}

Die Veröffentlichung von „Linnæus im Auslande“ hat neben einer Vermehrung unseres spärlichen biographischen Quellenmaterials auch in hohem Grade die Aufmerksamkeit auf den bibliographischen Zweig der Linnéforschung gerichtet. Eine Zusammenstellung aller LiNNéschen Notizen über sein Lebenswerk gibt es bis heute nicht. Diesem Manko soll hiermit abgeholfen werden! Es werden aber hier ausschließlich jene erschienenen Schriften von Linné angeführt, worin irgendein bibliographischer Hinweis auf das Erscheinungsjahr, Format, die Auflage einer seiner bis 1921 veröffentlichten Originalschriften wie Uebersetzungen zu finden ist. Mit Absicht wurde jedoch davon Abstand genommen, die vielen von LiNNÉ selbst übersehenen Auflagen, Uebersetzungen, Nachdrucke, Kompilationen, Extrakte oder sogar erschienenen Originalschriften zu berücksichtigen. Das würde sonst den Rahmen des festgesetzten Raumes bedeutend überschreiten. Auch konnten aus diesem Grunde die hie und da im Linnéschen Briefwechsel mitgeteilten Daten über das Fortschreiten seiner Arbeiten oder über etwaige geplante Ausgaben nicht verwertet werden, wie auch die unzähligen Zitate wegfallen mußten, die sich auf seine Disputationen oder andere Schriften beziehen ${ }^{1}$ ), insoferne sie kein bibliographisches Moment enthielten.

An der Hand des einschlägigen Materials soll nun aus seinen Schriften der bibliographische Kern herausgeschält werden. Wir lassen hier sozusagen LrNnḱ selbst seine eigene Bibliographie verfassen, indem wir uns darauf beschränken, unter allen seinen angeführten Schriften stets seine diesbezüglichen Bemerkungen wörtlich, oder gekürzt, mitzuteilen.

Aus praktischen Gründen werden die in folgendem Verzeichnisse angeführten bibliographischen Hilfsquellen jedesmal gekürzt in Klammern [] mit den unten angegebenen Abkürzungen mitgeteilt.

\section{Bibliographische HilfsQuellen.}

I. Acrel, J. G., Tal, om Läkare-Vetenskapens grundläggning och tilväxt vid rikets älsta lärosäte i Upsala, Stockh. 1796; $8^{0}$ [Tal.].

II. Ähríng, E., Några af de i Swerige befintl. Linnéanska handskr. Kritiskt skärsk., Lund $1878 ; 8^{\circ}$ [Handskr.].

1) Wie z. B. in Incrementa botanices (Amon acad. Vol. 3, p. 377 ff., 1756). 
III. Agardh, C. A., Antiquitates Linnæanæ. Programma, Lundæ 1826; in folio [Progr.].

IV. Bäck, Aвr., Åminnelse-Tal öfwer ... Herr Carl von Linné, Stockh. 1779; $8^{0}$ [Tal].

V. Beckman, J. W., Minnen af lediga stunder, Stockh. 1824; $8^{\circ}$ [Minnen].

VI. Beckmann, J., Schwedische Reise i. d. J. 1765-1766 (Herausg. Th. M. Fries), Upsala 1911; $8^{\circ}$ [Schw. Reis.].

VII. Bref och skrifvelser af och till Carl v. Linné (edid. Tit. M. Fries, J. M. Hulth), Stockh. 1907-1917; $8^{0}$ [L. Bref].

VIII. BRYк, F., Linné-Studier in: Meddel. f. bokvänner fr. A.-B. H. Klemmings antikr., Vol. I, Nr. 2, p. [45]-58, 1919, [Stud.].

IX. - Limnæus im Auslande, Stockh. 1919; $8^{\circ}$ [L. i. Ausl.].

X. - " " , , Nachtrag 1921; in Kleinfolio [Nachtr.].

XI. - Linnés Disputationer in: Nya Dagligt Allehanda, 23. Mai 1919; [N. D. A.].

XII. Choulant, L., Bibliotheca medico-historica, Lipsiae 1842; $8^{\circ}$ [Medhist.].

XIII. [Anonym] [= Cronstedt] Försök til Mineralogie eller Mineral-Rikets upställning, Stockh. 1758; $8^{0}$ [Míiner.].

XIV. [Anonym] [= Cronstedr] Versuch einer neuen Mineralogie aus d. Schwed. übers. Kopenhagen $1760 ; 8^{\circ}$ [Miner. germ.].

XV. Engelmann, W., Bibliotheca Historico-naturalis, Leipzig $1846 ; 8^{\circ}$ [Engelmann].

XVI. Fabricius, Joh. Christ., Briefe aus London vermischt. Inhaltes, Dessau-Leipzig; $8^{\circ}$ [Lond. Br.].

XVII. FÉE, A. L. A., Vie de Linné, Paris $1832 ; 8^{\circ}$ [FEE].

XVIII. Fries, TH. M., Om några nyl. uptäckta Linnéanska manuskripter in: Bilag. zu: M. til förhandl. v. d. skand. Naturforsk. syv. Möde Christiania, Christiania 1856; $8^{\circ}$ (p. 281-302) [Manuskr.].

XIX. - Anmerkungen zu: C. LinnæI Lappsk Flora in: Skrifter af C. v. Linné, I. Flora lapponica, Uppsala 1905; $8^{0}$ [Lappsk Fl.].

XX. - Linné Lefnadsteckning, (II Bde.), Stockh. 1903); $8^{0}$ [Fries].

XXI. Gertz, O., Olof Celsius d. ä. och Flora uplandica in: Jahresschr. d. „Svenska Linné-Sällskapet", III. p. [36]-56. 1920; $8^{\circ}$ [Fl. upl.].

XXII. Gistel, Joh., Fr. X., Carolus Linnæus, Frankf. a. M. 1873; $8^{\circ}$ [Gistel].

XXIII. Gronovius, Laur. Th., Bibliotheca Regni animalis atque lapidei, Lugd. Bat. MDCCLX; $4^{0}$ [Bibl.].

XXIV. Hagen, Herm. Aug., Bibliotheca Entomologica (I. II.) Leipzig, 1863; $8^{\circ}$ [Hagen].

XXV. v. Haller, Alb., Bibliotheca Botanica (I. II), Tiguri 1772; $4^{0}$ [Haller].

XXVI. Holmström, J. A., Almanachs-Adnotationer för år 1735 af Carl v. Linné, in: Botaniska Notiser, No. 12, p. 210-218, 1845; [Adnot.].

XXVII. Hulth, J. M., Bibliographia Linnæana, Upsala 1907; $8^{0}$ [Hulth]; unter [Hulru emend.] verstehe ich die Korr. Aufl.

XXVIII. [Lankester, E., RaY] A Catalogue of the Works of Linnæus, London 1907; $4^{0}$ [Cat.].

XXIX. v. Paykull, G., Samlade svenska skrifter, (Först. bd.) Upsala, 1814; $8^{0}$ (p. [139]

- $\quad-184$ ist ein Nachdruck seiner 1797 (Stockh.) erschienenen Rede: Tal etc.) [Tal].

XXX. Percheron, A., Bibliographie Entomologique, Londres 1837; $8^{\circ}$ [Percheron].

XXXI. Pritzel, G. A., Thesaurus Liter. botanicæ, Lipsiæ $1851 ; 4^{0}$ [Pritzel].

XXXII. Roberg, Laur. Diss. phys. Græs-œam repraesentans, [Ad. Werner], Upsaliæ, MDCCXXVII; $4^{0}$ [Gräsö].

XXXIII. - De monocerotis Cornu fossili [Jac. Neuchter]. Ups. 1729; $4^{0}$ [Fossil.].

XXXIV. - De Salmonum Natura [Dan. Bonge] Ups. MDCCXXX; $4{ }^{0}$ [Salmo].

XXXV. - Berettelse om blomman [L. Liliemark] Ups. 1735; $4^{\circ}$ [Blomman].

XXXVI. - Plantarum generatio [B. Lossberg] Ups. MDCCXXXVIII; $4^{0}$ [Pl. gen.].

XXXVII. Rosenhane, Sh., Anteckningar.... Vet. Akad. Historia, Stockh. $1811 ; 8^{0}$ [V. A. Hist.]. 
XXXVIII. Rudbeck, J., Bibliotheca Rudbeckiana, Stockh. 1918; $4^{0}$ [Bibl. Rudb.].

XXXIX. - O. fil., Nora Samolad s. Laponia illustrata, Upsalæ 1701; $4^{0}$ [Lap. ill.].

XL. Stöwer, Dietr. Heinr., Leben des Ritter Carl v. Linné, (II Bde), Hamburg 1792; klein $8^{\circ}$ [Stöwer].

Xli. Uppsala Bokauktionskamm. Kat. No. 24, 1908 [Torins Nachlaß]; $8^{0}$ [Torin].

XLII. Wieselgren, H., Bilder och Minen, Stockholm, 1889; $8^{\circ}$ [Bilder].

XLIII. Wikström, J. E., Conspectus litt. bot. in Suecia, Holm. $1831 ; 8^{\circ}$ [Wikström].

Die römische Ziffer, die jedesmal nach einer Linsti-Schrift folgt, bezieht sich auf die Folge der betreffenden Auflage, wobei folgende Abkürzungen eingeführt werden:

[Ant.] = Egenhänd. Anteckn. om sig sJälf. ${ }^{1}$ ) [Hulth, p. 162]; [B. B] = Bibliotheca botanica; [F. B.] = Fundamenta botanica; [Faun. Sv.] = Fauna Svecica; [Fl. Lapp] = Flora Lapponica; [Fl. Sv.] = Flora Svecica (opera botanica suecica); [Gen. pl.] = Genera Plantarum; [H. Cliff.] = Hontus Chiffortianus; [Orb.]= Orbis ERuditi judicium; [Spec. pl.] = Species plantarum (auctores); $[$ S. N.] = Systema Natura $;[$ Rat $]=$ Ratio editionis.

Eine bekannte Sache ist es, und auch menschlich allzuverständlich ist es, daß ein Verfasser nach seinem Debüt in der Regel überall, wo es nur geht, seine ersten Schriften anführt. Warum sollte gerade in dieser Hinsicht Linsaus eine Ausnahme bilden? Hatte er doch dazu noch vollen Grund, sich seiner Schriften nicht zu schämen. Wenn er aber so weit geht wie in seiner Fl. Sv. I unter dem Literaturnachweise seiner rein botanischen (!) Schriften (,Opera botanica“) ein „offizielles" Verzeichnis seines gesamten damaligen literarischen Schaffens zu veröffentlichen ${ }^{2}$ ), so muß man sich sagen - so willkommen alle diese Daten heute dem Bibliographen auch sind: hier tritt die Autoreneitelkeit, gepaart mit der Lust, dem Leser zu imponieren, zu stark zum Vorscheine; zu dieser billigen Auffassung muß man um so eher noch gelangen, wenn man sich vor Augen hält, daß gleichzeitig wertvolle schwedische botanische Schriften, die unbedingt Linné kannte, absichtlich unterdrückt wurden, was schon bei anderen Gelegenheiten mit Recht ein Paykull [Tal, p. 161] und u. a. später Fabricius [Lond. Reis., p. 102] rügten. Am meisten fällt hiẹr die stiefmütterliche, ganz unbegreifliche Behandlung seines hervorragenden Lehrers RoBerg auf. Während ARTEDI in seiner Ichthyologie (Bibl. Icht. p. 58) eine Disputation von Roвerg anführt, setzt sich Linszus notorisch über Robergs Schaffen ganz und gar hinweg, ignoriert völlig im Literaturnachweise zur Faun. Sv. seine Schriften; dabei ist es ja bewiesen [Fries I. p. 75], daß Linnæus wiederholt als Opponent bei Robergs akademischen Abhandlungen [Salmo] auftrat, sohin die Schriften kannte. Robergs interessante Abhandlung [Gräsö] ließ sich freilich nicht totschweigen, schon wegen der ersten Abbildung der Cornus Svecica [Fl. lapp. p. 38], die dort Roberg gab, aber weder unter den ,authores Sveci“ (ibid.) noch in irgendeiner Auflage seiner B. B, Fl. Sv., Gen. pl. wird, eigentümlich genug, diese oder eine andere Ronergsche Schrift erwähnt. Wir haben einen ganz besonderen Grund, warum wir uns gerade bei RoBerg länger, als es unser Thema gestattet, aufhalten. Daß Linnæus etwa seine [Blomman] in B. B nicht anführte, ist bei dem prälinnæanischen Standpunkte, der

1) Die wiederholt zu zitierende Seitenzahl 219 ibid. wird jedesmal in Unzinen angegeben, um auf die Fehlpaginierung 119 (!) hinzuweisen; ebenso Seite 220. Bei dieser Gelegenheit mache ich aufmerlsam, daß ich eine Variante besitze, wo das letzte Wort auf p. 127 nicht wie gewöhnlich mit didactylus, sondern linearis abschließt. (Vgl. Rättelser, ibid.). - Ein Rarissimum aber ist jedenfalls ein bisher für die Bibliographie unbekannter Auszug aus Ant. (p. 5-68) mit Noten aus dem Jahre 1858. Da es in der reichen Linnébibliothek in Uppsala fehlt und in der Suecanasammlung der Königl. Bibliothek zu Stockholm nur insofern defekt sich vorfindet, da $ß$ Umschlag und Tafeln fehlen, so gebe ich hiermit eine genaue Kollation dieses Druckes, der sich in meiner Bibliothel befindet. Titelblatt existiert überhaupt nicht. Umschlag blau: CarL Linnég / LefNadsteckning / om och af hovom SJelf. / (P. [1]): / Carl Linné. / Potest e casa vir magnus exire. / (Text folgt unmittelbar); p. 6, letzte Zeile / Stockholm. Hörbergska Boktryckeriet, $1858 /$ - Klein $4^{\circ}(?),(15,5 \mathrm{~cm} \times 17,1 \mathrm{~cm}) ; \mathrm{p}$. [1]-6, 3 Taf. (Ansichten von Råshult, Hammarby und Linnés Museum in altis; sauber ausgefülrte Holzschnitte mit der Signatur W nach den Bildern aus [Ant.], mit Zierleisten eingerahmt und mit aufgedruckten Aufschriften.)

2) Ja selbst in der zweiten Auflage von Flora Svecica wird noch ein rein mineralogisches Werk wic Museum Tessinianum unter botanischen Werken zitiert. 
noch 1735 in diesem Repetitorium zutage tritt, begreiflich. Aber rein unverständlich ist es, warum in keiner seiner Schriften, selbst nicht in B. B. II, Ronergs [Pl. gen], die doch eine selır bedeutende Linnéschrift ist, Erwähnung findet. Hat man doch gerade in RoBeras Pl. gen. die erste schwedische Disputation, die Linswus Pflanzenterminologie öffentlich akzeptierte, da dort p. [10] der $\$ 146$ aus F. B. I (p. 17) in extenso abgedruckt wird.

Dort (p. 5) ist zu lesen : ,Inter nostros nuper. Cl. Medicus D:r Carolus Lineus" , [!] ,Smolan",dus methodum \& ordinationem receptam deserere ausus est Tourneforty" (!), ,C Raji Cl. Virorum. „Novumque substituere systema Sexuale, nuptiarum, in regno vegetabili clandestinarum, publi,carum: ubi monandria, triandrice, pentandrice" etc. . (Hierbei wird auf [S. N. I] hingewiesen).

Aber noch melrr als diese völlige Ignorierung einer so bemerkenswerten Schrift verwundert es, daß Linnæus niemals einen Auszug aus seinem Mineralreich des [S. N. I] erwähnt: ich meine die seltenen Observationes in regnum lapideum, (sine dato). Laut Hulth (p. 3) ist ihr Herausgeber gerade RoBerg; Hulth teilt das Erscheinungsjahr aber nicht mit, weil es bisher mit Sicherheit nicht ermittelt werden konnte. Gistel (p. 231 Nota) verdanken wir die ersten Mitteilungen über die Existenz jener Schrift; er gibt 1792 [!] [= Errat.; gemeint 1742] ${ }^{1}$ ) als Erscheinungsjahr an und Torin, (p. 47 No. 990) das Jahr 1735. Vor 1735 kann diese Schrift schwerlich, auch wenn sie Linnæus viel früher, etwa vor seiner Reise ins Ausland als Abschrift an RoBerg anvertraut hätte, erschienen sein, weil die Aufschrift von einem M. D. spricht und Linn aus erst damals zum Doktor promoviert wurde; aber auch 1742. [GISTEL] kann sie nicht recht gut erschienen sein, weil sich in diesem Falle die Observationes an S. N. II [und nicht S. N. I] anlehnen sollten, was aber nicht der Fall ist. Läßt es sich doch ohne Mühe nachweisen, daß die Observationes eine Nach- oder sogar gleichzeitiger Druck von S. N. I. sind ${ }^{2}$ ).

Der einzige bemerkbare Zusatz, wodurch sich die Observationes von allen Auflagen des Steinreiches unterscheiden, ist der letzte Satz (p. 16), der sich direkt auf RoBERG bezieht, dies vielleicht der Grund, diese Schrift Roberg zuzuschreiben ${ }^{3}$ ). Die Observationes schließen sohin nach der Anführung des ruthenischen Terms, Mammotova Kost, mit folgendem Hinweis ab: V. D. et P. L. Robergii Ossa fossilia 1726.

Wenn diese, strikte genommen, zum Thema nicht gehörenden paar Beispiele eingangs mitgeteilt wurden, so geschah es einzig, um auf die unzulängliche wie subjektive Behandlungsart des Stoffes seitens Linné den Leser vorzubereiten.

\section{AUTOBIBLIOGRAPHIA LINNAANA.}

Posthum erschienent. Originalschriften und Inedita.

1729.

Caroli Linnfi Medic: \& Botan: Cult: Stipend: Reg: Preludia Sponsaliorum Plaxtarum in Quibus Physiologia earum explicatur, Srxus pemonstratur, Monus generationis

1) Worauf Gister. (p. 326) diese seine Behauptung begründet, weiß ich nicht; jedenfalls verdient Gistels im Zusammenhange aufgeworfene Hypothese, daß Orbis und Observationes beim gleichen Drucker gesetzt wurden eine gewisse Beachtung. Die Typen erscheinen freilich in beiden Schriften einander ungleich. Browallius könnte am Ende die Herausgabe besorgt haben. (Vgl. [Nachtr.]p. 17 Nota 3 ).

2) In S. N. II (p. 69) ist die Reihenfolge der 14 Thesen von der des S. N. I verschieden; [z. B. S. N. II (6. Apyros) entspricht S. N. I (14).] Die Observationes beginnen zunächst mit den 14 Thesen in der Reihenfolge von S. N. I, wobei jedoch die 14 Zahlen ausgelassen wurden. Auch das Latein ist stellenweise ein anderes, aber diese Aenderungen sind unbedeutend; (z. B. LiNs aus schreibt [S. N. I]: "Hinc generatio in Regno Lapideo nulla ex ovo". Im ,.Robergschen" Latein lautet derselbe Satz: „, Neq; enim ulla fit in regno lapideo ex ovo generatio." Ältere Herren pflegen sich um die jedesmal wechselnde Mode der Orthographie nicht zu kümmern; sie halten mit eiserner Hartnäckigkeit an der ihrigen fest. Aus ähnlichem Grunde werden dieselben schwedischen Wörter von LiNNeus anders geschrieben als

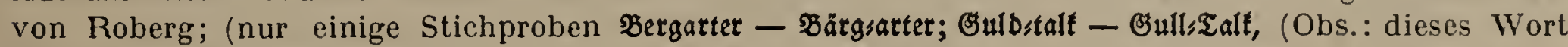
fehlt uberhaupt del II. Aufl. von S. N.), Säblag - Säbeglag). Nach den 14 Thesen folgt das eigentliche Regnum lapideuin (entsprechend S. N. (II, p. 2-I1).

3) Diese Robergsche Disputation [Fossil.], die abrigens 1729 (und nicht 1726) erschien, wird ebenfalls von Linné in keiner seiner Schriften erwähnt. - Vgl. auch [Nachtr.], p. 17 Nota 3 . - 
detegitur, Nec non sumia plantarum cum anmalibus analogia concluditur [Zicileiste, ge\%. von Linseus, stellt den Befruchtungsvorgang beim Kürbisse dar.] Upsal: 1729.

In: Skrifter af C. v. Linné utg. af Kungl. Svenska Vetenskapsakademien, IV. Upsala 1908: $8^{\circ}$ (2 f. p. [5]-20, 1 f. (davon zwei p. Illustrationen und Kopfleiste von L. gez.) (p. [23]-26 Noten von Fries). [Fries, Manuskir. p. 283-292]

a. Hortus. Upland. III [Edit. ÄHhLINa, p. 207 1888], [HULTH] p. I68. „Et quoniam nulla ,Methodus hactenus usu recepta mihi arrisit propriam secutus sum, quam propediem v. D. sul "nomine Nuptia Plantarum publicæ luci dare animus est."

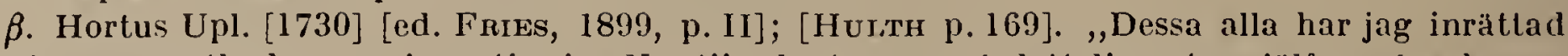
,äfter min egen method, som wisas uti mina Nuptiis plantarum, pả dett discentes siälfw måga kunna ",upleta samma sine præceptore." (Vgl. Fries ibid. Vorrede, p. 8 (Nota I). Eine Abschrift aus dem Jahre 1733 befindet sich in der Bibliothek der Königl. Akad. d. Wissenseh. in Stockh. [Ährling, Handskr., p. 12])

$\gamma$. [Ant., p. 15] Dort heißt diese Schrift de Sexu Plantarum; (p. 171), , $7^{0}$ Nuptia Plantarum... „Dieses Büchlein wird nun in Deutschland gedruckt" (!). (Deutsch. U'bers.)

$$
-1730-1731-
$$

II.

Hortus Uplandicus [1730], edit. Fries, 1899; [Hulth], p. 169 und Adonis Uplandicus [1731], edit. Ährling ${ }^{1}$ ), 1888, p. [271]-360; [Hulth], p. 168. Baron De Geer hat in einem Privatdrucke in Faksimile (XII numm. Exempl.) 1907 diesen Adonis herausgegeben.

a. Linvaus, Adonis Stenbrohultensis, I732 [1920]. Auf der Kehrseite des Titelblattes: „Ad: s: Ad. upl. C. Linnæi adonis uplandicus in qua plantæ exoticæ hortorum uplandicorum recensentur". - $\beta$. Hamburgische Berichte ${ }^{2}$ ) (Jan. 1732), p. 45-46 [p. 83-84]. - $\gamma$. [L. i. Ausl.], p. 296. $-\delta$. [Orb.], p. [I5]. $-\delta$ ) [B. B. I] p. 79: „Nos quas primum edimus adonis Uplandicus

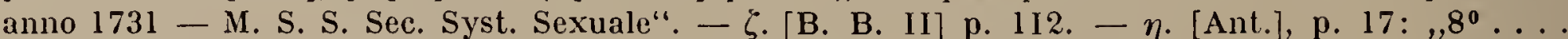
ebenfalls" [nach Deutschland] ,zum Drucke geschickt". (Deutsch Ubers.)

(Laut Acrer. [Tal], p. I63 trägt eines der Mslir. von Hort. upl. den Titel: Frora uprandica.)

III.

Der Urtext zur öffentlich verteidigten Schrift von Joh. O. Rudbeck De planta Sceptrum Carolinum; [Hulth], p. [1], wurde von Fries, [Manuskr.], p. 290-291, aufgefunden. Er wurde 52 Jahre später von seinem Entdecker unter folgendem Titel herausgegeben: Caroli LinnaI Dissertatio Botanica de Planta Sceptro Carolino dicta sub Prasidio D : ini launenti Robeng Profess: s. Publ. Theoret. et Pract. Responde [nte] Joh. Ol. Rudneck $1731 ; 8^{\circ}$, in: Skrifter af C. v. Linné, IV. Upsala 1908, p. [243]-256; (p. [257]-259 Fries Anmerk.).

Auf der Rückseite des Titelblattes ist (schwedisch) zu lesen: „Diese Disputation habe ich an einem Tage für 30 Taler Kupfermünze zusammengeschrieben; ein Anderer erhielt dafür die Ehre."

a. JoH. OL. Rudbecks Dispulation ${ }^{3}$ ). [J. Rudbeck, Bibl. Rudb., p. 367 Nr. I34I]; Variante [Hulth] p. [1]. - $\beta$. Gertz [Fl. upl.] p. 55, Zeile 1 I (v. o) bis Zeile 8 (v. u.) (= Linnæus ursprünglicher Text.) - $\gamma$. [B. B. I] p. 45 , ,V. . . Upsal. $1732^{\prime \prime}(!)$, ,sec. methodum conscr." $-\delta$. [Fl. lapp.] p. 197-201; (p. 199: ,Radix" . . . _, ,circumdatur" (p. 20I) entspricht Rudbecks Disputation p. $9-12)$; p. 198 ,Historia huius plantæ data est in Disp. de sceptro Carolino per Nobiliss. Rudbeckium nepotem, vide B. B. 45“. - $-\varepsilon$. [Fl. Sv. I] p. [XVI] wird sie unter seinen eigenen (!) Schriften folgend angeführt: „Rudbeck J. O. Diss. ac. Sceptrum Carolinum. Upsal. 1732" (!) ,Quart. 1. I". -

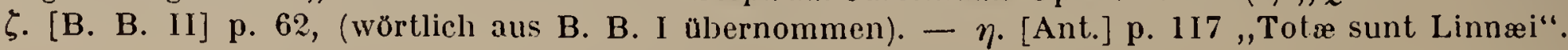

$$
\text { - IV. - }
$$

[Disputatio de Connus herba]

"Ich hatte eine Dissertation über diese Pflanze zusammengeschrieben und sie zum „Drucke befordert, aber als sie halbfertig gedruckt war, bekam ich von ... Prof. CELsius, un„serem Mäzen, zu wissen, daß berühmt. H. Dillensuss zuvor cine gleiche Meinung hatte und in

1) Leider ist in dieser Ausgabe, walırscheinlich infolge des während der Drucklegung erfolgten Todes des Herausgeber:, der Text stellenweise gekürzt.

2) Da diese Originalschrift eine große Seltenheit ist und z. B. in Schweden ganz unzugănglich ist, so wird stets neben den Originalseitenzahlen noch die Paginierung des Faksimils aus [L. i. Ausl.] in eckigen Klammern mitgeteilt. - [Diese Faksimile-Ausgabe ist auch separat erschienen unter dem Titel: Linneeus Beiträge aus den Hamburgischen Berichten 1732-1738, Stockholm 1919; $8^{\circ}$.]

3) Die zusammengefalt. Tafel, ein Holzschnitt, ist RuDBECK [Lap. ill.] entnommen; die Signatur B. T. taucht schon früher in RudBeck, d. ä., Alland auf einem Holzschnitte auf. - (Obs.: p. I4-I5; „.. . Botanico sane exercitatissimo D. Carolo Linnceo . . “, die erste Stelle, wo Linvæus Name in einer wissenschaftlichen Arbeit zu finden ist.) 
„,einem Briefe an ihn sie Cornus ... nannte. [Deshalb] zog ich sie lieber zurück, als in eines an„,deren Getreide illicitas falces zu führen." (Schwed. in: Upsal. Mscrpt. D. 64. nach Fries [Lappsk. Fl.] p. [347]-348.) Der noch erhaltene Urtext beginnt mit Mesomora alba . . . . (Vgl. Gertz [Fl. Upl.] p. 55, Zeile 8, (v. u.) - p. 56, Zeile 8 (v. o.).

a. [Fl. lapp.] p. 36-41. (Laut Gertz, ibid. p. 51-52, ist diese funfseitige Beschreibung ein Nachdruck der im letzten Augenblicke eingezogenen ursprünglichen Disputation.)

$$
-\mathrm{V} \text {. - }
$$

Caroli Linnai Med. Botan. \& Zoolog. Cult. Methodus avium Svethicarum sive enumeratio avium fere omnium QUa in tota Svecia Reperiuntur, SECUndum Novam et Naturalem a rostro desumtant nethodum in Classes distributa (!); ita ut cullibet generi proprius character, Unicuique speciei vera differentia adsignata Reperitur. [Fries Manuskr. p. 289.]

(Titel der Ausgabe: Caroli Linnai Med., Botan. \& Zoolog. cult. Methodus avium Svethicarum utgifven af Einar Lönnberg, Uppsala 1907 Almquist \& Wiksells boktryckeri A. -B. $8^{0} 1$ f., p. [1] -3 [Vorrede von Lönnberg], 2 f., p. [9]-[78], p. [79]-85 (Index), p. 86-96 (Anm. v. Lönnberg), 1 Taf. gez. von Linnæus in Faks.) ${ }^{\mathbf{1}}$ ).

a. Hamb. Berichte 15. III. 1732, p. 177 [p. 89]. Unter dem Titel: „Methodus avium Suethicarum, seu Enumeratio avium CG in Suethia observatarum. - $\beta$. [L. i. Ausl.] p. 294. $-\gamma$. [Ant.] p. 172: "Aves Sueciae".

$$
\text { - VI. - }
$$

Insecta Uplandica, Quorum per duas Aestates DCC collegta sunt. Dieses Manuskript, laut Fries, I p. 66 (Nota 3), unter der Aufschrift Insecta Suecica, das bisher noch nicht veröffentlicht wurde, befindet sich in der Londoner Linnæan Society; angemeldet ist es in: Uplandica's.

a. Hamb.-Berichte 15. III. 1732, p. 177, 178, [p. 89, 90]. - B. 1732. [Ant.] p. 172: „Insecta

$$
1732 .
$$$$
\text { VII } \left.{ }^{2}\right) \text {. }
$$

Caroli Linnai / Adonis / Stenbrohultensis / utgiven / av / Felix Bryk / Björck \& BörJesson / Sтоскноцм 1920 / Innenseite: / Stockholm 1920 / Cederquists Grafiska Aktiebolag, $8^{\circ}, 1$ f. (bla), 1 f., 1 f. (Karte nach Linsaus Zeichnung), 1 f., p. [7]-13, 2 f., 1 f. (Karte über Stenbrlt.), 1 f., 14 f. (Handschr.druck) mit folgendem Titelblatt: 1 f. (bla). -

Caroli Linnai / in Acad: Ups: Demonst: Bot:/ /Adonis / Stenbrhultensis / sive / enumeratio plantarum, quas in horto suo / Stenbrohultensi intulit venerandus par / ens Clariss Dnus Nicolaus Linneus / Pastor et Ecclesiastes ejusdem / loci laudatissimus. Secundum / methodum propriam in Ado - / nide Uplandica traditam / recensio stirpium / facta est / / Stenbroh. 1732 / - (Umschlag: Linnés / Adonis Stenbrohultensis / [Vignette, unterz.: C L inv., nach Linvaus Entwurfe aus Hort. upl. (Ed. Fries; [Hulth] p. 169) von Bryk umkomponiert] / Sтоскноцм / Bјörск осн Börjesson /).

VIII.

Caroli Linnai Iter Lapponicum (1732); [Hulth], p. 168.

Ähruing, edidit 1888; Fries, Ed. II, 1913; englische Übers. von Smith unter Titel: LACHESis lapponica, 1811; (Hulth, p. 161) ${ }^{3}$ ).

a. Hamb. Ber. 1733, p. 524 [p. 97]. „Anjetzo hat er auf eben die Art eine sogenannte Lachesin Lapponicam ${ }^{4}$ ), unter Händen" . . . - $\beta$. Commerc. Litt. Norimb. 1733, p. 73 [Nachdruck Stőwer, II, p. 307] „Lachesis Lapponicam elaborandam". - $\gamma$. Hamb. Ber. 1735, p. 387 [p. 103] „ein anderes Werk, genant OEconomia Lapponica" . usw. - $\delta$. [B. B. I] p. 102, ,Lachesis Lapponica“ (mit Inhaltsverzeichnis). - $-\varepsilon$. [B. B. II] p. 144 (wörtlicher Nachdruck aus Ed. I.). - $\zeta$. [S. N. X

1) Laut Fries ibid.: „Upsal: d: „1731 1. Jan.“ datiert. [Ups. Mscpt. D. 155].

2) Inwieferne ein Hinweis in Adonis Upl. (Vgl. Bryk Vorrede zu Ad. Stenbr., p. 8) sich aut diese Schrift bezieht, oder ob hiermit nur das Linnæus bekannte Pflanzenmaterial des Gartens gemeint war, sei dahingestellt.

3) Das erste mir bekannte posthum erschienene Zitat aus dieser Reise veröffentlichte Bäck [Tal, p. 61, 62 (Note)]; es entspricht der p. 70 der Originalausgabe von ÄhrLiva; jedoch ist die Wortfolge eine ganz andere, weshalb es möglich erscheint, daß B̈̈ck eine Abschrift vom Originale vorlag, falls er etwa nicht selbst die redaktionelle Änderung vorgenommen haben sollte.

4) Diese ursprünglich als Titel gedachte Aufschrift wird wohl Smith dazu veranlaßt haben, den Titel des It. Lapp. dementsprechend zu ändern. 
(Rat.)]: „Itinera ... Lapponicum $1732 \ldots$ inedita.“ - $\eta$. [S. N. XII (Rat.)]: „Iter lapponicum(1732) ineditum". - $\vartheta$. [Ant.] p. 172: „Lachesis Lapponica" ${ }^{1}$ ).

1733.

IX.

Caroli Linnai Iter ad podinas [Ed. Ährling, (1888)]; [Hulth], p. 169.

[Vgl. AGrel (part.) ibid.]

1734.

$\mathrm{X}$.

Caroli Linnat Iter Dalekarlicum (3. Aug. 1734) (Ed. Ährling 1888); [Hulth], p. 169.

a. Hamb. Ber. 1735 , p. 586-590 [108-112]. - $\beta$. [B. B. I] p. 102-103 . . „Etiamnum in $\mathrm{m}$. s. s. Jatet, forte cura doctissimi Historici-Naturalis \& Polyhistoris Mag. Johan. Browatimi prope diem lucem videb". $-\gamma$. [B. B. II] p. $144-145^{2}$ ). - $\delta$. [S. N. X (Rat.)] „Itinera ... Dolekarlicum 1734 inedita". - $\varepsilon$. [S. N. XII (Rat.)]: „Iter Dalekarlicum (1734) ineditum" ").

$\mathrm{X}$ a.

C. Linnai Flora Dalecarliga [1734] (Ed. Ährling ${ }^{4}$ ), 1878); [Hulth], p. 166; Fries [Manuskr.] p. 293.

XI.

Dieta naturalis comprehensa. (Inedit. M.S in Linnæan Society, London.)

a. [Ant.] p. 172, ,Diceta Naturalis"“

\section{Zu Linnés Lebzeiten erschienene Schriften.}

1731.

XII.

Dissertatio bot. de planta Sceptr. Carolinum .... auctor Johannes Olavus RudBECK OL. FIL. [Vgl. BrYK, Nachtrag p. 14; ibid. (Nota 3)].

1732.

XIII.

Hamburg. Berichte ${ }^{\overline{5}}$ ), Januar 1732, p. 45-46 [p. 83-84]; [Bryk], Stud. p. 46.

$\alpha$. [L. i. Ausl.], p. 294. - $\beta$. [Orb.], p. [15] "de Horto Upsaliensi".

XIV.

Hamburg. Berichte, Februar 1732, p. 94-95 [p. 86-87].

a. [L. i. Ausl.], p. 294. - $\beta$. [Orb.] p. [15] „Fundamenta Botanica“.

$\mathrm{XV}$.

Hamburg. Berichte, 15. März 1732, p. 177-178 [p. 89-90].

a. [L. i. Ausl.] p. 294. - $\beta$. [Orb.], p. [15] „de avibus \& insectis Sveciae".

XVI.

A) (?) In: Stockholms Post Tidningen vom 1. Mai 1732, (Faksim. in: Bryk [L.i. Ausl.] p. 12 .

a. [L. i. Ausl.] p. 294, 296: „Stockholmske Post-Tidningar, anno 1732. Maj 1. Nr. 18“.

1) ACrel [Tal] p. 163 hat den Titel des Mskrpt. folgend verändert mitgeteilt: ITER AD SuPERos et Inferos in Campis Elysis et Aula subterranea, ubi Regio Hyperboreorum et Regnum Plutonis cum descriptione Beatorum et infelicium susceptum A:o $1732 \& 1734$ [,worin er [= LiNnæus] auf verblümte Art aber seine lappländ. Reise und seinen Aufenthalt in Faluns Gruben erzăhlt." (Deutsch. übers.) Vgl. Acres ibid. - Auszäge aus der Lachesis finden sich in Fl. Lapp., und im Mínnesbok, von Browallius mitgeteilt, [L. i. Ausl.] p. 269-274.

2) Wörtlicher Nachdruck aus Ed. I mit folgenden Änderungen: anstatt „Baroni" — ,Baronis"; anstatt ,peregr." - ,peregrinantis"; anstatt „videb." - „videbit".

3) In [S. N. II] p. 77 und den späteren Auflagen wird eine zoologische Beobachtung, die auf jener Reise gemacht wurde, zitiert. - Laut C. Forsstrand, Linné i Stockholm (1915, p.56), wurde die an seinen Gönner Baron Reuterholm von Linn wus vor seiner Auslandsreise hinterlassene Abschrift des Mskr. von Reuterholms Sohne Gustaf Gottrried abgeschrieben. [„,Den 29. März: Nachmittag begann ich Linnæi Dahlresa zu kopieren; sie ist 8 Sexternen lang." (Deutsch. Ubers.)] Diese Abschrift, wenn sie überhaupt zustande kam, ist bisher nicht aufgefunden worden.

4) Laut Ähri.ings C. v. Linnés Svenska Arbeten I, H. S. p. 59 (1879) beabsichtigte Browaldius eine: Flora Dalekarlica Caroli Linnei aucta herauszugeben. Auf Grund dieses Anhaltes könnte die in [B. B. I, II] bereits mitgeteilte Anmeldung einer von Browaldius vorzubereitenden Ausgabe von Iter Dalekarlicum auch auf die Flora Dalecarlica bezogen werden.

5) Gegenüber Fries I (p. 114 Nota) schließe ich mich der Anschauung von Stöwer, Ährlivg an, wonach Linsaus direkte Urheberschaft am Löwenanteil an den in den Hamburg. Berichten von 1732-1739 veröfentlichten Linnéana außer Frage steht. (Vgl. BRYK [Stud.] p. 45-54). 
B) Deutsche Uebersetzung davon in: Намв. Benichte, Juni 1732, p. 398-399 [p. 92 bis 93$]$.

a. [L. i. Ausl.] p. 297. - $\beta$. [Orb.], p. [15] ,iter Lapponicum“.

XVII.

A) Намв. Berichte, 1733, p.523-525, [p. 106-118]. Eine schlechte dänische Uebersetzung B) davon in: Hafniensis Nye Tidende om Lärde og Curieuse sager anno 1734 (!) octob. 14. No. 41, p. $643-645$.

a. [L. i. Ausl.] p. 295 „Observationes Lapponicæ“, p. 296 „Hafnienses Nye Tidender om laerde og curieuxe anno 1734. octobr. 14. No. 41."

$\beta$. [Orb.] p. [15] „observationes Laponica"; p. [16] "Tidender an Larde og curieuxe“.

XVIII.

Car. Linnei Epistola de itinere suo Lapponico, [edidit A. Celsius] in: Commercium LitTerarium, ad Rei Med. et Sc. Nat., Annus 1733 Hebd. V No. 2, p. 34; Hebd. X $73-74$. (Nachdruck in STöWER, II, p. 302-306).

$\alpha$. [L. i. Ausl.] p. 296. „Commercia litteraria Norinbergica“. - $\beta$. [Orb.] p. [16].

$$
-1734 .-
$$

XIX.

Hamb. Berichte, Juli 1734, p. 494 [p. 100] [edidit Nettelbladt]. Linnæus eigenhändige Abschrift [L. i. Ausl.] p. 295; Bryk [Stud.] p. 46, 47, Fig. 9. (Faksim.).

$\alpha$. [L. i. Ausl.] p. 296. - $\beta$. [Orb.] p. [15] „Canones Rei herb.“

$$
-1735-
$$

$$
\mathrm{XX} \text {. }
$$

Hamburg. Berichte, 10. VI. 1735, p. 386-390, [p.112-116]; [Bryk, L. i. Ausl.], p. 250. a. [Orb.] p. [15]. „Varia“.

\section{XXI.}

Dissertatio medica . . . HYPoth. Nova DE FEbR. . . ; [ [Hulth $\left.]^{1}\right)$, p. 2.

a. [L. i. Ausl.] p. 291. - $\beta$. Hamb. Berichte 1735 No. LXXV p. 617 [p. 113-114] = Linnæus eigenes Referat. $-\gamma$. [Fl. lapp] (Prop. Scr.). $-\delta$. [Orb.] p. [4]. "Quart." $-\varepsilon$. [Ant.] p. 117.

Der Nachdruck von CaMPer in Amoen. Acad., Vol. I [Ed. Lugd. Bat., 1749] wird in [Ant.] p. 117 angefnhrt: „Lugd. 1749. 8:0“.

XXII.

Hамв. Ber. ). 20. Sept. 1735, p. 617-618, [p. 113-116]; [Bryk, Stud.], p. 49-54. $\alpha$. [Orb.] p. [15] ,de febribus".

A) S. N. I $\%$ (1735); [HuLth], p. 2-3.

XXIII.

a. [L. i. Ausl.] p. 277 wird diese Schrift ,Geographia Natura" genannt (Browallius);

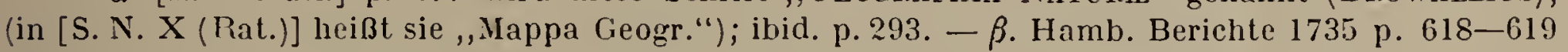

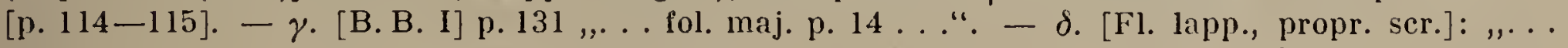
char. max." $-\varepsilon$. [H. Cliff.] Nr. 223 (sine pag), ,. . fol. $\max$. p. $14 \ldots$. . $-\zeta$. [Orb.] p. [4]. $\eta$. [Fl. Sv. I] „.. . Fol. latine, nominibus sueticis". -. . [B. B. II] p. $178, \ldots$ fol. $\max . . . "-\iota$. [FI.

1) Laut Laxkester [Cat.] p. 16 , This thesis was reprinted at Stockholm the some yar" (!); offenbar ließ sich LANkester von einem Errat. in [Ant.] p. 117 ,Stockh. 1739. 8: o." irreführen.

2) Alle weiteren Beiträge in den Hamb. Berichten, wovon einer sogar C.L.D. signiert ist (Hamb. Ber. 1737 [p. 141]) hat Lixw zus merkwürdigerweise in keiner seiner Schriften weiter erwähnt. Ubrigens läßt sich aus den Linnéschen bibliographischen Angaben über die in den Hamb. Berichten erschienenen Referate keineswegs deutlich ersehen, als ob er damit sich selbst als deren Verfasser ausgeben wollte. Wir haben [Studier, p. 52] nachgewiesen, daß selbst die Notiz vom 9. Sept. 1736 (Hamb. Berichte [p. 135-136]) Linvaus zum Verfasser hat; diese Stelle wurde später von Lesser in seinen Auflagen der Insektotheologie (III. Aufl. p. 29-30), auch in der Lyosverschen franz. Ubersetzung nachgedruckt (1742, p. 31 Nota). Die französische Ausgabe kannte Linseus besonders gut. De GeEr schreibt ihm hierüber. ,, Sonst attaquiert Lyonnet Professors Insektensystem, nach meiner Ansiclıt haut er dabei gründlich ins Blaue." (Original schwed.); [L. Bref] V p. 336, 1911.

3) Das M. S. von [S. N. I] hatte Lins eus am 15. Juli fertig; am 13. Dezember hatte es die Presse verlassen. (Holmström [Adnot.] p. 217, 218.) Der mineralogische Teil ist teilweise nach dem M.S. von Pluto suecicus (Ed. posth. BexDix 1907) verfaßt. Laut Cronstedt [Min. germ.] in d. Vorrede [unpag.] lıătte Browallius an dem Mineralreiche mitgeholfen. „Der Herr Browallues liatte Gelegenheit und Einsichten genug, um in seiner Handschrift etwas im Aufsatze des Herrn Liswaus zu verbessern, und zu machen." Aus dem schwedischen Urtexte [Miner.], Företal p. [4], scheint aber diese Auffassung, wie sie der Ubersetzer vorträgt, nicht gerade bestimmt hervorzugehen. Vielleicht bezieht sich diese Behauptung auf die Herausgabe der sog. RoBergschen Observationes? In der praefatio von [S. N. XII] Tom. III gibt Linnæus 1736 (!) als das Jahr an, wo er sich zuerst mit seiner systematischen Einteilung des Mineralreiches befaßte. (Die anonyme Mineralogie von CrosstedT wird übrigens auf derselben Seite besonders hervorgehoben; ,1756" (!).)

Bryb, Linnacus im Auslande. 
Sv. I] „, . . Fol. latine, nom-sueticis p. 13“ (!). - «. [S. N. X (Rat.)] „, . Fol. imper. pag. 12" (!) ,a me per J. F. Gronovium. Conspectus tantum operis \& quasi Mappa Geogr." - $\lambda$. [S. N. XII (Rat.)] idem. - $\mu$. [Ant.] p. [69]-70.

B) $[$ S. N. II], Halæ $1740 ;$ [HuLth] p. 3.

a. [Orb.] p. [4]. - $\beta$. [B. B. II], p. 187. „. $4^{0}$ nominibus latino-germanicus". $-\gamma$. [Fl. Sv. I) „.. Ouart, latino-germanice". $-\delta$. [Fl. Sv. II). $-\varepsilon$. [S. N. X (Rat.)]. Hier als dritte (!) Auflage .. angeführt. „Quart- oblong. pag. 70 p. J. J. LANGEN Latino-germanice, caeterum idem

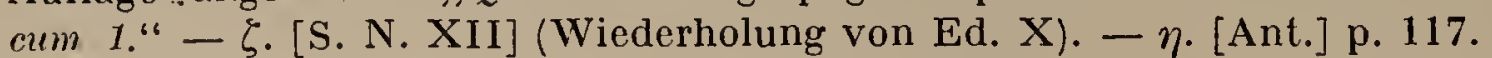

\section{XXIV.}

A) S. N. III $\left.{ }^{1}\right)$ (= II. Original), Holm. 1740; [Hulth $]$ p. 4.

a. [Orb.] p. [4] ,idem auctius. Stockh. 1740" (als Ed. II (!), sonst wird diese Auflage von Linneus stets als III. Aufl. gezählt). - $\beta$. [Fl. Sv. I] "Octav. auctum. Nom. sueticis". $-\gamma$. [B. B. II] p. $187,8^{\circ}$ maj. p. 80 auctum nominibus sueticis" [B. B. II]. - $-\varepsilon$. [S. N. X (Rat.)] „Octavo pag. 80 a me ipso revisum. Auctum Animalium nomencla-

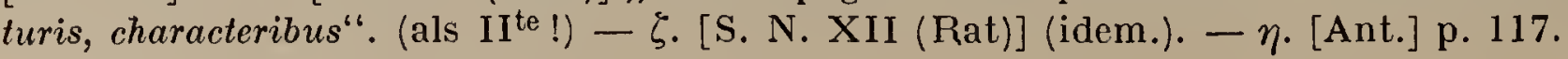

B) S. N. IV, 1744; [Hulth], p. 4.

$\alpha$. [Fl. Sv. I] „Octav. Auctius. Nom. gallicis“. - $\beta$. [B. B. II] p. $187,8^{0}$ maj. p. 108 auctius nominibus gallicis". $-\gamma$. [Fl. Sv. II] (wie Ed. II). - $\delta$. [S. N. X (Rat.)] „Octavo. pag. 108. t. I per B. Jussieun. Adjecta nomina Gallica idem cum $2^{\prime \prime}(2$ bezieht sich auf II. Originalaufl.) $-\varepsilon$. [S. N. XII (Rat.)] (idem). - $\zeta$. [Ant] p. 117.

C) [S. N. V] 1747; [Hulth], p. 5.

a. [B. B. II] p. 187 [wird diese Ausgabe völlig ignoriert (!)]. $-\beta .[F]$. Sv. II] „,Octav. p. 87" - $\gamma$. [S. N. X (Rat.)] „Octavo pag. 88“ (!) „per M. G. Agnethler. Nomina Germanica, cceterum idem cum 2." $-\delta$. [S. N. XII (Rat.)] (idem). - $\varepsilon$. [Ant.] p. 117.

\section{$\mathrm{XXV}$.}

A) S. N. VI, 1748 (III. Originalausgabe); [Hulth]. p. 5.

a. [B. B. II) p. 187: ,,80 maj. p. 224. t. 8. nominibus sueticis. - $\beta$. [Fl. Sv. II) ,Octav. auctius. p. 223" (!) „t. 8“. - $\gamma$. [S. N. X (Rat.)] „Octavo. pag. 232"(!) ,t. 8. auctum a me ipso. Characteres essent. Vegetabilium. Species Anim.\& Lapid". - $\delta$. [S. N. XII (Rat)] (idem). - $\varepsilon$. [Ant.] p. 117.

B) S. N. VII, 1748 Lipsiæ. [Hulth], p. 5.

a. B. B. II, p. $187,8^{\circ}$ maj. p. 224. t. 8. nominibus germanicis, c. iconc authoris annorum 47. Cum Systematc Lapidum, Quadrupedum, Avium, Insectorum \& c." - $\beta$. [Fl. Sv. II] „Octav. nom. germ. p. $123^{\prime \prime}($ !) ,t. 8.“ - . [S. N. X (Rat.)] „Octavo. pag. 232" (!) ,t. 8. per Typographum. Nomina Germanica, cceterum idem cum 6. - $\delta$. [S. N. XII (Rat.)] (idem.). - E. [Ant.] p. 117.

C) S. N. ViII, [ed. Haartman (1753); Möller ${ }^{2}$ ) (1755 (?))] [Hulth], p. 6.

a. [S. N. X (Rat.)] ,,Holmiæ 1753 Octav. p. 136. Vegetabilia per J. J. HaARTMan. At regnum Lapideum Scarae 8 : vo per MöLLER". - $\beta$. [S. N. XII (Rat)] (idem). - $\gamma$. [Ant.] p. 216 ,,8. c. tab. 3 aneis, Regnum Vegetabile auctius, Svethice per J. J. HAARTMAN". (MÖLLER wird hier ignoriert.)

D) S. N. IX, 1756 [Нulth], p. 5.

a. [S. N. X (Rat.)] „Octavo p. 226“ (!) ,per Gronovium. Paucissima de Avibus, Piscibus.

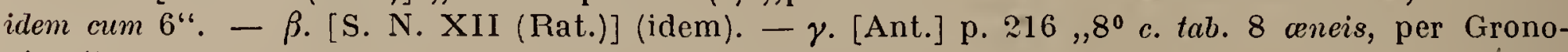
vium".

\section{XXVI.}

A) S. N. X, 1758-1759 (IV. Originalausgabe); [Hulth], p. 6.

a. [S. N. X (Rat.)] ,longe auctius factum a me ipso". - $\beta$. [S. N. XII (Rat.)] (idem.). $\gamma$. [Ant.] p. 56, 58, 59, 216 ,,longe auctius"

B) S. N. XI, Lipsiæ 1762 [Lankester], p. 7, [Pritzel] p. 16I, [Stöwer] p. 172 (,Ed. XIII . . " (!)).

a. [S. N. XII (Rat.)] „Lipsiae 1762. Octavo. furtim prodiit vitiosa. Nil additum". B. $\left[\right.$ Ant. ${ }^{3}$ ) p. 217 ,Lips. $1762.8^{\circ}$. Voll. $2^{\prime \prime}$.

\section{XXVII.}

S. N. XII, 1766-1768 (V. Originalauflage); [HuLth], p. 9.

$a$. [S. N. XII (Rat.)] „Holmensi hac propria ultima penultimaque editione“. - $\beta$. [Ant.] p.62,63; 217, ,Holm. 8:0. Tom. I. 1766, Tom. I. P. 2. et Tom. II. 1767, Tom. III. 1761, perfectum ".

XXVIII.

C. Linnai Florula lapponica ${ }^{4}$ ) [1732]; Hulth], p. [1].

1) Ist zusammen mit Fundamenta Bot. II erschienen, hat gemeinsame Errata auf einem Blatte.

2) Wegen Regnum animale vgl. BRYr [Stud.] p. 65-71, sowie die vorletzte Seite des Umsclilages von BRYK [Nachtr.]

3) In [Ant.] p. 216 wird die laut Нúth (p. 7) allgemein als elfte Auflage aufgefaßte Magdeburger Ausgabe von 1760 vor Linnés ,elften" (= Lips. 1762) zitiert: "Halæ, 1760. 80. Voll. $2^{\prime \prime}$

4) Laut Fries [L. Bref], Vol. V p. 251 (Nota 3 und 4) ist diese Schrift nicht vor 1735 und der II. Teil sogar erst $1742(!)$ erschienen. 
a. [L. i. Ausl.], p. $291,1732 \%$ B. [Fl. Lapp.] ,Upsal. 1732, in actis Lit. Suec. a pag. $46-48^{\prime \prime}(!) .-\gamma$. [Orb.] p. [4], $1735^{\prime \prime}(1) .-\delta$. [Fl. Sv. 1], ,1732" (!).

$$
\begin{array}{r}
-1736- \\
\text { XXIX. }
\end{array}
$$

A) B. В. I, 1736; [HuLth], p. 17.

a. [L. i. Ausl.] p. $293 .-\beta$. H. Cliff. (unpag., Cl. XV1, 288), ,80 p. $153^{\prime \prime}$ - $-\gamma$. [Fl. lapp.] ,editio prima"(!) - $\delta$. [Orb.] p. [4], ,735 (!) oct." $-\varepsilon$. [F]. Sv. 1],,1735" (!), ,octavo". $-\zeta$. (B. B. 11] p. $214,, 173612^{\circ \prime \prime}(!),, p .153^{\prime \prime}$ - - $\eta$. [Fl. Sv. 1I] p. X11,,1735" (!) etc. etc. - . [Ant.] p. $71,117,1736.8: 0 "$; p. 170 .

B) B. B. II, 1747 (Nachdruck) $\left.{ }^{1}\right)$; [Hulth], p. 17.

u. [B. B. II] (ohne jede Angabe!). - $\beta$. [Fl. Sv. II] p. X11. „Octavo p. 124“. 8. [Ant.] p. 74,117 .

XXX.

B. B. II, 1751 (zweite Originalauflage); [Hulth], p. 17.

a. El. Sv. Il p. X11 „Octavo p. $220 "$. - $\beta$. [Ant.] p. 117.

A) F. B. I ${ }^{2}$ ), 1736; [HuLth] p. 17.

$\alpha$. [B. B. I) p. 123 ,Amstel. 1735 (!) $8^{0 \prime \prime}$ - $\beta$. [Fl. Lapp.] ,Amst. $17368^{0 \prime}$. $-\gamma$. [L. i. Ausl.] p. 292. $-\delta$. (H. Cliff.] (Class. X) ,1736, 80, p. 35 aphoristice Paucis multa". $-\varepsilon$. [Orb.] p. [4]

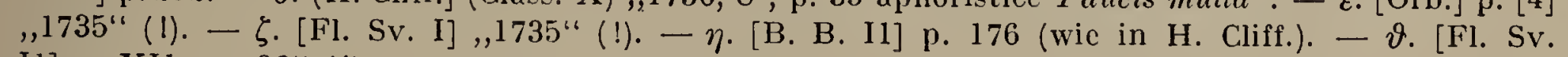
I1] p. XI1 ,p. 36" (1). - ८. [Ant.] p. 71, 117.

B) $[$ F. B. (II)], Abœ 1740; [Hulth], p. 18.

$\alpha .[\mathrm{Fl} . \mathrm{Sv}$
$\delta[$ Ant $]$ p. 117.

\section{XXXI.}

\section{XXXII}

A) F. B. Holm. 1740. II. Originalausgabe; [Hulth], p. 18.

$\alpha$. [Orb.] p. [4]. ,eadem emaculata". $-\beta$. [Fl. Sv. 1]. - $\gamma$. [B. B. I1] p. 176. $-\delta$. [Fl. Sv. II] p. XI1. - E. [Ant.] p. 117.

B) F. B. (III), 1740 (edidit Alston); [Hulth], p. 18.

[B. B. 11] p. 100 (nicht unter eigenen Schriften, sondern unter den englischen ,,Adonistæe: "Alston Carolus. Index plantarum Horti Medici Ediburgensis. Edinb. 1740. 80, p. 66 . Systematice Synonymis".

\section{XXXIII}

A) F. B. III (1741), III. Originalausgabe; [НuLth], p. 18.

$\alpha$. [Orb.] p. [4] ,,cadem emaculata. Lgdb. $1740^{\prime \prime}($ !) „Oct.“. $-\beta$. [Fl. Sv. 1]. - $\gamma$. [B. B. I1] p. $176,, 8^{\circ}$ maj. p. 51 aucta $\&$ emendata". $-\delta$. [Fl. Sv. 11] p. X11. - - . [Ant.] p. 117.

B) F. B. (IV.) (Paris 1744); [Hulth] p. 18.

a. [Fl. Sv. 11) p. XII ,p. $26^{\prime \prime}$. $-\beta$. [Ant.] p. 117.

C) F. B. (V), Halæ 1747; [Hulth] p. 18.

a. [Fl. Sv. II] p. XII ,p. 31 "(!). - $\beta$. [Ant.] p. 117.

\section{XXXIV.}

Caroli Linnei Methodus, 1736; [Hulth], p. 20.

a. [L. i. Ausl.], p. 292 „Lugdbat. Fol. maj. plag. 1“. - ß. [Fl. Lapp.] „Lugd. 1736 p. 1.“ $\mathrm{XXXV}$.

Caroli Linnai Musa Cliffortiana, 1736; [Hulth], p. 20.

a. [L. i. Ausl.] p. 293. - $\beta$. Hamb. Berichte (28. 11. 1736) p. 150 [p. 122]: M. Cliff. . . ,,inter Lugdunum \& Harlemum in Belgio descripta \& depicta. Sic wird in gros $8^{\text {vo }}$ (!) mit der Figur 6 . Bogen

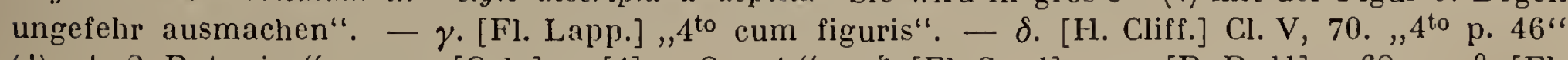

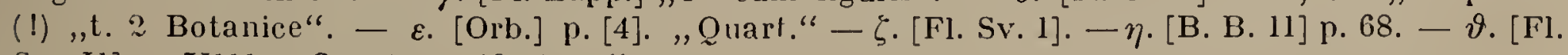
Sv. I1] p. X111. ,Quart. p. 46. t. 2."

1) Laut Choulant [Medhist.], p. 135, ist Agnethler der Herausgeber.

2) F. B. 1 sind zusammen mit B. B. 1 erschienen. Linnæus hatte bereits seit 1730 verschicdene Male sich an die Fundamenta herangemacht. Das älteste Manuskript befindet sich laut ÄmrLris (C. v. Linnés Ungdomsskrifter I p. 93) in der Lond. Linnæan-Society und trägt den Titel:

Caroli linnai Shol-Sveci Medici et Histor. Nat. stud. Fundamenta Botanica. . UPSAL: 1730 .

Es wurde von Ährling (1. c.) in extenso abgedruckt. [Vgl. auch Beckmaxn [Schw. Reis.] p. 105 und Frres (ibid. p. 165).] In Hamb. Berichte [p. 100] wird bereits 1734 die Herausgabe der F. B. von Nettelbladt angezeigt. Noch so spät wie am 20. Juli 1736 (!) wird vom sclben Nettelbladt in den Hamb. Berichten [p. 118] das Erscheinen derselben ,,in gros Fol. und ctwa 9 Bogen Anmerkungen“" angezeigt; während es laut HuLth (p. 17) bereits am 3. September (alt. St.) 1735 (!) erschicnen war. (Vgl. anch Bryk [L. i. Ausl.] p. 10, 47 (Note 5).) 
XXXVI.

Cl. Linnai I cones methodi sexualis (Edid. D. Ehret, 1736); Bryk [L. i. Ausl.] p. 247. a. [L. i. Ausl.] p. 294.

Ed. II unter verändertem Titel: C. Linnai CLasses S. Litera 1737 [ed. Gronovius] ${ }^{1}$ ); [Bryк, L. i. Ausl.] p. 247; [Hulth emend.], p. 23, Zeile 4 (v. o.).

a. [L. i. Ausl.] p. 294.

\section{$-1737-$ \\ XXXVII.}

Linnai Caitica botanica I, 1737; [Hulth], p. 21; [Becimann (Schw. Reis.)].

a. [L. i. Ausl.] p. $290 .-\beta$. [B. B. I] p. $134, \ldots$ in animum edere habemus". $-\gamma$. [H. Cliff.] (Crit. XII, 229) , . . 8 $8^{\text {vo }}$ maj. p. 270". $-\delta$. [Orb.] p. [4]. $-\varepsilon$. [Fl. Sv. 1]. $-\zeta$. [B. B. II] p. $191 .-\eta$. [Fl. Sv. II] p. XII. $-\vartheta$. [Ant.] p. $72,117$.

\section{XXXVIII.}

FL. LAPP., 1737; [HuLTh], p. 21.

a. Hamb. Berichte 1733 (!), p. 524 [p. 97] ,und bestehet solches, nachdem er es bereits geendigt, aus 36 Bogen, und 80 Figuren". $-\beta$. [L. i. Ausl.] p. $290-291$. $-\gamma$. [B. B. I] p. $85-86^{\circ}$ ). -

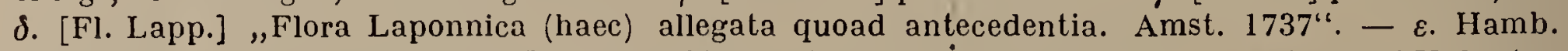
Berichte (28. Febr. 1736) p. 150 [p. 122; 129]. „Die 83 dazu gehörigen Figuren sind auf Unkosten der Herrn Professorum des Athenoei Amstelodamensis, sehr sauber und schön in Kupfer gestochen" 3 ).

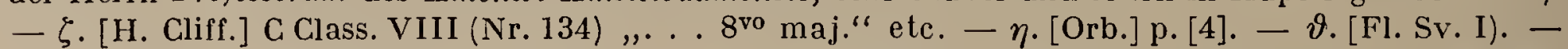
i. [B. B. II) p. $121,8^{0}$ maj. p. 327 (!) t. 12, fig. plures $\left.{ }^{4}\right)$ - $\%$ [FI. Sv. II] p. XII. - $\lambda . .[$ Spec. Pl. I]. $-\mu$. [Spec. Pl. II]. $-v$. [Ant.] p. 79, 117 .

XXXIX.

Gen. plant. (Ed. I.), 1737; [Hulth, emend.] p. 22.

a. [L. i. Ausl.] p. 293. - $\beta$. Hamb. Berichte (28. Februar 1736 p. 149) [p. 121]. $-\gamma$. H. Cliff. (Class. XI Nr. 222) ,...p. $384^{\prime \prime} .-\delta$. [Orb.] p. [4]. $-\varepsilon$. [Fl. Sv. I]. $-\zeta .[$ B. B. II] p. $186 .-\eta$. Fl. Sv. II p. 'XII. „.. gen. $935^{\prime \prime}$.

XL.

A) Gen. Plant. (II. Originalausgabe), 1742; [Hulth] p. 23.

$\alpha$. [Fl. Sv. I] ,emendatum". - $\beta$. [B. B. II p. 186 ,aucta \& emendata". $-\gamma$. [F]. Sv. II] p. XII " . . 1752" (!) . . ,gen. 1021". - $\delta$. [Spec. Pl. I] ,1752" (!).

B) Gen. Plant. (III), Paris. 1743; [Hulth], p. 23.

$\alpha$. [Fl. Sv. I]. - $\beta$. [B. B. IL] p. 186. $-\gamma$. [Fl. Sv. II] p. XII ,gen. 1021 ".

C) Gen. Plant. (IV), Halæ 1752; [Hulth], p. 24.

a. [Fl. Sv. II], p. XII, „. . gen $1090^{\prime \prime}$.

XLI.

Gen. Plant. (V) (= III. Originalausgabe), 1754; [Hulth], p. 24.

$\alpha$. [Fl. Sv. II] p. XII : „.. . gen. 1105“. $-\beta$. [Spec. Plant. II]. $-\gamma$. [Ant.] p. 54.

XLII.

Caroli Linnei Corollarium, 1737; [Hulth], p. 23.

$\alpha$. [H. Cliff.] (Class. XI § 222). $-\beta$. [Fl. Sv. I]. $-\gamma$. [B. B. II] p. 186. $-\delta$. [Ant.] p. 118. XLIII.

Caról Linñet. Method. Sexualis, 1737; [Hultit $\left.]^{5}\right)$, p. 23.

a. [H. Cliff.] (Class. XI $\S 222$ ) „Conjunctim. - Soli characteres secundum omnes partes fructificationis" $\left[8^{\circ}\right.$ maj.]. $-\beta$. [L. i. Ausl.] p. 290. $-\gamma$. [Orb.] p. [4]. $-\delta$. [Fl. Sv. I]. $-\varepsilon$. [B. B. II] p. 186 (Wiederholung aus H. Cliff.). - $\zeta$. [Ant.] p. 118.

\section{XLIV.}

Hortus Cuffortianus, 1737 („Dabam 30 Jul. 1737); [Hultil], p. $27-28$.

a. [L. i. Ausl.] p. 289. - $\beta$. Hamb. Berichte, 11. Februar 1738, p. 91-93 [p. 145-147] \%).

1) Vgl. Ehrets Brief an Linneus, worin er sich wegen Grovovius Nachdruckes beklagt. (Vgl. BRYk [Nachtrag] p. 9.) Diese Tafel war eine der populärsten schematischen Abbildungen; sie wurde wiederholt nachgedruckt, zuerst von Linné in seinem S. N. III. Als eine der letzten „Auflagen" kann wohl die in Birmingham geprägte originelle Gedenkmüne mit "The 24 Classes of Plants by Linn «us" gelten.

2) „M. s. s. spes affulget proxime ed. continet plantas per lapponiam s. 100 milliaria Svecica in lon,git. \& 50 . in latitud. collectas, quarum proprium est, perdurare in summo frigore, longissima hyeme, bre„,vissima æstate \&c. conscripta est Fl. Nostra secundum meth. sexualem, cum synonymis, descriptionibus ", \& figuris rariorum plantarum, nec non usu earundem quotidiano œconomico \& medico apud Lappones."

3) Vgl. BRyk [L. i. Ausl.) p. 23; [Nachtrag] p. 9.

4) Die Inhaltsangabe aus [B. B. I] (vgl. [Nachtr.] p. 20 Note 2) wird wörtlich wiederholt.

5) In [Hulth emend.] p. 23 wird irrlümlich $4^{\circ}$ anstatt $8^{\circ}$ angegeben.

6) ,.. . . siehet man dieses Werk durch 40, von der berühmten Hand des Hn. Vardedars gestochene Kupferplaten, verschönert, davon der blosse Stich einer ieden Plate 24 holländische Gul- 


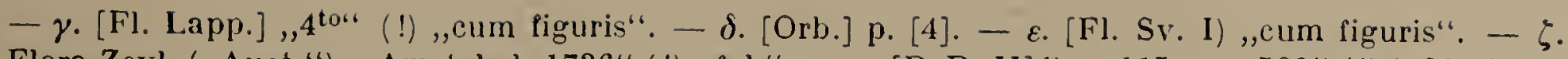
Flora Zeyl. (,,Auct.“). ,Amstelod. 1736“ (!) ,, fol.". - - - [B. B. II] ") p. 115 : ,p. $502^{\prime \prime}$ (1) t. 32 nitidæ

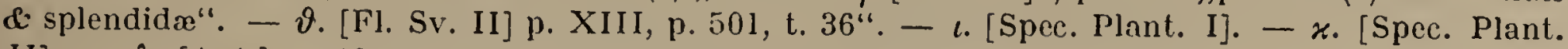
II]. $-\lambda$. [Ant.] p. $73,117$.

XLV.

Caroli Linn fi Viridarium Cliffort., $1737^{2}$ ); [Hulth], p. 28.

$\alpha$. Hamb. Berichte [16/1] 25. Februar 1738, p. 132 [p. 151]. $-\beta$. [Orb.] p. [4]. $-\gamma$. [F]. Sv. I]. $-\delta$. [Spec. plant. I]. $-\varepsilon$. [Ant.] p. 73, 118.

\section{XLVI.}

A) Caroli Linn ei Classes plantarum (Ed. I), 1738; [Hulth], p. 28.

$\alpha$. Hamb. Berichte $\left.{ }^{3}\right)[16 / 1]$, 25. Februar 1738, p. 132 [p. 151]. - $\beta$. [Orb.] p. [4]. $-\gamma$. [F]. Sv. I]. $-\delta$. [B. B. II] p. 187. - $\varepsilon$. [Fl. Sv. II] p. XII. - . [Spec. PI. II]. - $\eta$. [Ant.] p. 72, 118.

B) Class. plant. [II], 1747; [Hulth] p. 29.

a. [Fl. Sv. II] p. XII. - $\beta$. [Ant.] p. 118.

1739.

XLVII.

J. Eb. $\left.{ }^{4}\right)(\text { !) Ferber, Hortus Agerum, 1739; [Hulth }]^{5}$ ), p. 31.

$\alpha .[$ Orb.] p. [4]: ,,secundum Leges Linnæi sunt sequentia“. - $\beta$. [Fl. Sv. I] „Hortus proprius secundum systema sexuale conscriptum". - $-\gamma$. [B. B. II) p. 118 (Wiederholung aus Fl. Sv.). $-\delta$. [Fl. Sv. II] p. XIV (wie Ed. I). - - . [Ant.] p. 116 ,"Totus LINNAI est."

\section{XLVIII.}

A) Tal om Märkvärdigheter uti insecterna, (I. Ed) 1739 ; [Hulth] p. $31,32$.

a. [S. N. II] p. 76 , ,oratio nostra de Proprietatibus Insectorum, Stockholm, 1739, $8^{\mathrm{vo}}$. Svec. $-\beta$. [Orb.] p. [4]. $-\gamma$. [Fl. Sv I]. - $\delta$. [Tal om märkw. III] p. 32. $-\varepsilon$. [Tal om märkw. IV], p. 32.

B) $\mathrm{T}_{\mathrm{AL}}$ etc. etc. II, $1741 ;$ [Hulth] p. 32.

a. [Fl. Sv. I) "Lugdbat. 1741. Duod. belgice". - $\beta$. [Tal om märkw. etc. III] p. 32. $\gamma$. [Tal etc. IV] p. 32 .

C) TAL etc. etc. III, 1747; [Hulth], p. 32.

a. [Tal om märkw. III] p. 32 „Editio 3 denna, med nägra fá anmärkningar förökt och med numrer vid hvart och et insect, efter Fauna suecica" ...., pá det läsaren mátte nogare förstå hvilket djur jag visar." $-\beta$. [Tal om märkw. IV] p. 32. (Wiederhol.) - $\gamma$. [Ant.] p. 118.

D) Tal etc. etc. IV, 1752 ; [Hulth], p. 32.

a. ibid. p. 32 ,,denna 4 och sista $\left.{ }^{6}\right)$ Edition utkommit $1752^{\prime \prime}$.

\section{XLIX.}

Rön om växt. Plant. (1739, in: V. Ak. Handl.); [Hulth], p. 32.

a. [Fl. Sv. I] ,,cult. plant. naturalis".

L.

- om renarnas brömsk. (1739, in: V. Ak. Handl.); [Hulth], p. 33.

a. [Fl. Sv. I] ,oestr. rangif." . . ,1740" (1).

1740.

LI.

ANM̈̈RKN. ÖFW. LAPPSK. LIM. (1740, in: V. Ak. Handl); [Hulth], p. 34.

a. [Fl. Sr. I]: ,Glutea lapponum e perca ... 1739“ (!).

den zu stehen komt.“ . . . , ,pagg. 502" (!) außer den $4^{0}$, „(? oder 40$)^{\prime}$ Seiten, so die Prolegomena einnehmen". (ibid. p. 93 [67]). Bekanntlich sollte das Werk ursprünglich in $4^{\circ}$ erscheinen.

1) In: [B. B. I] p. 81 schreibt LiNneus: ,desiro" (hortum), ,descriptum", was in [B. B. II] natürlich nicht mehr aktuell war und weggelassen wurde.

2) Hallers Angabe (Bibl. p. 249), diese Schrift sei 1748 (!) in Amsterdam erschienen, beruht offenbar auf einem Druckfehler; er fügt ja hinzu: „,non vidi".

3) Laut jener bibliographischen Quellenangabe sollten die Classes unter folgendem abweichen-

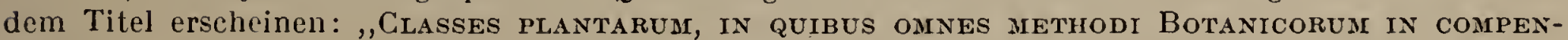

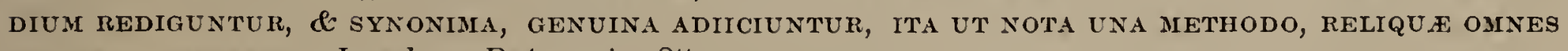
Facile appareant, Lugdun. Batav. in $8^{\prime \prime}$.

4) Laut Rosenhane [V.A. Hist.] p. 458, Note 2 hieß Ferber nicht, wie Linnzus angibt, Johan Eberhard sondern Johan Henrik.

5) Acrel ([Tal.] p. 163) ist der erste, der diese Schrift Linnasus zuschrieb. Haller [Bibl.] II, p. 305, ließ sich wahrscheinlich von der Tatsache, daß Rotharas die Vorrede verfaßt hat, dazu verleiten, die ganze Schrift Rothman zuzuschreiben. Bemerlienswert ist ein diesbezüglicher Passus aus einem Briefe von Linneus an Rudbeck d. J.; vgl. AGardir [Progr.] p. [9], nola b. (,quac adulationem quandam redolet").

6) Percherox [Cat. I] p. 253 erwähnt noch eine lateinische Ausgabe vom Jahre 1739, die sicher nie erschienen ist; er erwähnt ferner eine Pariser Ausgabe 1743, wie sie ebenfalls von LiNxé [Ant. p. 118] angegeben wird, was aber voll Afzerius (ibid.) berichtigt wird. 
LII.

Beskr. Ny Fogel. (1740, in: V. Ak. Handl.); [Hulth], p. 34.

a. [Fl. Sv. I] ,,Picus pedibus tridact."

LIII.

ANmäriking öfw. diUREN . . Norrige (1740, in: V. Ak. Handl.); [Hulth], p. 34. $\alpha$. [Fl. Sv. I] „Mures alpini Lemures".

LIV.

Besk RIFN. Pà SNö-SPARFw. (1740, in: V. Ak. Handl.); [Hulth], p. 35.

a. [Fl. Sv. I] "Passer nivalis".

LV.

Beskrifn. om Guldfisiken (1740, in: V. Ak. Handl.); [Hulth], p. 35.

a. [Fl. Sv. I] „Piscis aureus Chinensium".

LVI.

Tanckar om Grund t. Oeconomien (1740, in: V. Ak. Handl.); [Hulth], p. 35.

a. [Fl. Sv. I] "Fundamenta oeconomice".

1741.

LVII.

Orbis ERUditi JUdicium ${ }^{1}$ ) (1741); [Hulth], p. 36. (Faksim. von Junk 1901.)

LVIII.

A) Oratio, qua peregränationum . . (I Ed.) 1741; [Hulth], p. 36.

a. [Fl. Sv. I] ,Upsal. 1742" (!) „Octav.“ (!).

B) Oratio .... (II Ed.) 1743; [Hulth], ibid.

a. [FI. Sv. I].

LIX.

Herr Doct. Caroli Linnai högstnytt . . hus-curer. (Alm. 1742); [Hulth], p. 37. $a$. [Fl. Sv. I] „Euporista in febribus interm. Calendariis I742". - $\beta$. [Ant.] p. 1 I5.

LX.

ANm. ÖFw. Wisen hos myrorna (V. Ak. Handl. 1741); [Hulth], p. 37.

$\alpha$. [Fl. Sv. I] ,Formicarum sexus".

LXI.

Prof. Linnai upSats pá . . medicinalwäxter, etc. (V. Ak. Handl. 1741); [Hulth], p. 37. a. [Fl. Sv. I] "Centuria pl. in Suecia rariorum".

1742.

LXII.

ANMÄrkn. OM INLÄNDSK. WäXter. (Alm. 1743); [Hulth] p. 38.

a. [Fl. Sv. I] „Pini usus œeonomicus . . 1743“.

LXIII.

Animalia per Sveciam observata ${ }^{2}$ ) [1736], 1742; [Hulth], p. 38.

a. [Orb.] p. [4] ,1736“. - $\beta$. [S. N. II] p. 77, ,I736“. - $\gamma$. S. N. III (idem etc. etc.). $\delta$. [Fl. So. I] ,animalia regni Sueciae ... 1736".

LXIV.

Förtekning af FÄrgegräs; (V. Ak. Handl., 1742); [Hulth], p. 39.

a. [FI. Sv. I] "Plante tinctorice indigence".

LXV.

Ammärkn. Öfwer Amaryllis, (V. Ak. Handl., 1742); [Hulth], p. 39.

a. [Fl. Sv. I] "Amaryllis formosissima".

LXVI.

Beskrifn. Ṗ SÄltings-PRäSEt (V. Ak. HandJ. 1742); [Hulth], p. 39.

a. [Fl. Sv. I] „Gramen Scelting (Triglochin.).

1) Inwieferne das sehr ausführliche Referat in den Hamb. Berichten vom Jahre I74I [BRYK, Studier p. 50-52, Fig. 10-I2] von Linsaus direkt veranlaßt wurde, ist schwer zu entscheiden. In [L. i. Ausl.] p. 253 ff. wurde auf die genetischen Beziehungen zwischen dem Mskr. des Stammbuches und jener anonymen Schrift hingewiesen. Ein gewisses Interesse hat die bisher ubersehene Mitteilung von Beckman [Minnen] p. 125, wonach Browaldius (!) der Herausgeber jener Apologie wäre. Eine Theorie vorläufig, für die noch der Indizienbeweis fehlt. Die erste bibliograph. Notiz über diese Schrift findet man bei $\mathrm{B} \ddot{\mathrm{Ack}}$ [Tal.] p. 35; nach Bäck ist dieses Büchlein in $12^{\circ}$ erschienen.

2) Diese erste schwedische Fauna erscheint hier aus den drei Mskr.: PAN eunopaus (Fries I p. 66 (Note 2)), Meth. Avium und Ixsecta Upi. zu einer Schrift zusammengeschmolzen. 
LXV.II.

Swenskt höprö (V. Ak. Handl. 1742); [Нulth], p. 39.

[Fl. Sv. I] „Foenum Suecicum (Medicago).

LXVIII.

Beskr. pi. . . . Ostindiska Ärter. (V. Ak. Handl., 1742); [Hulth], p. 40.

$\alpha$. [Fl. Sv. I] "Phaseoli chinensis species".

LXIX.

Rön om ons. Til fallande soten. (V. Ak. Handl., 1742); [Hulth], p. 40.

a. [Fl. Sv. I] „Epilepsia territorii vernensis causa".

1743.

LXX.

On nyttan af WäXt. Olika kiön (Alm. 1744); [Hulth], p. 41.

$\alpha$. [Fl. Sv. I] „Sexus plantarum 1744". $-\beta$. [Ant.] p. 115.

LXXI.

ANmäRKn. ÖFv. Jackashapuck. (V. Ak. Handl. 1743); [Hulth], p. 41.

a. [Fl. Sv. I] „Jackas-hapuch (Arbutus repens)“"

LXXII.

de Betula nana. (Disp. Klase, 1743); [Hulth], p. 41.

$\alpha$. [Fl. Sv. I] ${ }^{1}$ ). - $\beta$. [B. B. II] p. 66 . - $\gamma$. [Ant.] p. 117 ,Totae sunt Linnæi“.

1744.

LXXIII.

Continuation af . . anmärkn. om inl. Wäxter (Alm. 1744); [Hulth], p. 38.

$\alpha$. [Fl. Sv. I] ,Sexus plant. usus ceconomicus ... 1745". - $\beta$. [Ant.] p. 115.

LXXIV.

Siberiskt вокhvete (V. Ak. Handl. 1744); [Hulth], p. 42.

a. [Fl. Sv. I] ,Fagopyrum sibiricum".

LXXV.

Petiveria (W. Akad. Handl. 1744); [Hulth], p. 43.

a. [Fl. Sv. I].

LXXVI.

Ficus ... (Disp. C. Hegardt, 1744); [Hulth], p. 43.

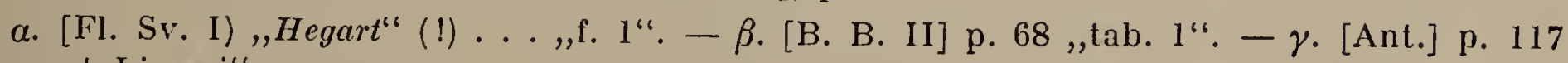
"Totæ sunt Linnæi".

\section{LXXVII.}

de Peloria ${ }^{2}$ ) (Disp. D. Rudberg 1744); [Hulth], p. 43.

a. [Fl. Sv. I]. - $\beta$. [B. B. II] p. 182.

\section{LXXVIII.}

Species Orchid. Ups, Act. Soc. Scient [1740] 1744; [Hulth], p. 42.

$\alpha$. [Fl. Sv. I] "Orchides iisque Affines . . 1740".

1745.

LXXIX.

A) Flora Svec. (Ed. I), 1745; [Hulth], p. 44.

$\alpha$. [B. B. II] p. 121 ,p. 420 t. I Fig. nitidissima“. - $\beta$. [Fl. Sv. II] p. XII ,,p. $392{ }^{3}$ "“ (!) „L. 1 plant. $1140 " .-\gamma$. [Spec. plant. I]. - $\delta$. [Ant.] p. 118 ,c. figura Linncea".

B) Flora Svec. (Ed. II) 1755; [Hulth], ibid.

a. [Spec. plant.] II. - $\beta$. [Ant.] p. 217 , ,aucta et emendata“.

1) Die Disputationen von Klase, Hegardt, Rudberg, Fougt, Hast, Rudbeck werden in [FI. Sv. I) nicht allein direkt unter deren betreffenden Namen angeführt, sondern sie sind außerdem noch einer höheren Kategorie - dem Sammelnamen Linnæus unterstellt.

2) Es ist recht merkwürdig, warum gerade diese allgemein Linseus zugeschriebene Disputalion (vgl. auch Beckmanx [Schw. Reis.]) in [Ant.] p. 119, unter den ,sunt-Linnæi"-Disputationen nicht angeführt wird. Freilich hätte man einen Anhalt für die Linnésche Autorschaft in der bibliographischen Behandlung dieser Disputation unter der einzigen (!) summarischen Nummer 1745, eine Nummer die anfangs all die bis 1745 veröffentlichten Linnéschen Arbeiten umschließt. (FI.SV.) Auch in Phil. bot. p. 8 werden unter ,Monographi" viele Disputationen als "Nostri" mitgeteilt; wir nehmen aber Abstand davon, sie jedesmal zu zitieren, weil ihnen keine bibliographischen Daten folgen.

3) Die Schrift der Flora an und für sich umfaßt 392 Seiten. Rest Namenregister oder Einleitung. 


\section{LXXX.}

ÖLÄNDSKa OCh GothlïndsKa Resa, 1745; [Hulth], p. 45.

a. [Fl. Sv. I] ,Iter Elandicum \& Gotlandicum" . . ., suetice“. - $\beta$. B. B. II p. 145 : ,p. 344 t. 3". $-\gamma$. [S. N. IX] (Elench. auct.) "Stockh. 1742" (1). - $\delta$. Spec. Plant. I ,1745". -

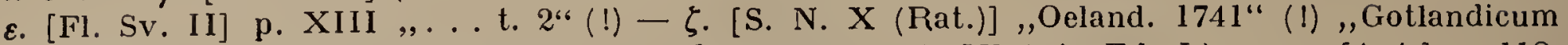

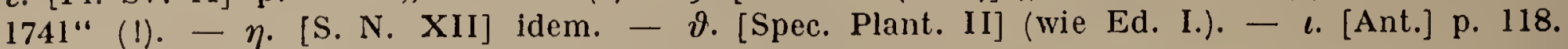
LXXXI.

Anmärkn., om thée och thée - Drickandet. (Alm. 1746); [Hulth], p. 45. $\alpha$. [Fl. Sv. I] . ., ,1740" (!) $\left.{ }^{1}\right)$. $-\beta$. [Ant.] p. 116: , ,1746“".

\section{LXXXII.}

Storm-väders-Fogelen. (V. Ak. Handl. 1745); [Hulth], p. 45. a. [Fl. Sv. I] "Passer procellarius".

\section{LXXXIII.}

Corallia baltica (Disp. Henr. Fougt, 1745); [Hulth], p. 46. a. [Fl. Sv. I] ,Corallia Balth(!)ica".

\section{LXXXIV.}

Amphibia gyllenborgiana (Disp. B. R. Hast, 1745); [Hulth], p. 46. a. [Fl. Sv. I] „Host." (Die Tafel wird nicht mitgeteilt.)

\section{LXXXV.}

Hortus Upsaliensis (Disp. Nauclér, 1745); [Hulth] ${ }^{2}$ ), p. 47.

a. [B. B. II] p. 112 ,NAUCLERUS . . Descriptio Horti Upsaliensis.“

LXXXVI.

Passiflora (Disp. Hallman, 1745); [Hulth], p. 47.

a. [B. B. II] p. 65.

\section{LXXXVII.}

Anandria (Disp. Tursén, 1745); [Hulth], p. 47.

a. [B. B. II ] p. 64 .

\section{LXXXVIII.}

Acrostichum (Disp. Heiligtag, 1745); [Hulth], p. 47-48.

a. [B. B. II] p. 68 ,,Tab. I ${ }^{3}$ ) fig. $4^{\prime \prime}$.

1746.

LXXXIX.

Fauna Svecica (Ed. I) $\left.{ }^{4}\right), 1746$; [Hulth], p. 48.

a. [Fl. Sv. I] ,,animalia Suecice descripta . . 1745“ (1) „Octav. Cum descriptionibus \& Synonymis". - $\beta$. [FI. Sv. II] p. XIII ,,p. 411 t. $2 “ .-\gamma$. [Ant.] p. 112,1745 begynte tryckas"; p. 118. $\mathrm{XC}$.

Fauna Svecica ${ }^{5}$ ) (Ed. II) 1761 ; [Hulth], p. 48.

Ant. p. 217 ,,aucta".

XCI.

Anmärkn. om coffé (Alm. 1747); [Hulth], p. 49.

a. [Ant.] p. $116,1747^{\prime \prime}$.

Lobelia [1741] 1746; [Hulth], p. 49.

a. [B. B. II] p. $65,, 1746 \ldots$ ad ann. 1741. t. I".

XCIII.

Decem PLaNt. GEN. [1741] 1746.

$\alpha$. [FI. Sv. I] ,Genera plantarum nova . . . 1741". - $\beta$. [B. B. II] p. $186,1746 \ldots$ ad Ann. 1741 t. 1".

1) Offenbar ein Druckfehler weil in der chronologisch geordnelen, fortlaufenden Aufzählung dieser Schrift eine andere Schrift aus 1745 vorangeht.

2) In meiner Bibliothek befindet sich eine Variante, deren Taf. IV mit II paginiert ist.

3) Diese Tafel, die laut Hulth in der Regel fehlt, ist mit "HaLlman sculps." unterzeichnet, wodurch sie sich prima vista von den verschiedenen Nachdrucken der Amoen unterscheidet.

4) Die Titelblattvariante des Lugd. Bat. Nachdruckes vom Jahre 1746 wird in [S. N. IX] (Elenchus auct.) zitiert.

5) Vgl. STöwer p. 308-309; HaGeN schreibt p. 484 ,,an dieser Ausgabe haben Linnés Schüler mit gearbeitet"; am 2.VII. 1760 schreibt L. an BunMaNN ,Faunce Suecica altera editio, quee mihi multum laboris constitit, jam ad finem perduxi". (Vgl. HaLL, Epist ined. C. L., 1830, p. 52.) 
XCIV.

Sponsalia plantarum (Disp. Wahlbom, 1746); [Hulth], p. 50.

$\alpha$. [B. B. II] p. 173.

\section{7.}

$\mathrm{XCV}$.

Flora zeylanica 1747 ; [Hultil], p. 51.

$\alpha$. [B. B. II] p. 138 "Genera triginta nova“. $-\beta$. [Sp. pl. I]. $-\gamma$. [FI. Sv. II] p. XII ,p. $245^{\prime \prime}(1) .-\delta$. [Spec. pl. II]. $-\varepsilon$. [Ant.] p. $76,118$.

\section{XCVI.}

WeStGöta-RESA ${ }^{1}$ ), 1747; [HuLth], p. 51.

$\alpha$. [B. B. II] p. 145 ,Iter Westrogothicum". $-\beta$. [Spec. pl. I]. $-\gamma$. [FI. Sv. II] p. XIII „p. $1745 "(1) .-\delta$. [Spec. pl. II]. - E. [S. N. IX] (Elench. auct. $-\zeta$. [Ant.] p. 118

\section{XCVII.}

ANMÄRININGar ON BRÄNNWIN (Alm. 1748); [Hulth], p. 52.

a. [Ant.] p. 116.

\section{XCVIII.}

Vires plantarum (Disp. Hasselquist, 1747); [Hulth], p. 54.

a. [B. B. II] p. 208, ,1744" (!).

\section{XCIX.}

Nova Plent. Gen. (Disp. Dassow, 1747); [Hulth], p. 54.

a. [B. B. II] p. 186 (sine dato!) „Nuper edita in Amoenitatibus academicis, dein compendiose proposita in Flora Zeylanica".

\section{8.}

C.

Hontus Upsaliensis, 1748; [Hulth], p. 55-56.

$\alpha$. [B. B. II] p. 112. - $\beta$. [Spec. pl. I]. $\quad \gamma$. [Fl. Sv. II] p. XII. $-\delta$. [Spec. pl. II]. E. [Ant.] p. 118 .

$$
\text { CI. }
$$

Beskrifn. om öL. [Anonym], (Alm. 1749); [Hulth], p. 56.

a. [Ant.] p. 116.

1749 .

CII.

Materia medica, 1749; [Hulth], p. [60].

$\alpha$. [B. B. II] p. 208, , Stockholmiæ 1748“ (!) ,.. t. I“. $-\beta$. [Spec. pl. I]. $-\gamma \cdot$ [Fl. Sv. II] p. XIII „p. $188^{\prime \prime}(!) .-\delta$. [Spec. pl. II]. $-\varepsilon$. [Ant.] p. 47, 76, p. 118 „Holm. 1749. 8: o, c. fig. Ophiorrhizæ“. CIII.

Sida FloRum [1743], 1749; [Hulth], p. 61.

a. [B. B. II] p. $63,4^{\circ}$ A. $1749 \ldots$ ad Ann. $1743^{\prime \prime}$.

CIV.

Lign. colubrinum (Disp. Darelius, 1749); [Hulth], p. 61. a. [B. B. II] p. 51 .

CV.

Radix Senega (Disp. Kiernander, 1749); [Hulth], p. 63.

a. [B. B. II] p. 63.

CVI.

A) Am qnitates academica I (Lugt. Bat.) 1749; [Hulth], p. 65.

a. [Spec. pl. I]. $-\beta$. [Fl. Sv. II] p. XIII. $-\gamma$. [Spec. pl. II]. $-\delta$. [Ant.] p. 118, ,I Lugdb. . . o opera Petri Camper" (!).

A) idem I (Holmiæ Lips.) 1749; [Нuцth], p. 66.

$\alpha$. [Spec. pl. 1] „Lipsice". - $\beta$. [Fl. Sv. II] p. XIII „Lipsia“" - $\gamma$. [Spec. pl. II]. $\delta$. [Ant.] p. 119 "Holm. et Lips. $1749,8^{\circ}$ c. tabb. æneis Linnfi" (!).

$$
1751 .
$$

B) idem, Vol. II (Holm. 1751); [Hulth], p. 66.

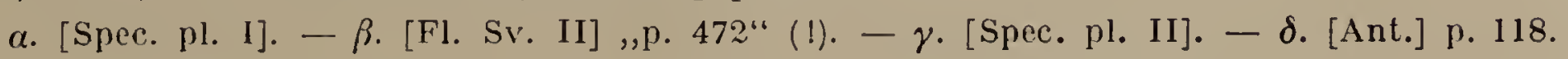
1756.

C) idem, Vol. III. (Holm. 1756); [HuLth], p. 66.

a. [Fl. Sv. II] p. XIII ,Holmice sudat". - $\beta$. [Spec. pl. II]. $-\gamma$. [Ant.] p. 217.

1) Laut Lankester, p. [5], ist von der deutschen Auflage eine II. Ausgabe 1774 erschienen! Bryk, Linnæeus im Auslande. 
1759.

D) idem, Vol. IV. (Holm. 1759); [HuLTh], p. 68.

a. [Spec. pl. II]. - $\beta$. [Ant.] p. 59, $2 \mathrm{I} 7$.

1760.

E) idem, Vol. V. (Holm. 1760); [Hulth], p. 68, 69.

a. [Spec. pl. II]. - $\beta$. [Ant.] p. 217.

1763.

E) idem, Vol. VI. (Holm. 1763); [Hulth], p. 69.

a. [Spec. pl. II] „Holmiæ ined.“. - $\beta$. [Ant.] p. 2I7: ,c. tab. 4“ (!) ,æn.“ 1769.

F) idem, Vol. VII (Holm. 1769); [Hulth], p. 69.

a. [Ant.] p. 217.

1762.

B. idem, Vol. II [Ed. II], 1762; [Hulth], p. 66 (Vgl. Begkmann [Schw. Reis.] p. 110 Nota).)

a. [Ant.] p. 217 ,auctum."

1764.

$\mathrm{C}_{1}$ ) idem, Vol. III [Ed. II], 1764; [HuLtiI], p. 67.

a. [Ant.] p. 217 .

1762.

[A $A_{2}$ ] Miscell. Rel. Nat. Hist. [engl. Übers. von Stillingfleet, 1762]; [Hulth], p. 74.

a. [Ant.] p. 217 ,,Vol. I. Lond. I762, $8^{0}$ Anglice mut.“; ibid. p. [2I9] ${ }^{1}$ ).

1750.

CVII.

Splachnum (Disp. Laur. Montin, 1750); [Hulth], p. 77.

a. [B. B. II] p. $69,, f$. plures nitidxe"; p. I44 „Lapponiam illustravit vide Dissertationem de Splachno I"

1751.

CVIII.

A) Pinlosophia botanica (Holm. 1757); [Hulth], p. 78.

$\alpha$. [Spec. pl. I]. $-\beta$. [II. Sv. II] p. XII ,1750" „L. I2“ (!). $-\gamma$. [Spec. pl. II]. $-\delta$ [Ant.] p. 77, 119.

$\mathrm{A}_{1}$ ) [J. LeE. Introd. . . science of Botany, 1765]; (= Second. ed.) [Lankester] ²) p. 10.

a. [Ant.] p. $2 \mathrm{I} 7$ „Philosophia botanica, Lond. 1765, S:o per J. LeE contracta“.

CIX.

A) Skinska Resa 1751; [Hulth], p. 81.

a. [Spec. pl. I] ,Iter scanicum". - $\beta$. [FI. Sv. II] p. XIII. $-\gamma$. [Spec. pl. II]. $-\delta$. [S. N.

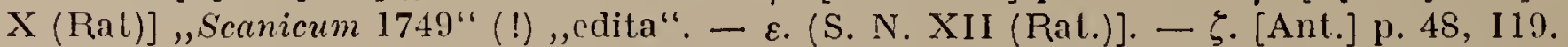

1756.

A) Reisen durch das Königreich Schweden ... (übers. Klein), 1756; [Hulth], p. 82.

a. [Ant.] p. $217, \ldots$. Lips 1756, 80, Germanice".

1753.

$\mathrm{CX}$.

Museum Tessinianum, 1753; [Hulth], p. 89.

$\alpha .[$ S. N. IX] (Elench.). $-\beta .[F I$. Sv. II] p. XIII. $-\gamma .[$ S. N. X (Rat.)]. - $8 .[S . N . X I]$ (Rat.)]. - E. [Ant.] p. 210.

\section{CXI.}

A) Species Plant. (Ed. I) 1753; [Hulth], p. 89.

a. [Fl. Sv. II] p. XIII. - $\beta$. [Spec. plant. II]. $\gamma$. [Ant.] p. 78, 217.

B) idem (Ed. II), 1763; [НuLTH], p. 90.

a. [Ant.] p. 78,217, ,perfecte".

1) Auf p. [219] wird dieselbe Arbeit nochmals unter den sog. „Plagiaten" aufgezälltt; ibid. p. 98 wird aus StiLlingFieET p. XIII abgedruckt.

2) Nicht im Prírzed. Es ist merkwürdig, daß Lisxé die erste Auflage davon (vgl. [Ant.]p. [219] (LFE 1760) als cin „Plagial“ und nicht als cine Ubcrsetzung von Phil. bot. behandelt. 
1754.

CXII.

Museum Se R: a Mitis. Adolphi Friderici . ., 1754; [Hulth], p. 95.

$\alpha$. [Fl. Sv. II] p. XIII. $-\beta$. [S. N. X]. $-\gamma$. [S. N. XII (Rat.)]. $-\delta$. [Ant.] p. 55, 217. 1755.

CXIII.

A) Centuria I plant. (Disp. Juslenius, 1755); [Hulth], p. 100.

$\alpha$. [S. N. X (vol. II, Præf.)]. $-\beta$. [S. N. XII (vol. II Præf.)].

B) Centuria II. 1756.

1756.

$\alpha$. ibid. $-\beta$. ibid.

CXIV.

Elementa botanica (ed. Solander), 1756; [Hulth], p. 101.

a. [Ant.] p. (219) „Jedes Wort von Linvé entlehnt".

1757.

[CXV.]

Manetti, Caroli Linnei Regn. Vegetab., 1756; [Hulth], p. 101, 102.

a. [Ant.] $\left.{ }^{1}\right)$ p. 216 (unter Ausgaben von S. N. angeführt).

1759.

CXVI.

TaL, vid deras K. Majest. . ., 1759; [Hulth], p. 113.

a. [Ant.] p. 217 ,oratio.Regia“.

\section{[CXVII.]}

Animalium specierum . . . dispositio, 1759; [Hulth], p. 7.

a. [Ant.] p. 217.

1760.

CXVIII.

Disquisitio . . S Sexum plantarum, 1760; [Hulth], p. 119.

a. [Ant.] p. 59, 217.

1763.

CXIX.

Genera morborum, 1763; [Hulth], p. 117.

a. [Ant.] p. 217 ,nomin. Svecanis".

1764.

CXX.

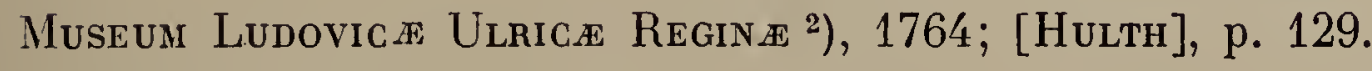

a. [Ant.] p. 217.

CXXI.

Museum Se Re M:tis Adolphi Friderici Regis, 1764; [Hulth], p. 95.

a. [Ant.] p. 217 ,Tomi Secundi Prodromus Holm. 1764. 8:o, una cum Museo Rearini“" s).

1766.

CXXII.

Clavis Medicine, 1766; [Hulth], p. 133.

a. [Ant.] p. 190, 203, 216.

1767.

CXXIII.

A) Mantissa Plantarum, (Pars I.), 1767; [Hulth], p. 25.

a. [Ant.] p. 218.

1771.

B) idem, (Pars II), 1771; [Hulth ], p. 25.

a. [Ant.] p. 218. „... altera, Holm. 1771. 8:0".

1) In: Lärda Tidningar Nr. 92 (23. XI. 1758) p. 368 ist hieruber ein Referat veroffentlicht. Autor: Linneus?

2) Laut Percheron (Vol. I, p. 251) wäre eine ,autre edit." davon in $4^{0}$ Holmiæ erschienen.

3) Nach Rosenhane (p. 176) ist diese Schrift mit der vorgehenden zusammengebunden erschienen; mein Exemplar ist ebenfalls zusammengebunden. (Vgl. Lärd. tidn., Nr. 78, p. 308 (1764); Autor: Lisve!) 
AM gNitates AGAD. SUETice.

(,LinNei PÅ SWENSKa ÖFVERSaTte Disputationer.")

Unter dieser Aufschrift führt Linsé in [Ant.] p. 218, 219 alle - mit Áusnahme von Wollraths Übersetzung von Horticultura und von Oratio de telluris habitabilis increm von einem Unbekannten. - in schwedischer Sprache erschienenen Übersetzungen seiner Disputationen an, die, falls zusammen erschienen, einem mageren Bande von schwedischen ,Auserlesenen Abhandlungen" entsprechen würden. Ich habe in einem Falle [N. D. A.] so gut wie nachgewiesen, daß das schwedische Konzept zu einer jener Disputationen von Linnæus selbst ursprünglich vor dem lateinischen Texte verfaßt wurde, weshalb es nicht zu unkritisch ist, wenn ich behaupte, daß auch die übrigen lier mitgeteilten Übersetzungen zum Teile direkt auf LiNn \&us Konzept zurückzufülıren sind.

I) Flora Econ., hushálls-nyttan, [Aspelin], 1749; [Hulth], p. 58.

a. [Ant.] p. 218.

II) Sponsalia Plant, Blomstrens Biläger, [Wahlbom], 1750; [Hulth], p. 50.

a. [Ant.] p. 218.

III) Economia Nature, Skaparens allvisa Inrättning, [Biberg], 1750 ; [Hulth], p. 62.

$$
\text { a. [Ant.] p. } 218 .
$$

IV) Plante Esculente Patriat, inländska Äteliga wäxter, [Hjorth ${ }^{1}$ ), 1752 ; [Hulth], p. 84. a. [Ant.] p. 218.

V) Cui Bono? Hwartil duger det? [Gedner], 1753; [Hulth], p. 86.

a. [Ant.] p. [219].

VI) Cynographia eller beskrifning om hunden, [Lindekrantz], 1756; [Hulth], p. 95. $\alpha$. [Ant.] p. [119] „Canis familiaris, Beskr." etc. etc.

ViI) Calendarium Flora, Blomster-Almanach, [Berger], 1757; [Hulth], p. 103.

a. [Ant.] p. [219]. (Vgl. Lärda Tidn., 1750, Num. 20, p. 79.)

VIII) Sättet at Wara Sin Egen läkare, [GRysSelius], 1770; [Hulth], p. 138.

a. [Ant.] p. [219] ,Medicus sui ipsius, Sättet att . . .".

\section{„Opera Non proprie aUCTORIS, SED tamen aUCTORI maXime OPEROSa."}

[Ant.], p. 116.

1. Petri Artedi Ichthyologia, 1738; [Hulth], p. 29-30.

a. [Fl. Sv. I]. - $\beta$. [S. N. V1] p. 212 „Hujus opera posthuma didi Lugdb. 1747 “ (1). $-\gamma$. [S. N. VII] p. 212 (Wiederholung)! $-\delta$. [S. N. 1X] p. 216 (Wiederholung!). $-\varepsilon$. [Faun. Sv. I (Auctores)] „Artedia" (!). - $\zeta$. [Faun. Sv. 11 (Auctores)]. - $\eta$. [Fl. Sv. II] p. XIII „p. 65, 92, 84, $\left.118,102^{2}{ }^{2}\right) . \quad \vartheta$. [Ant.] p. 116 ,E schedulis corrasit demortui".

2. a) Browalli Examen epicriseos Siegesbeck., (Ed. I), 1739; [Pritzel], p. 34. No. 1350.

$\alpha$. [Orb.] p. [4] ,1740“ (!). - $\beta$. [Fl. Sv. 1] , agit causam Linnæi in apologia contra Sieg. Epicrisin". - $-\gamma$. [Fl. Sv. I1] p. X11I. - $\delta$. [Ant.] p. 116.

2. b) idem (Ed. II), 1743; [HuLth], p. 36.

$\alpha .[$ Fl. Sv. 1] (ibid.). - $\beta$. [Fl. Sv. 11] ibid. $-\gamma$. [B. B. II] p. 172. - $\delta . ~[A n t$.$] p. 116$,Multa communicavil".

3. Royeni Prodron. Flor. Leyd, 1740; [Hulth], p. 33. vit $1738 . "$

$\alpha .\left[\right.$ Orb. $\left.{ }^{3}\right)$ p. [4] , $1739^{\prime \prime}(!) .-\beta .\left[\right.$ Ant.] p. $116,, 1739^{\prime \prime}$ (!) 8:0 „Simul cum Auctore elabora-

4. J. Fr. Gronovii Flora virginica ${ }^{4}$ ), 1739; [Pritzel], p. 105 No. 3919.

$\alpha$. [Orb.] p. [4] (unter: Secundum Leges Linnai sunt sequentia). - $\beta$. [Ant.] p. 116 „Una cum auctore elaboravit."

1) In „Cui Bono" gibt Linneus als den Ubersetzer Löwenhjelas an, der doch eigentlich nur die Vorrede geschrieben hat.

2) Diese kollationierte Reihenfolge entspricht der Hulthschen Einleitung, der ich mich schon früher, ohne diese Linnésche Bibliographie bemerkt zu haben, anschloß. (BRYk [Studier] p. 55.)

3) ibid. p. [4] wird die Seite 16 aus Royen abgedruckt. In [B. B. II] p. 102, sowie in den beiden Auflagen von Spec. pl. wird dieses Werk in irgendeinem Bezug auf LiNs aus angefuhrt. Solche Notizen werden von uns künftig nicht berücksichtigt.

4) Auch aus Fl. virg. wurde p. 3 in [Orb.], p. [6]-[7] teilweise abgedruckt. 
5. J. Fr. Gronovi Index supellectilis Lapidea: (Ed. I) ${ }^{1}$ ), 1740; [Gronovius], p. 116.

$\alpha$. [Orb.] p. [4] „Musæum Lapideum" (unter: ",Secundum Leg. Linn." etc.). — $\beta$. [Ant.] p. 116 "Museum Lapideum" . „Pariter et totaliter" fere".

6. ,Gleditsch Consideratio Epicriseos Siegesde ckian a, Berl. 1740 8:0; [Pritzel], p. 98.“

$\alpha$. [Orb.] p. [4] "Quart." (!). - $\beta$. [B. B. II] p. 173. Linneus hat aus typischer Gelehrtenzerstreutheit an Stelle des richtigen Titels den der SIEgesbeckischen Antwort gesetzt. $\gamma$. [Ant.] p. 116.

7. Fredr. Hasselquists Iter paläestin., 1757; [Hulth], p. 105.

$\alpha$. [Fl. Sv. II] p. XII. $-\beta$. [Spec. pl. II]. $-\gamma$. [S. N. X (Rat.)], ,in cegyptum \& Palcestinam". - $\delta$. [S. N. XII (Rat.)]. - $\varepsilon$. [Ant.] p. 57,24 juni: Linnæus erhiclt vom Drucke fertig und gab Hasselquists Reise" heraus. (Deutsch. Ubers.); p. 217, "Siethice".

8 a) Petri Loefling . . . Iter hispanicum, 1758; [Hulth], p. 110.

$\alpha$. [Spec. pl. I] "Pl. hispanice in epistolis, Msc." $-\beta$. [Spec. pl. II]. $-\gamma$. [S. N. XII (Rat.)]. - $\delta$. [Ant.] p. 59, 217. „Svethice".

8 b) P. Loeflings . . Reise . . [Kölpin übers.], 1766; [Hulth], p. 111.

a. [Ant.] p. 217, ,Berl. 1766. $8^{\circ}$, Germanice".

\section{„Plagiate".}

(„Jedes Wort Linnæus entnominen." [Ant.] p. [219].

a) Löwenhjelm, C. G., Tal om Landtskötsel, (Präsid.rede; 1751). [Haller] II p. 410.

b) Solander, Elementa botanica, 1756; $8^{\circ}$ [Hulth], p. 101. [Ant.] ,4:0" (!).

c) Clerck, Nomenclator Extenporaneus 1759; [Hulth], p. 7.

d) Lee, Introduction to Botany 1760; [Lankester] p. 10.

e) Stillingfleet, Miscellan. Tracts. 1762; [Hulth], p. 74. (Vgl. [Ant.] p. 98.)

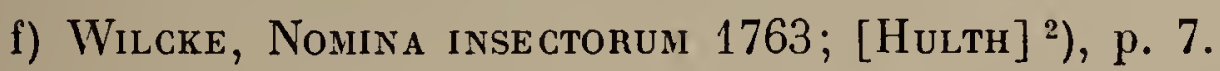

g) Berkenhout, Clavis anglica Linque Botanice, 1764; [Pritzel], p. 20, No. 774.

h) Lipp, EIXeipiaion Botanikon Specimen 176j; [Pritzel] No. 6175, p. 170, [Hulti],

p. 110. (,,Specimen Botanicum".)

i) Beddeus, Diss. inaug. de verme Tenia dicto, 1767; [Engelmann], p. 559.

j) Hoffberg, Anwisning til Naturens Kännedom Första Delen. Om Wäxtriket efter . Linnés Bot. Grunder, 1768; $8^{\circ}$ [Wikström], p. 105.

k) Jacquin, Index regni vegetab. . . Q Qu a habentur in Linneani Syst., 1770; 40 [Pritzel], No. 4834, p. 130.

„LINNaANa Methodo scripsere“". ([Ant.] p. [219]).

a) de Gorter, D. Flora Gelro Zutphan., 1745; [Pritzel] p. 101, No. 3781.

b) De Gorter, D. Flora Ingrica, 1761; [Pritzel] p. 101, No. 3783.

c) Dalibard, Tir. Fr., Flor. Paris. Prodr., 1749; [Pritzel] ${ }^{3}$ ), p. 56, No. 2122.

d) Gronovius, Flora orientalis, 1755 [Pritzel], p. 105, No. 3920.

e) Browne, P., The civil and nat. hist. ... Jamaica ${ }^{4}$ ), 1756; [Pritzel] p. 36, No. 1388.

f) Kramer, W. H., Elenchus veget. et anim. P. Austriani in f. 1756; [Pritzel] p. 143, No. 5380 .

g) Meese, D., Flora Frisica, 1760; [Pritzel], p. 188, No. 6737.

h) Hill. J., Flora brittanica, 1760; [Pritzel], p. 119, No. 4475.

i) Leysser, Flora Halensis, 1761 ; [Pritrzel], p. 156, No. 5840. - (Bei Linné „Leyser“.)

j) Hudson, W., Flora anglica, 1752; [Pritzel], p. 126, No. 4744, (vgl. [Ant.] p. 97).

1) Von diesem Werke kenne ich bisher nur die Editio altera Lugd. Bat. MDCCL (Upsal. Bibl.); sie enthält eine vier-Seiten-lange Widmung an Linseus; vgl. ein Referatin: Lärd.tidn., p. 327, 1750.

2) Linnaus gibt als Formal $4^{0}$ an; offenbar hatte Linnaus im Sinne die Disputation: Dissertatio .... Linnei nomina insectorual ([Percheron], Vol. II p. 129; [Hagen] Vol. II p. 287). (Die von Hulth zitierte Separatausgabe im Oktavformate muß sehr selten sein, wenn sie HaGEN nicht kannte.)

3) Linnaus ibid. sowie Pritzel, Haller (II p. 383) geben als Format olitav an; es handelt sich aber wie ich nach einem Exemplare in meiner Bibliothek feststellen konnte offenbar um 12:0.

4) „Historia Naturalis Jamaica ... Anglice." 
k) Gouan, A., Hortus Reg. Monspeliensis, 1762; [Pritzel], p. 101, No. 3795.

l) von Jacquin, N. J., Enumeratio stirpium ... . in agro Vindoboniensi ${ }^{1}$ ), 1762 ; [Pritzel], p. 129 , No. 4826 .

m) von Jacquin, N. J., Select. stirp. amer. hist. ${ }^{2}$ ), 1763; [Pritzel], p. 129, No. 4828.

n) Reyger ${ }^{3}$ ), Gottf., Tentamen Flor. Ged., 1764; [Pritzel], p. 245, No. 8533.

o) Bergius, P. J., Descriptiones plant. ex cap. bon. Sp. ${ }^{4}$ ), 1767; [Pritzel], p. 19, No. 764.

p) Burmannus, N. L. Jr., Flora indica, 1768; [Pritzel], p. 41, No. 1585.

„Genera Linnfana s. artis principia assumere“. ([Ant.] p. [220]).

a) Séguier, J. Fr., Plante Veronenses, 1745; [Pritzel], p. 273, No. 9538.

b) von Wachendorff, E. J., Horti Ultraject. index, 1747; [Pritzel], p. 313, No. 10863.

c) Gmelin, J. G., Flora sibirica (IV. V.) ${ }^{5}$ ), 1747-1769; [Pritzel], p. 99, No. 3703.

d) Guettard, J. E., Observationes S. L. Plantes, II Vol. $8^{06}$ ), 1747; [Pritzel], p. 106, No. 3953.

e) Sauvages, Methodus Folionum La Haye $1751.8^{\circ}$.

f) Plumierus, C., Plant. amer. fasc. illustr. J. Burmannus 7), 1755-1760; [Pritzel], p. 231, No. 8091.

g) Allioni, C., Rar. Ped. Stirp. Spec. ${ }^{8}$ ), 1755; [Pritzel], p. 4, No. 156.

h) Allioni, C., Stirpium precip. lit. et agr. Nic.eens. enym. ${ }^{9}$ ), 1757; [Pritzel], p. 4 , No. 157.

i) Zinn, J. G., Ciatal. Plant. hort. Gotting. 1757; [Pritzel], p. 329, No. 11457.

j) Miller, Ph., The Gard. and Flor. dictionary ${ }^{10}$ ) [Ed. ViI], 1759; [Pritzel], p. 194, No. 6936.

k) Scopoli, J. A., Flora carniolica . ordine Linnaano, 1760; [Pritzel], p. 272, No. 9503, (vgl. [Ant.], p. 97).

1) Gerard, L., Flora Galloprovincialis 1761; [Pritzel], p. 96, No. 3577.

m) Wheeler, J., The bot. A. Gard. new diction. acc. syst. of Linnaus ${ }^{11}$ ), Lond. 1763.

n) Gunnerus, J. E., Flora norwegica, 1766, $1772^{12}$ ); [Pritzel], p. 106, No. 3983.

o) Barnades, M., Principios de botanica ${ }^{13}$ ), 1767; [Pritzel], p. 12, No. 480.

\section{LINN AANA.}

Von Linnæus angeführte Zitate über ihn, etc.

In: [Orb.]: p. [6] a) Burmannus, J., Thesaurus Zeylanicus, 1737; [Pritzel], p. 41, No. 4578.

- p. [11] b) v. Haller, A. in: ,Act. Germ. erudit. pag. 288“ (= Referat über Gen. plant.).

- p. [12] c) Breynius, Prodromi fasc. rar. Plant. 1739; [Pritzel], p. 32, No. 1263.

- p. [13] d) Kohl in: Hamburg. Ber. No. LXXI, 1740; [Bryк] Stud., p. 48.

- - p. [15] e) Referate ${ }^{14}$ ) aus N. Acta Erudit. Lipsie, 1737 (p. 64-71); [Hulth], p. 3.

1) Bei Linnaus unter "Stirpes vindobonenses".

2) Bei Linnaus unter: "Stirpes AMERicana . . Voll. 2".

3) Bei Linnaus "REYer" (!) Flora gedanensis.

4) Bei Linneus "Plantae capenses".

5) Linneus zitiert bloß: „Tom I-III 1747-1768."

6) Linndus führt diese Schrift unter dem lat. Titel an: „Observationes plantarum, Paris 1748 "(!) ,12:0“ (!) ,Gallice“.

7) Linneus: „Burmannus, Plantæ Americanæ Plumieri, Fasc. I-X. Amstel. 1755-176 F:0".

8) Linnaus: "Allioni, Pedemontii Stirpium Specimen".

9) Linnæus: „Stirpes Nicæenses“.

10) Linnaus "Lexicon Horlulanum, cd. $7:$ a . . anglice".

11) Linnaus: Lexikon Botanicorum et IIortul. . . . (anglice).

12) LINn zeus zitierl bloß Pars I.

13) LiNnæưs führt den Titel lateinisch an, fügl hinzu „Hispanice“.

14) Diese zwei letzten Zitate hat Linnæus schon früher im Album amicorum ([L. i. Ausl.] p. 296) mitgeteilt, wo außerdem noch ein in Orbis absichtlich (!) ausgelassener Hinweis auf ein Referat über Bibl. Bot. in: N. Act. Erud. Lips. 1737 p. 187-185 zu finden ist. L. gibt irrtümlich 1739 an. (Vgl. L. i. Ausl. p. 253 Note 1). 
In: [Orb.] p. [14] f) Referate alis N. Acta Erudit. Lipsia, 1738 (p. 459 ff.); [Hulth], p. 23. - p. [15] g) " " " " $, \quad, \quad$ " 1739 (p. 256); [Hulth], p. 28.

- p. [16] h) Referate aus: Republica Erudit. S. Bibliotieca Europaza, 1735, (p. 556. Nov.).

- p. [16] i) Referate aus: Republica Erudit. S. Biblotheca Europ.ea, 1737, (p. 73-87. Aug.).

- [Bibl. B. II] p. 172. j) Siegresbek J. G. Botanosophia ver. sciagr. 1737; [Pritzel] p. 277, No. 9639.

- [S. N. VI] p. 3, [S. N. VII] p. 3, [S. N. IX] (Elenchus), p. 3 (Nr. 8), [S. N. X] p. 27 (unter: Jacchus). k) Klefin, Suma dubiorum circa Class. C. Linnæi 1740, [Laukster], p. 8.

- Mantissa plant. II (1771) p. 552. l) Bolten, J. F., Nachricht v. einer neuen Thierpflanze; (latine ibid.) AD ... C. A. Linné ... EPISTOLA DE novo QUOD zOOPH. GEN. Hambg., $4^{0}$; mit Koll. Doppeltafel $1770^{1}$ ).

- [Ant.] p. 96 unter „Urteile gelehrter Männer über Linnaus“. - m) [Juncker] Heise J. G., De insect. Noxio . . 1757; [Hagen] p. 354.

n) Sulm in: Act. Nidrosiens. $\left.{ }^{2}\right)$. [Ant.], p. 98.

o) Baltimore, Gaudia Poetica. [Ant.] p. 98.

p) Haller, De Studio medico [Ant.] p. 98.

q) - Biblioth. Bot. Vol. II. 1772 (p. 244) [Ant.] p. 99.

1) Rousseau, J. J. (an: Buörnstàhl) in: Gjörwells Almänna Tidningar No. 152. 1770. (Reimp.: Resa til Frankr. etc.; ed. Gsörwell, Vol. I, 1780 p. 98-99) und [L. Bref] I. Vol. III p. 240 (Nota 2) [Ant.] p. 99-100.

Das ist alles, was ich aus Linnés Originalschriften an Autobibliographischem herausklauben konnte. Daß auf gewisse Schriften kein Hinweis zu finden ist, darf nicht verwundern. Manche kleinere Aufsätze erschienen ihm zu unbedeutend, hinsichtlich anderer Schriften wollte er dagegen gerne die Vaterschaft von sich abwälzen: wie im Falle Orbis oder den vielen Autoreferaten in den Hamb. Berichten oder Lärda Tidningar.

Im ersten Teile von L. i. Ausl. hatte ich bereits in einer Note (p. 47 N. 4) auf ein Autoreferat aus den Lärda Tidningar 1767 (non 1768!) hingewiesen. Dieser eigenartige bisher ganz unbekannte ${ }^{3}$ ) Fund, der hier zum erstenmal mitgeteilt wird, eröffnet dem Bibliographen ungewöhnliche Perspektiven, weil man endlich dafür einen Haltepunkt erhält, manche anonym erschienenen Anzeigen, Selbstkritiken, Notizen auf Linné als Urheber zurückzuführen. Was ein Wieselgren [Bilder] p. 293 in einem anderen Falle nur vermutete, das wird hier endlich unwiderlegbar bestätigt. Es genügt dás als Beilage mitgeteilte Autogramm, dessen Original sich in der Akademie der Wissenschaften befindet, mit dem Texte der betreffenden Seiten (134-136) zu vergleichen. Kann man dann noch etwa im Zweifel sein, wer jenes Referat

1) Linvæus führt ibid. diese interessante Schrift an, unter dem Titel: „EPISTola AD Linnæum. Hamb. 1771" (!) ,quart. c. fig." Auch bei [Engelarav] p. 559, 573, [Stöwer] II p. 184 wird für die lateinische Version das Jahr 1771 angegeben, während HuLtu [L. Bref] (Abl. II. Vol. I. p. 317) als Erscheinungsjahr 1770 angibt. Wer hat nun Recht: Hulti oder Linné? Beide!, ich besitze selbst neben der Auflage von 1770 die „Variante" von 1771; in beiden Fällen ist der deutsche Text angebunden, (STöwer kennl außerdem noch eine Auflage von 1776 (!); ist wohl ein Erratum?).

2) Ich kenne davon nur die deutsche Ausgabe der "Drontiein. Ges. Schriftex", Kopenh. Teil II, 1765. Dort ist p. 85 zu lesen: ,,der unsterbliche LINNeus etc"; also wird dort keineswegs die Linnésche Unsterblichkeit in einem Atemzuge direkt an die der übrigen fünf Unsterblichen (GALLILEI, Newton, Gram, Leibititz, Bofmianve) angereiht, was man sonst nach Linnæus schon monomanischem Zitate zu schlicßen geneigrt gewesen wäre.

3) Zur Steuer der Wahrheit, die für die Wahrnehmung des Prioritätsrechtes uner]äßlich ist, diene die Nachricht, daß Dr. J. M. Hulti diese wirklich sensationelle Entdeckung schon vor mir gemacht hat, wie er mir dies freundlichst schriftlich nach Bekanntgabe des Fundes meinerseits mitteilte. Die Selbständigkeit meiner spontan vollzogenen Entdeckung wird dadurch jedoch keineswegs beeinträchtigt. Auch Dr. Hultri ist geneigt die ubrigen Referate über Linné auf Grund dieses Fundes ihm zuzuschreiben. 
verfaßt hat? Die mit anderer Tinte und mit gotischen Buchstaben geschriebenen Wörter, die hie und da in den Text, oft an Stelle des entsprechend gestrichenen Textes, eingefügt wurden, rühren vom Redakteur Salvius her. Wegen Raummangel nur eine Stichprobe aus diesem Selbstreferate! Nachdem LinNé das ständige Anwachsen der verschiedenen Auflagen des Natursystems erwähnt hat, schreibt er zum Schlusse, daß diese zu ,,so einer Höhe anwuchs, worüber wir nicht nur dem Autor" (also Linné sich selbst!), ,,sondern auch der ganzen kuriösen Welt gratulieren (Salvius fügte hinzu ,auch unserer schwedischen Nation"). Auf einer anderen Stelle sagt Linné: „Die Einleitungen zu einer jeden Klasse sind wirkliche Meisterstücke“....

Verwundern muß es.jedenfalls, daß er die Urbeschreibung der arabischen Heuschrecke in: J. Sven. Flodmans De victu \& amictu Johannis Baptistæ, Ups. 1755, (p. 10-13), (abgedruckt in: L.-Bref. I. Vol. VI. p. 104) in keiner seiner späteren Auflagen des S. N. oder in seinem Mus. Lud. Ulv. erwähnt, obwohl er doch dazu diese Schrecke bei FLodman noch abbilden (!) ließ (J. Gezelius del. A. А́kerman sc.) und ihr sogar einen binären Namen Gryllus Arabum gab, der dann später bald „arabicus", (HasselQuists Resa, p. 413), bald „cegypticus" (Mus. Lud. Ulr., p. 138) heißt und in S. N. XII p. 699 gar als Synonym von cristatus beliandelt wird. Vielleicht liegt sohin wie in vielen ähnlichen Fällen im Verschweigen jener Mitarbeiterschaft an Flodmans Disputation eine besondere Absicht vor.

Der Erklärungsgrund, warum das kleine Verzeichnis, jener zahlreichen Autoren, die sich seiner Methode öffentlich bedienten, nicht erschöpft ist, ist wohl darin zu suchen, daß seine bibliographischen Notizen mit dem spätesten Datum 1772 abschließen, daß sohin die spätere Literatur überhaupt nicht berücksichtigt wurde. Unerklärlich wird es, warum er bei Scopoli nicht auch dessen Entomologia carniolica, 1763 (HaGen II, p. 146) erwähnt, ist doch auf dem Titelblatte ausdrücklich „Methodo Linnæana“" zu lesen. Ja, jeder Bibliograph übersieht leicht manches. Daß er Extrakte aus seinen Schriften, die auf dem Titelblatte ausdrücklich sich auf Linnaus berufen, wie bei Hoffberg, CLĖrck, LipP, etc. schlechthin als eine Art von Plagiate bezeichnet, gehört ebenfalls zu den Eigentümlichkeiten seiner äußerst persönlichen Bibliographie. Eine Anführung von Suнм wirkt sogar rein lächerlich, wenn man daneben die Unterdrückung eines Referates aus den N. Act. Erud. hält, das er sich im Album amicorum notiert hatte, aber in Orbis ausgelassen hat, einzig, weil die Kritik nicht gerade besonders schmeichelhaft für ihn ausfiel.

Der Raum gestattet es nicht, hier auf alle einzelnen, sehr interessanten Eigenarten der Linnéschen bibliographischen Methode einzugehen: dort führte die richtige Angabe eines Formates zur Wiederauffindung der Urschrift (WILCKE), hier gibt sich LinNæus als Autor seiner unter einem anderen Namen (RUDвEck) verteidigten Schrift öffentlich aus, ein andermal erfahren wir über die geplante Ausgabe seiner Dalekarlischen Reise oder die ganz übersehene Mitarbeiterschaft an Gronovius mineralogischem Kompendium. Seine ganze Bibliographie trägt den Stempel des rein Persönlichen. Sie wird uns dadurch viel wertvoller. 


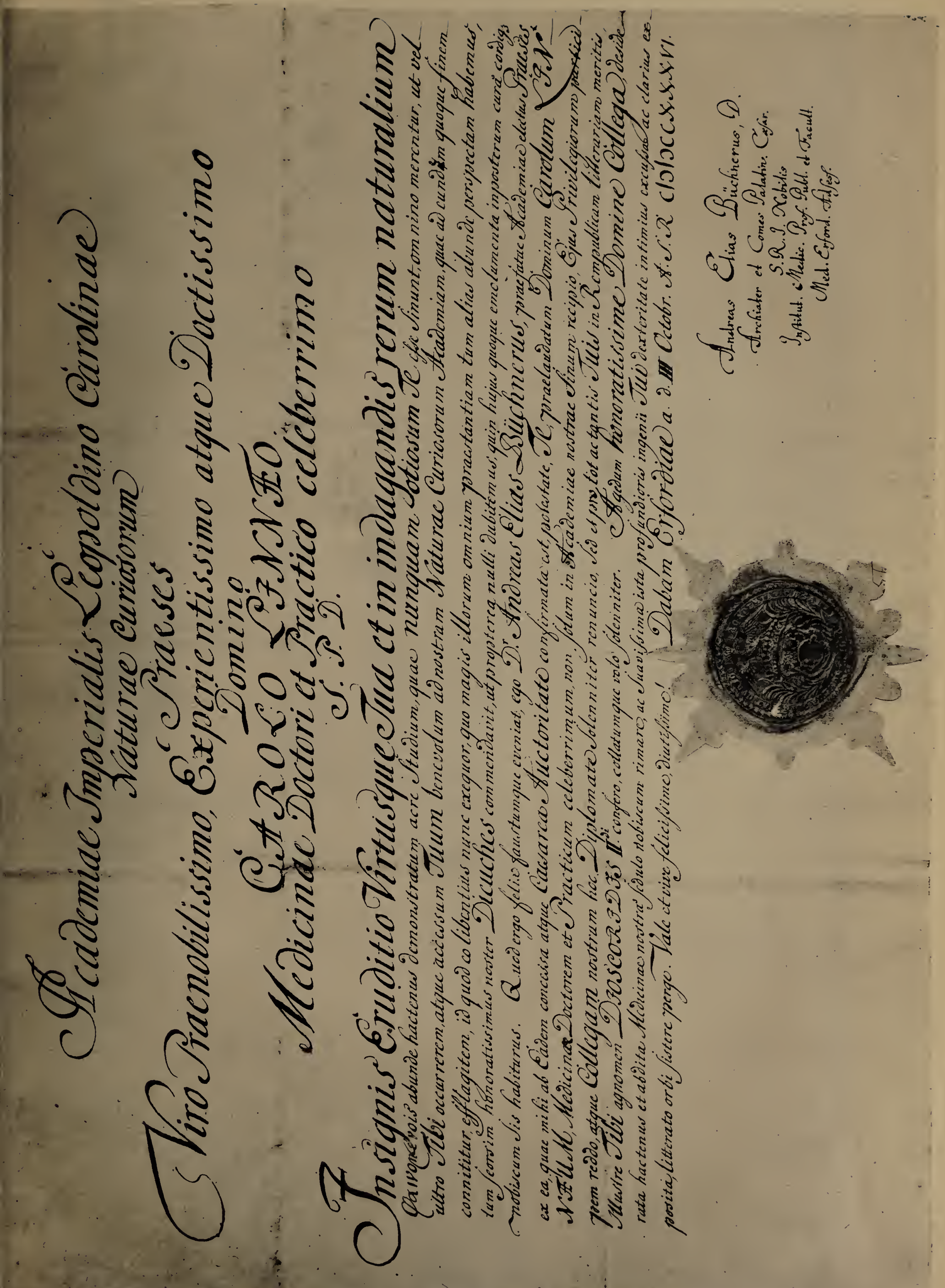





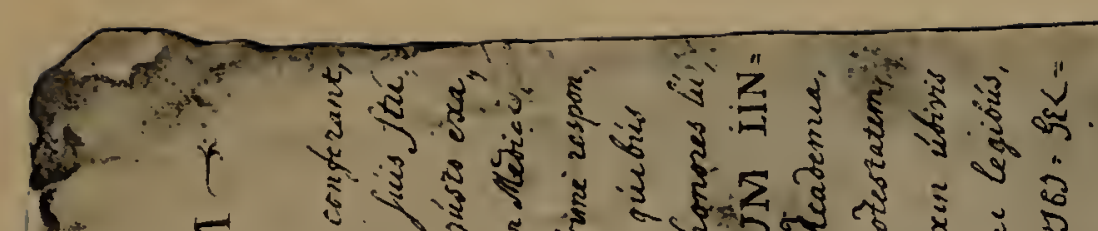

( 5 sis

$\begin{cases}0 \\ 5\end{cases}$

(

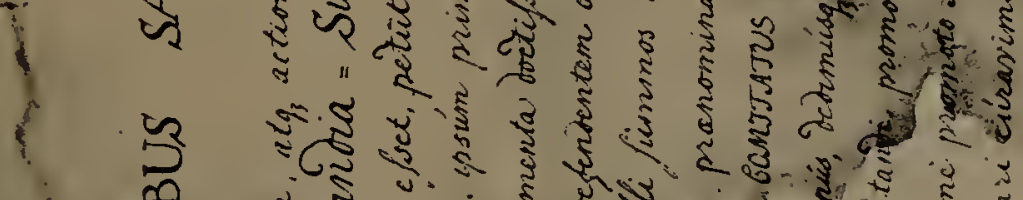

o

3. nt

$n$, n

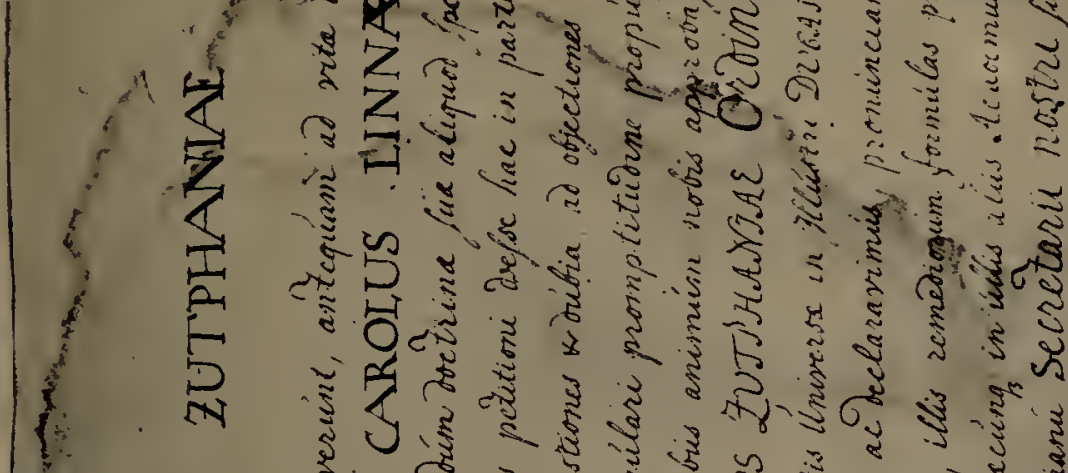

क म.

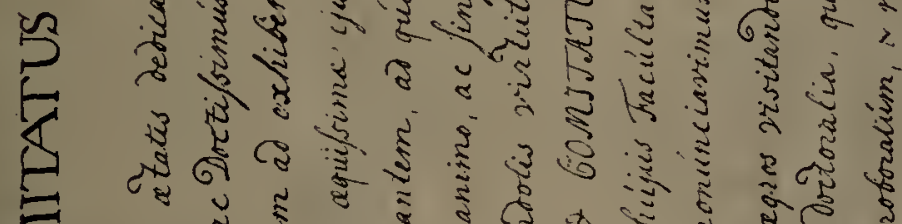

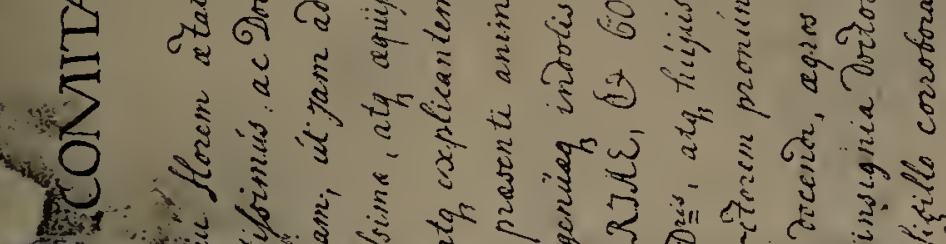

a d yt

๘

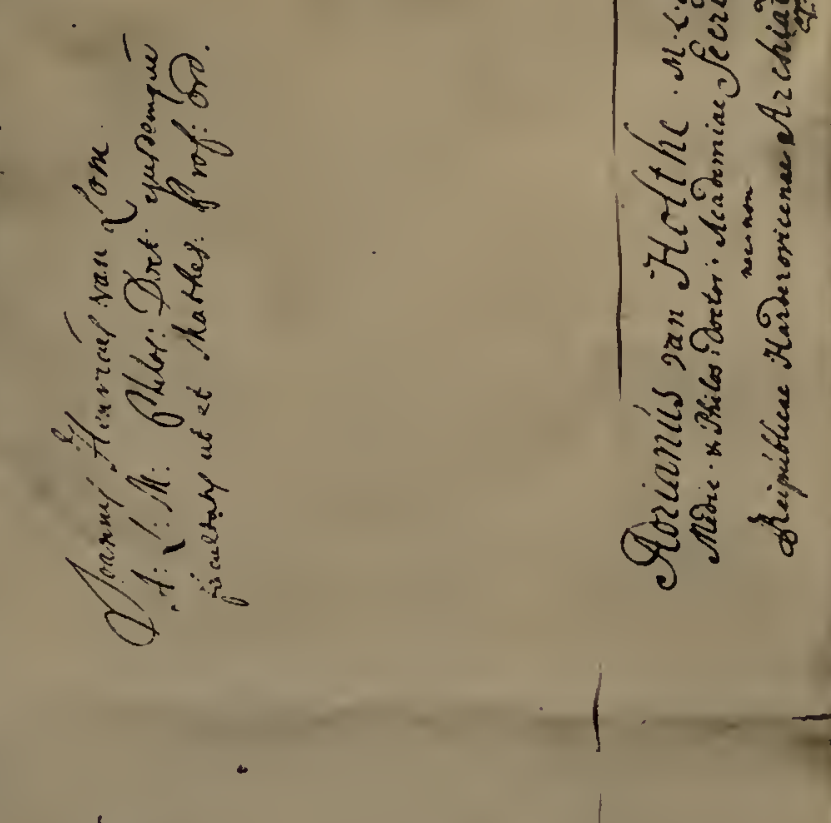

(4) H. W

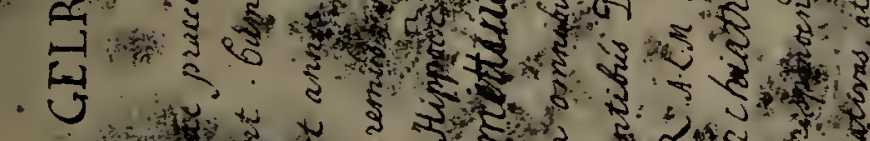

की

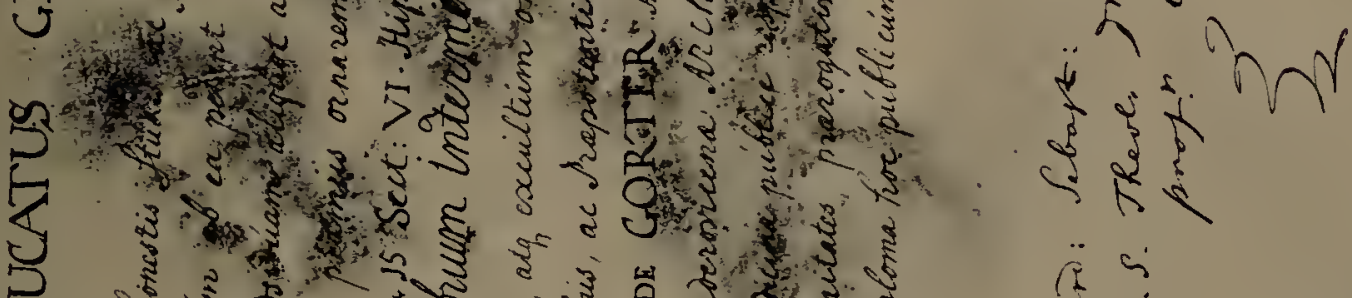

( $\begin{array}{ll}0 \\ 0 \\ 0\end{array}$

(2)

$$
\text { ind }
$$
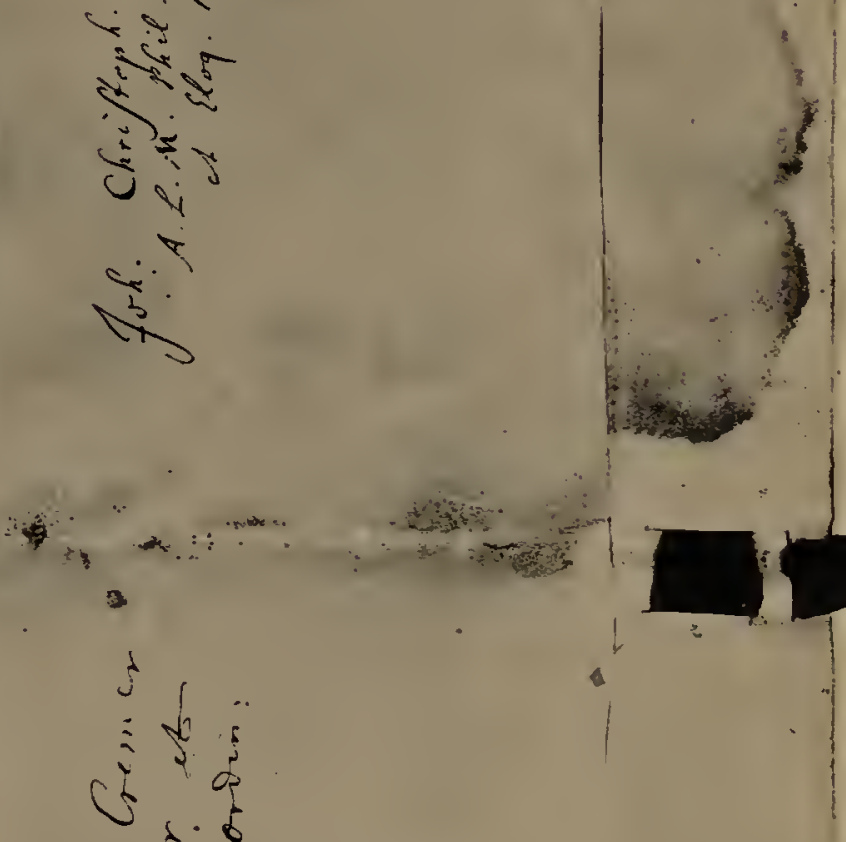

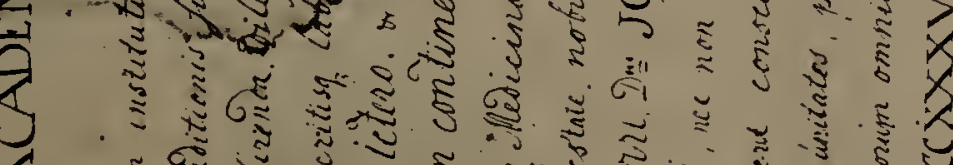

- 3 (I)

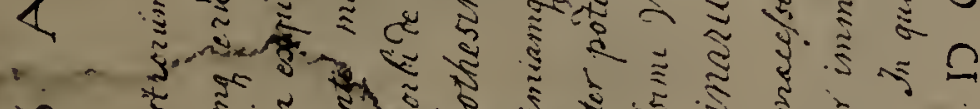

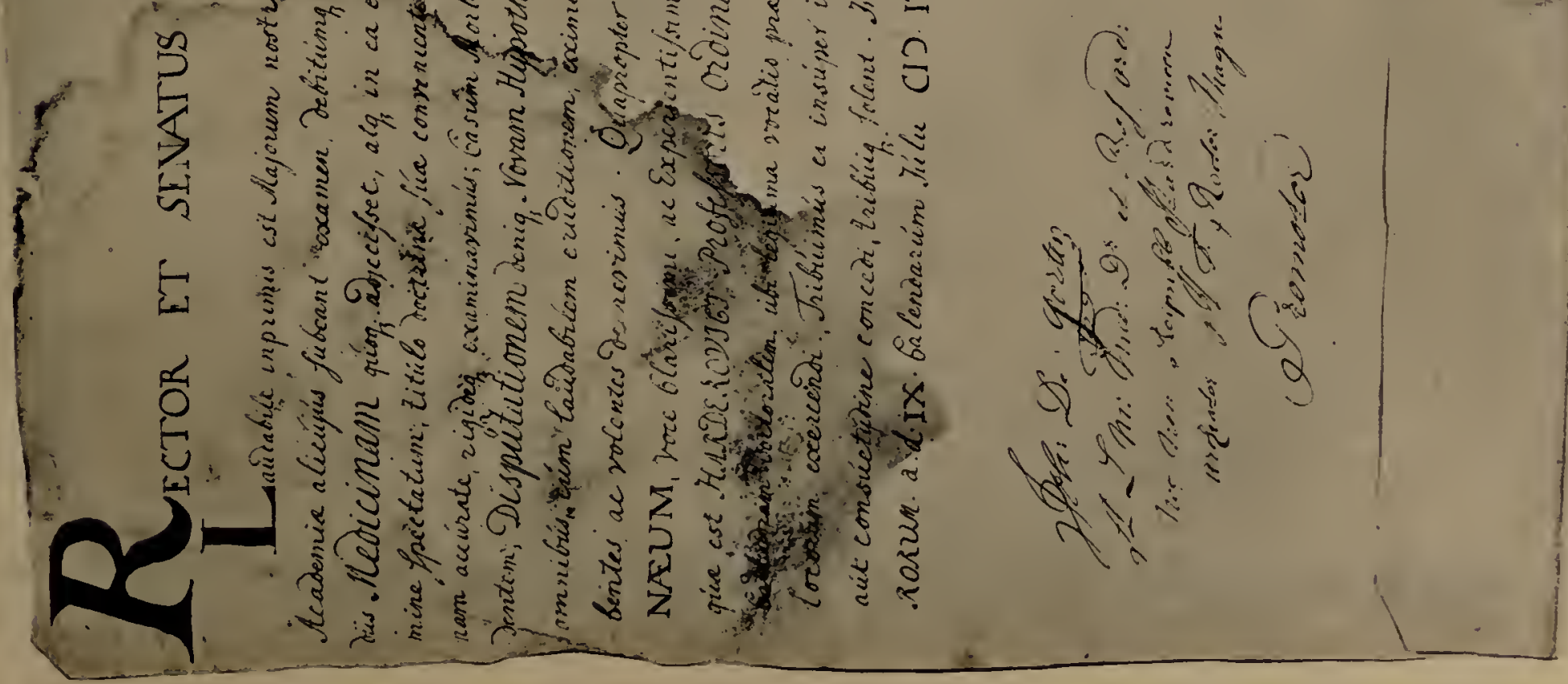







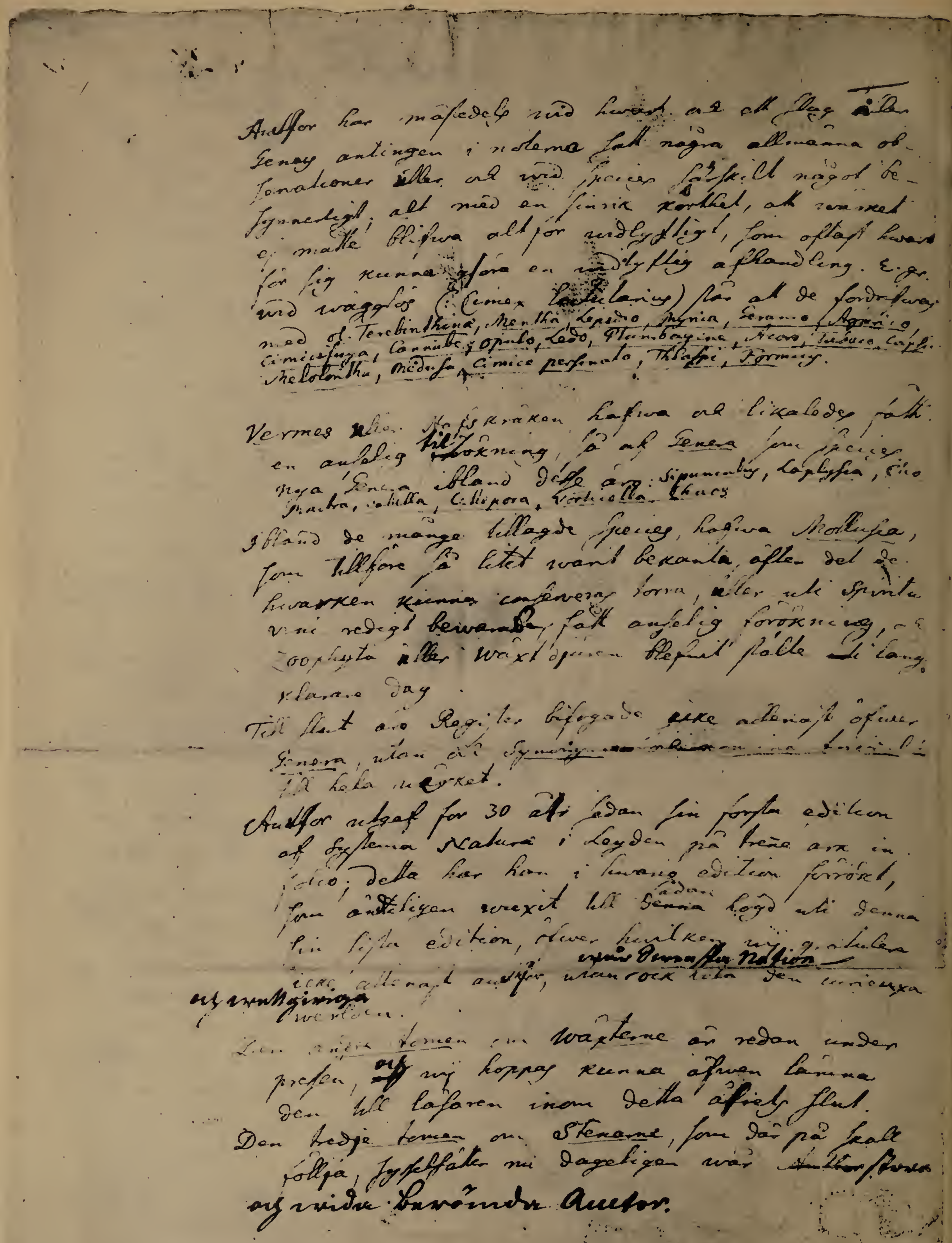




\section{INHALTSVERZEICHNIS.}

Vorwort des Herausgebers . . . . . . . . . . . . . . . . . . . . . . . . . . 4

Ehrets Briefwechsel mit Linnæus . . . . . . . . . . . . . . . . . . . . . . . 7

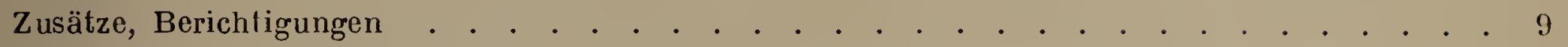

Linné als sein eigener Bibliograph . . . . . . . . . . . . . . . . . . . . . . . 10

Bibliograph. Hilfsquellen . . . . . . . . . . . . . . . . . . . . . . . . . . 10

Autobibliographia Linnæana . . . . . . . . . . . . . . . . . . . . . . . . . . 13

Posthum erschienene Originalschriften und Inedita . . . . . . . . . . . . . . . . . . . 13

Zu Linnés Lebzeiten erschienene Schriften. . . . . . . . . . . . . . . . . . . . . . 16

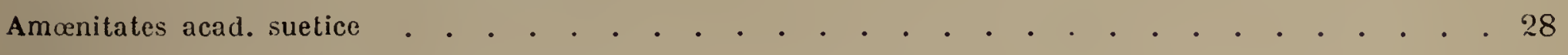

„Opera non proprie aucloris, sed tamen auctori maxime operosa" . . . . . . . . . . . . . 28

„Plagiate" . . . . . . . . . . . . . . . . . . . . . . . . . . . . . . . . . . . 29

„Linnæana methodo scripsere“ . . . . . . . . . . . . . . . . . . . . . . . . . 29

„Genera Linnæana s. artis principia assumere" . . . . . . . . . . . . . . . . . . . . 30

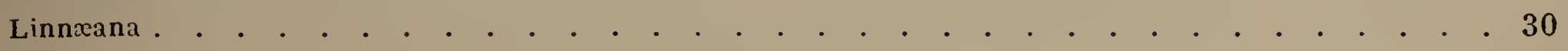

Drei Beilagen in Handschriftdruck

1. Diplom der ,Academia Leop.-Carol. Nat. Curiosorum".

2. Linnés Doktordiplom.

3. Linnés eigenhändige Handschrift zu seinem Autoreferate in Lärda tidniagar N. 767, Num. 34, p. 134-136, (1767). 

Vom selben Verfasser

erschienen im eigenen Verlage folgende Linnéschriften:

Linnés Minnesbok, Stockholm rgrg.

Delineatio Regni animalis sec. C. Linnæi Syst. Nat., Holmix 1919; (vergriffen).

Linnæus im Auslande, Stockholm rgrg.

Linnæus Reise ins Ausland, 1919; (vergriffen).

Linnæus Randaufzeichnungen zu M. S.

Merianins Eruc. ortus, I920; (vergriffen).

Linnæi Adonis Stenbrohultensis, 1920.

(Verlag Björck \& Börjesson, Stockholm.) 


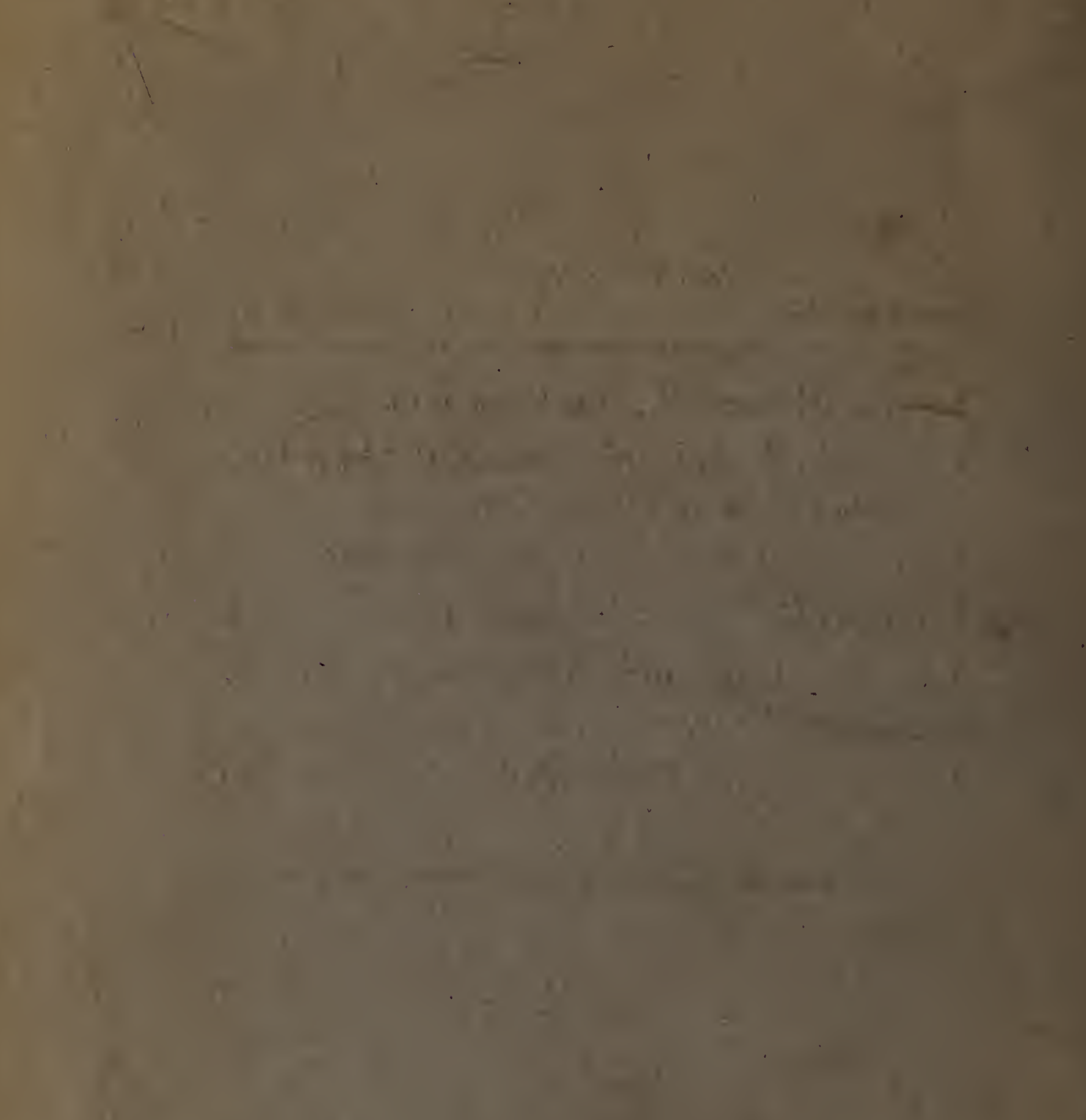

Umschlag von H. Laupp jr in Tabingen. 


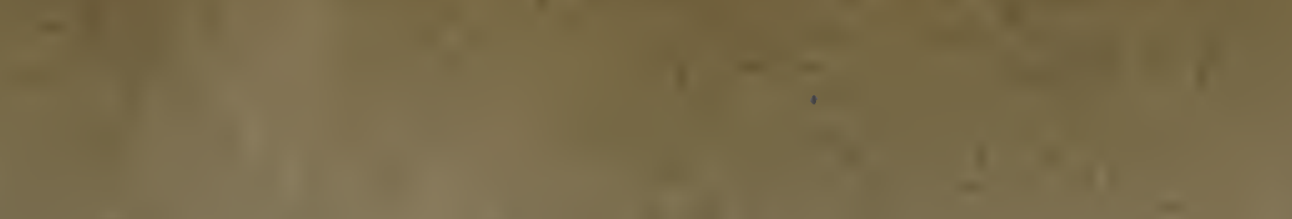

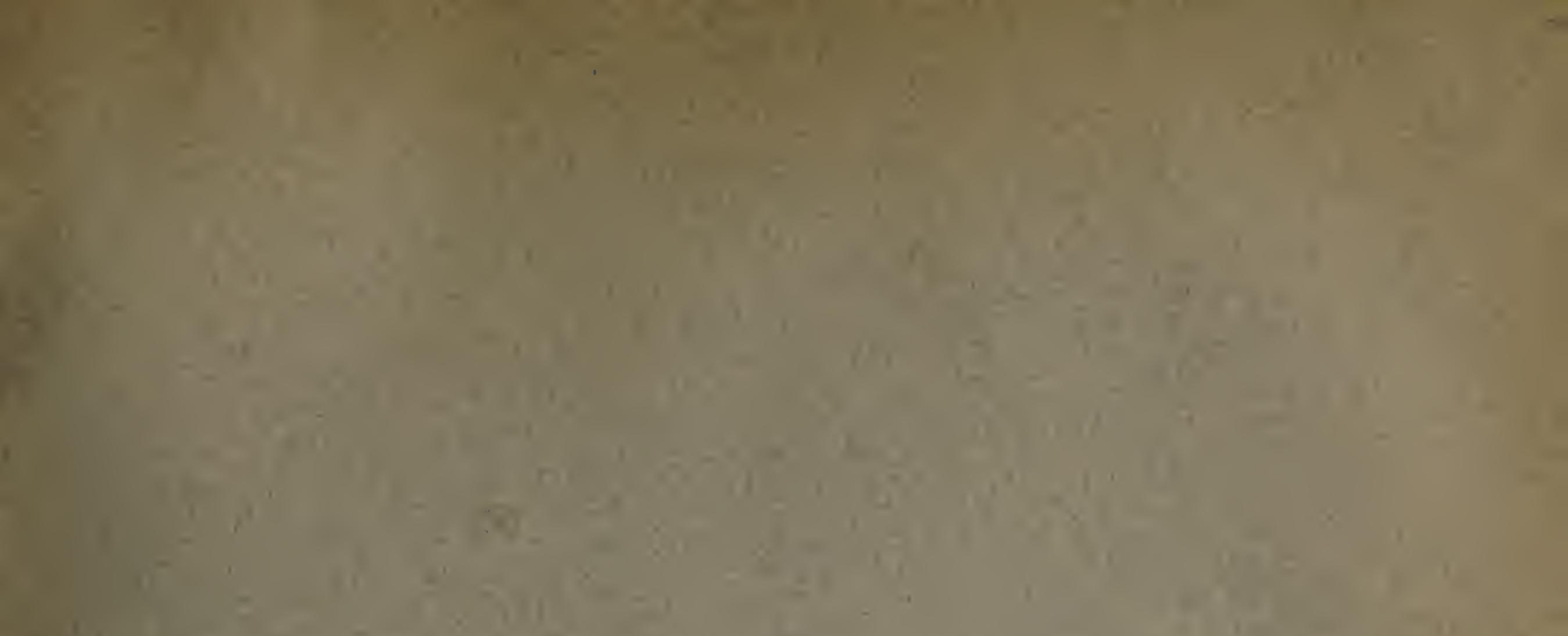

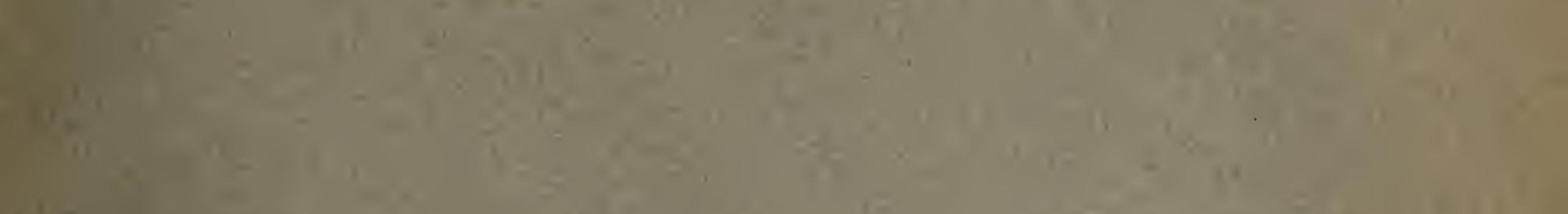

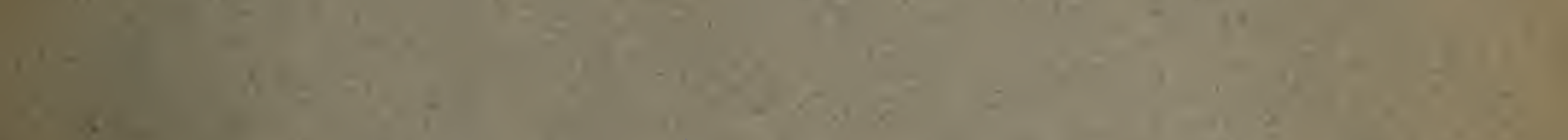

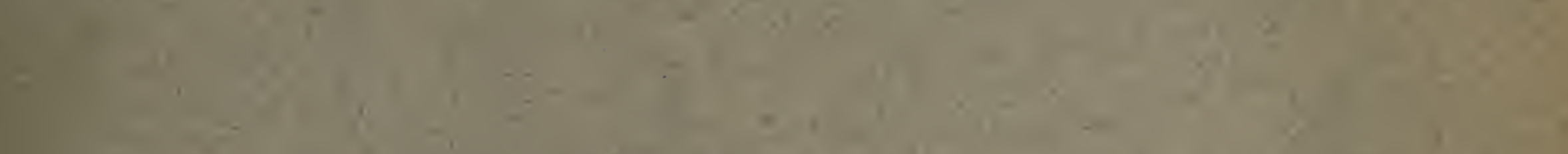

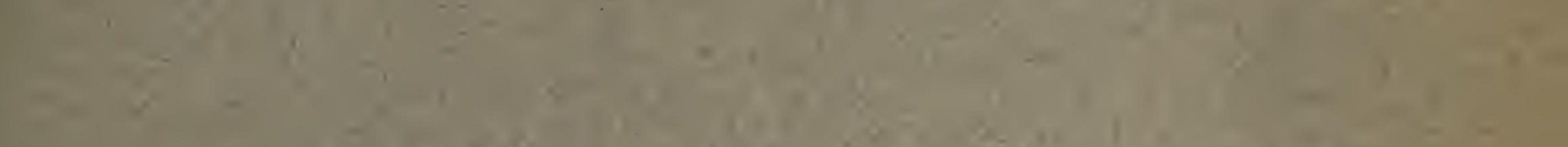

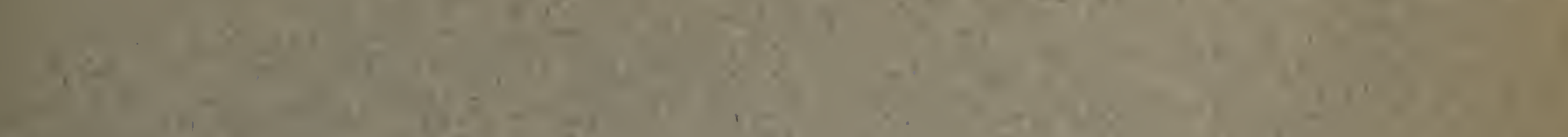

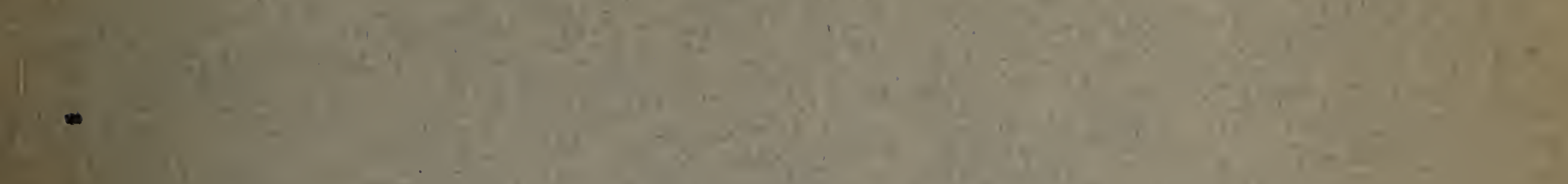

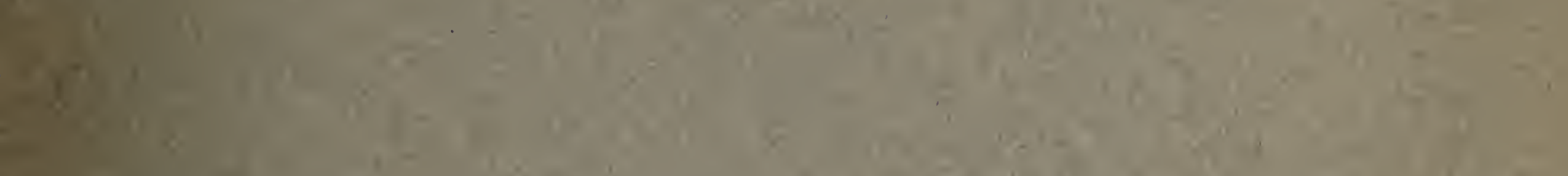

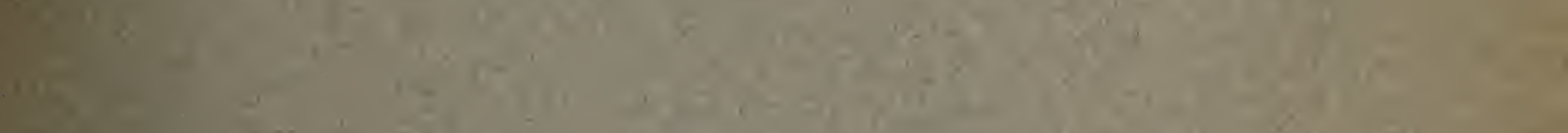

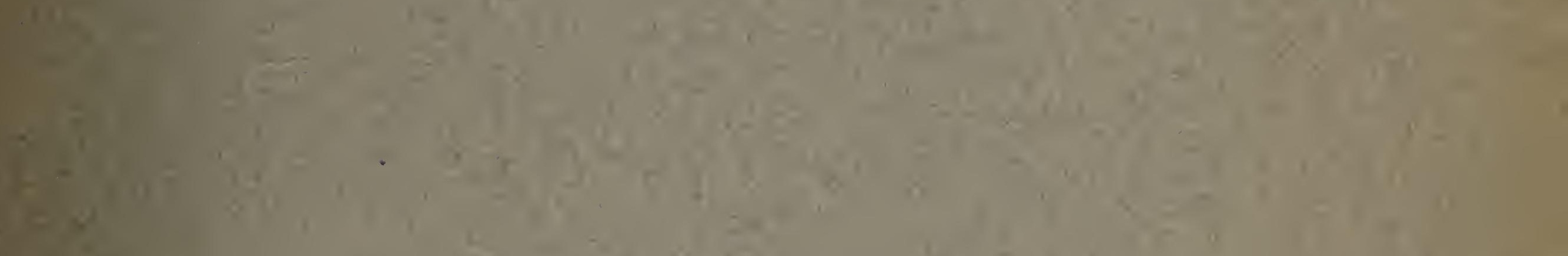

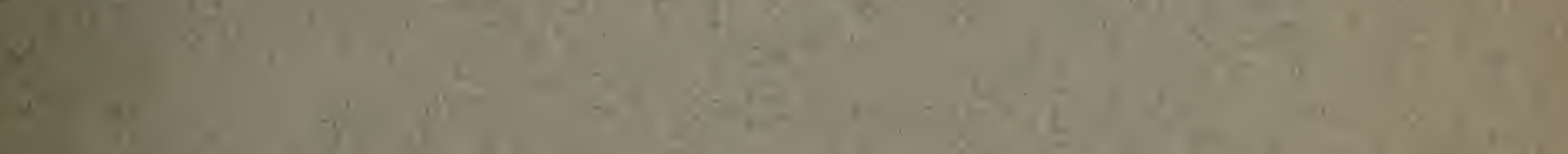

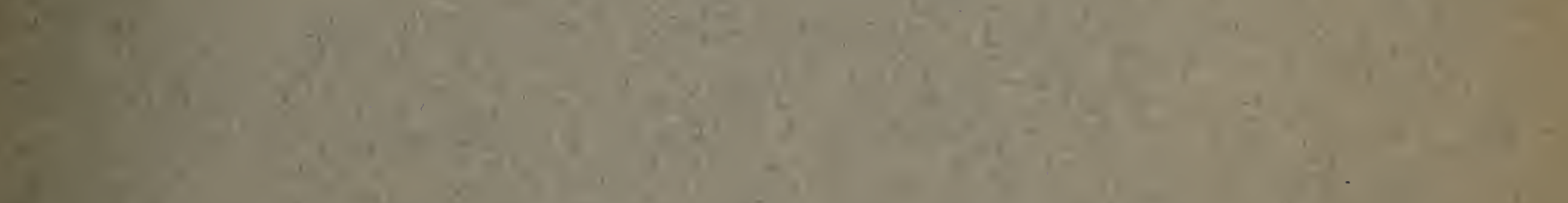

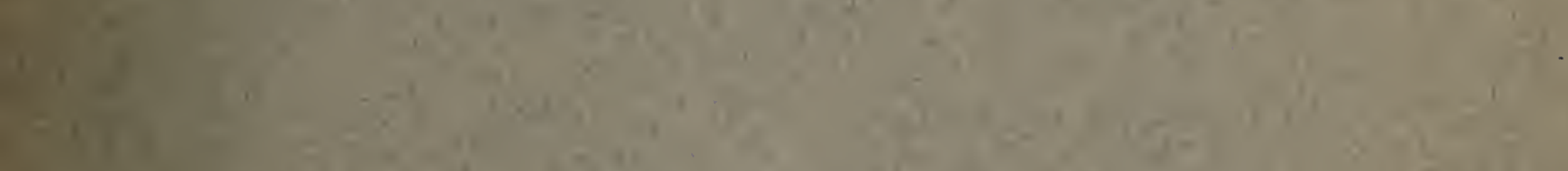

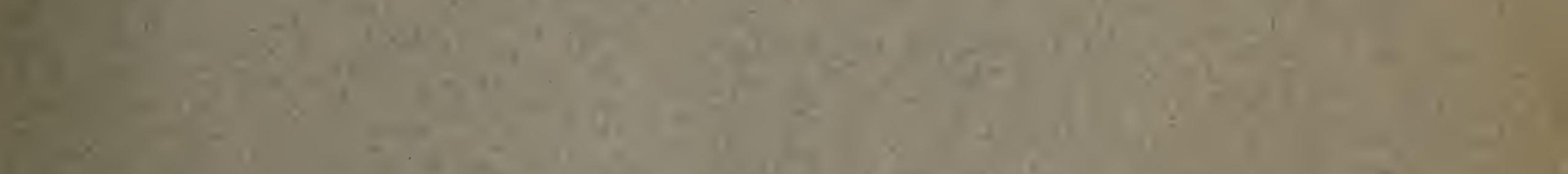

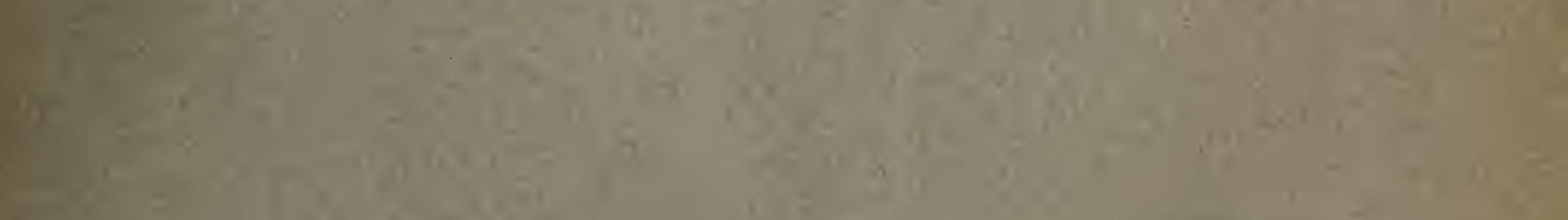

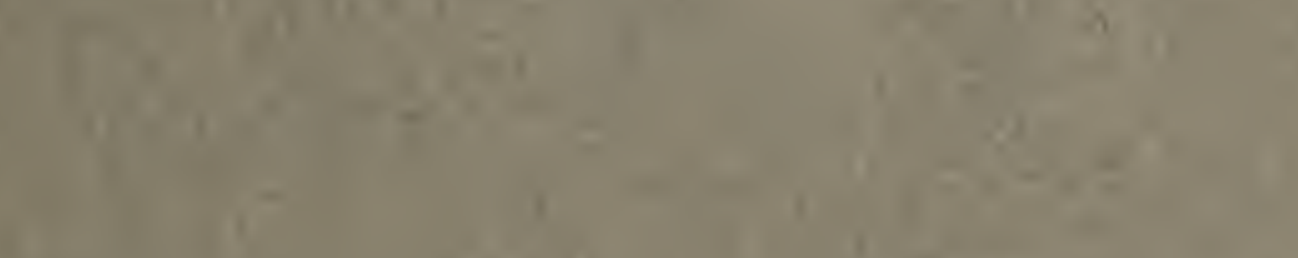

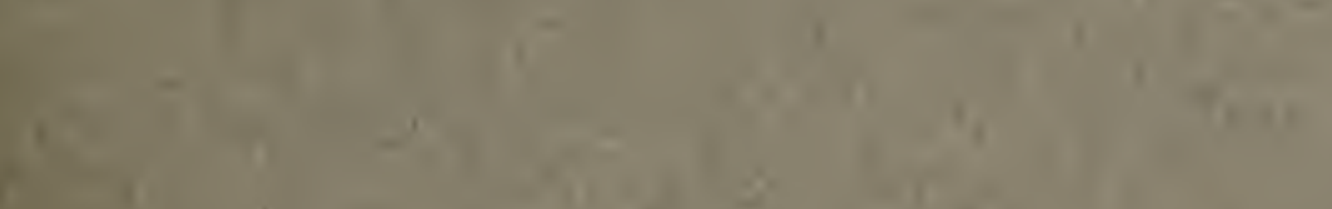

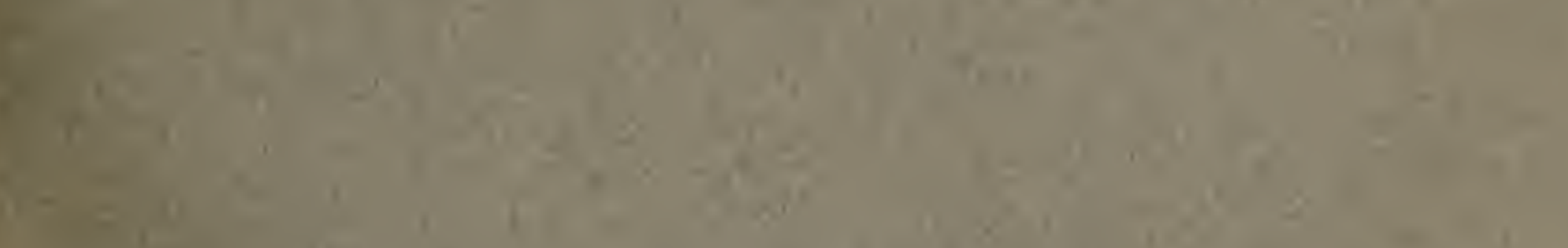

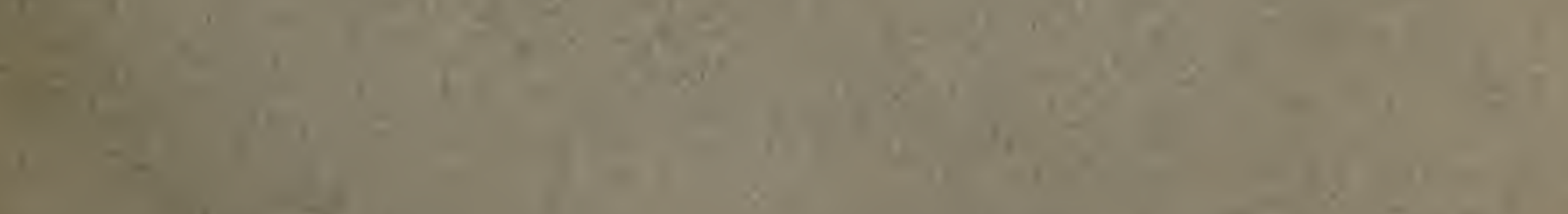

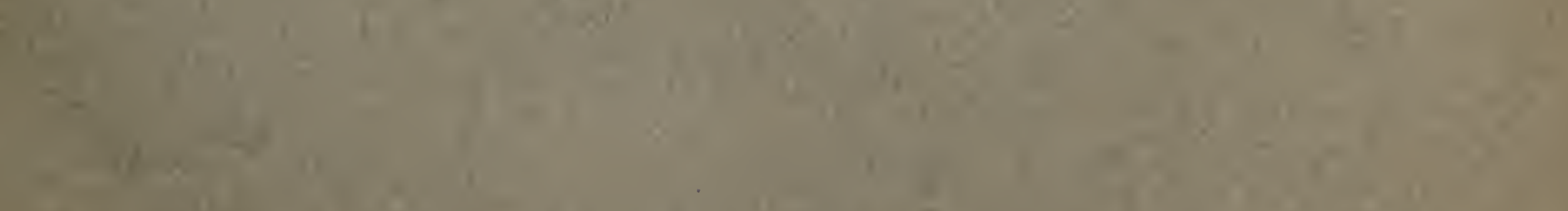

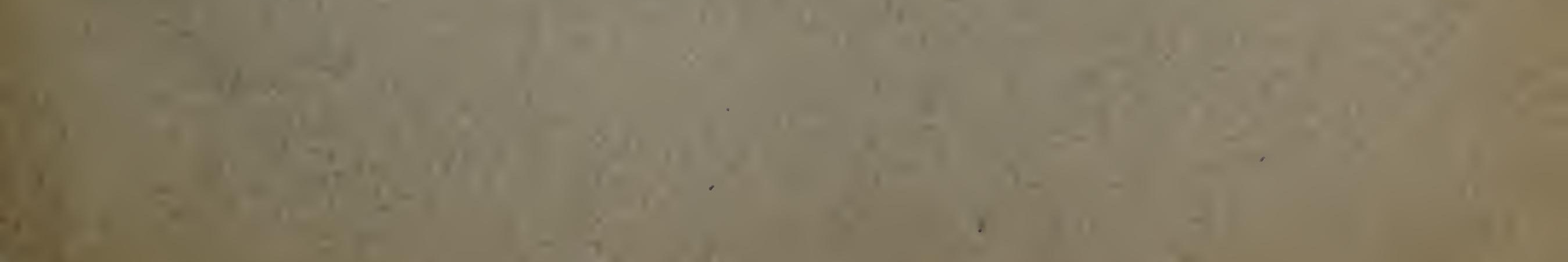
45 



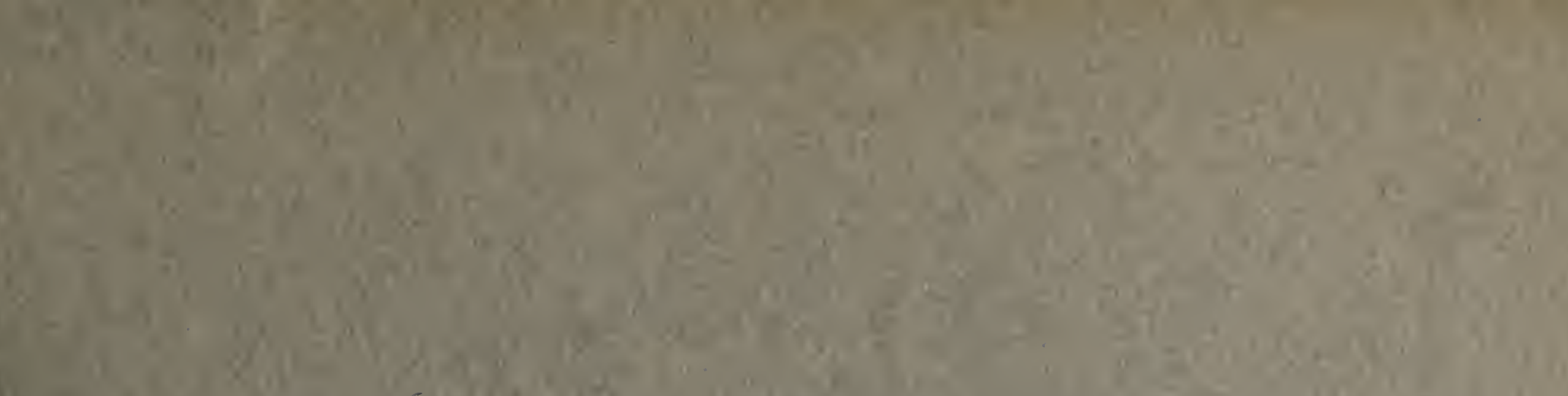

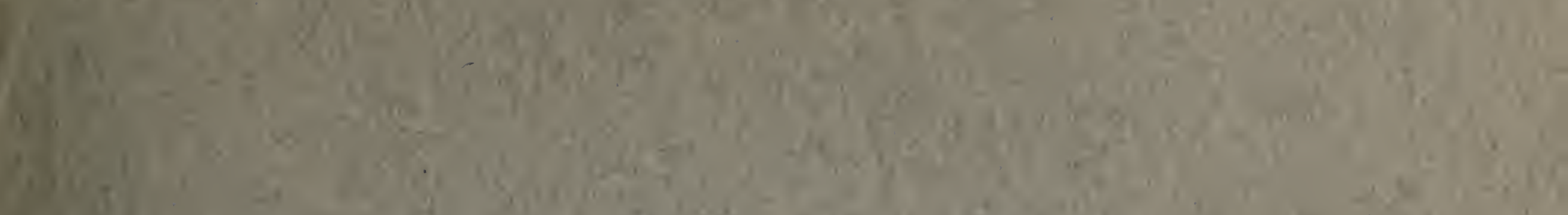

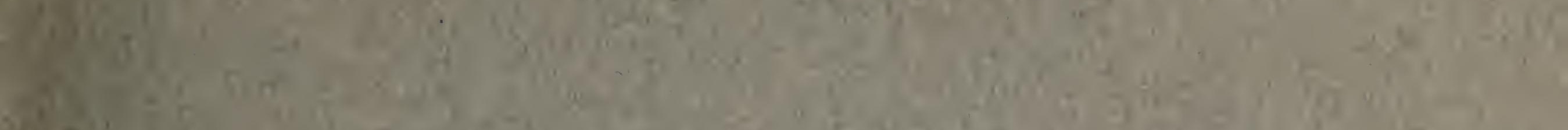

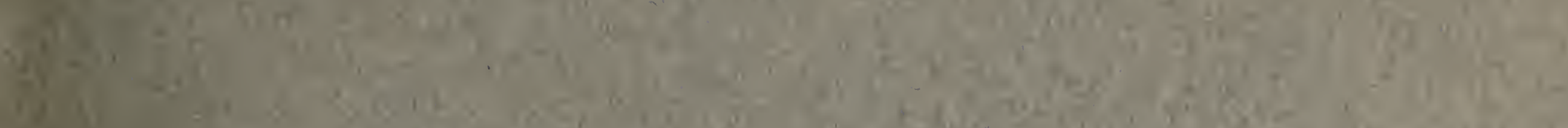

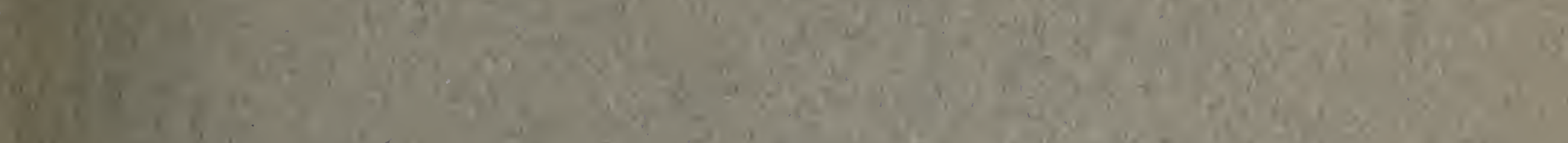

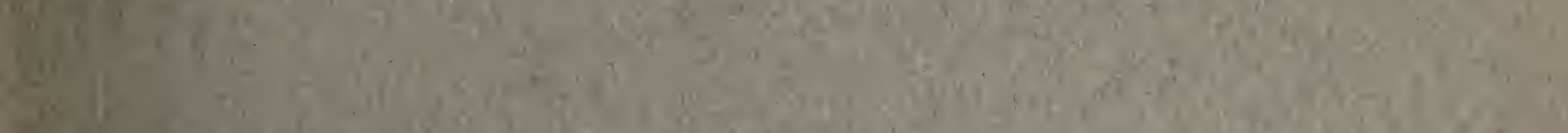

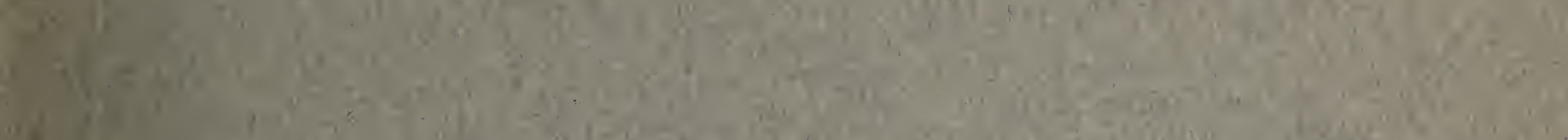

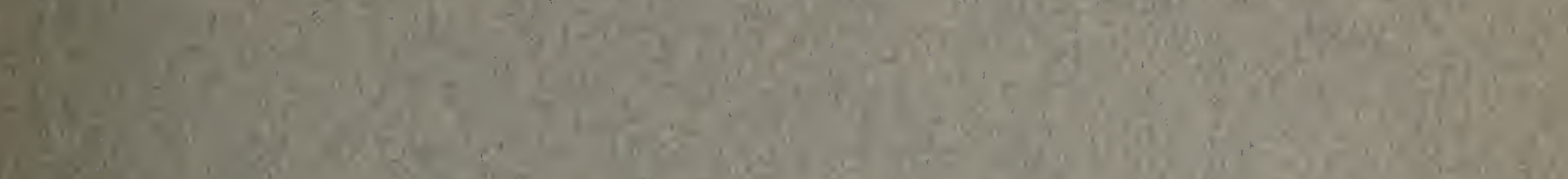

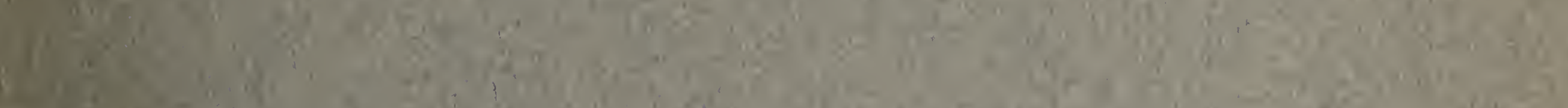

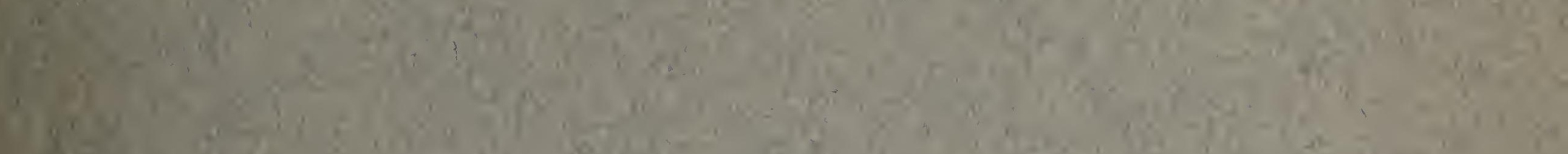

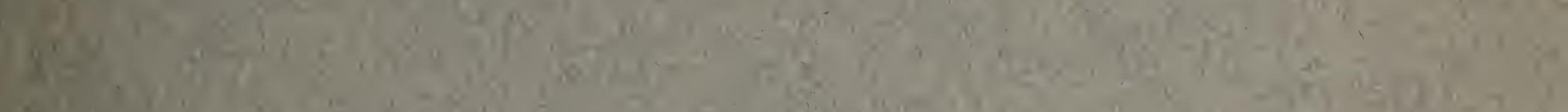

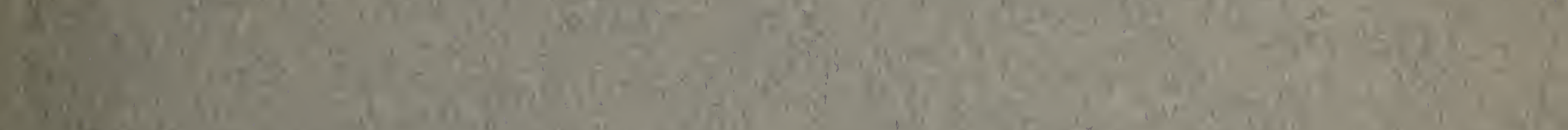

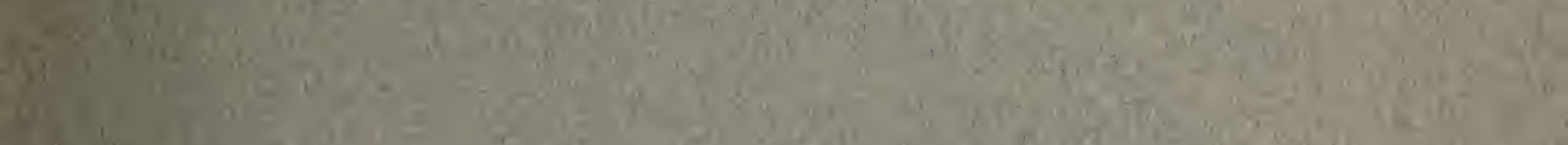

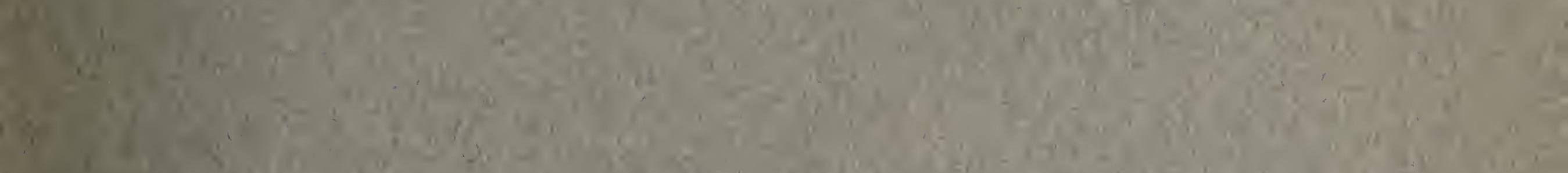

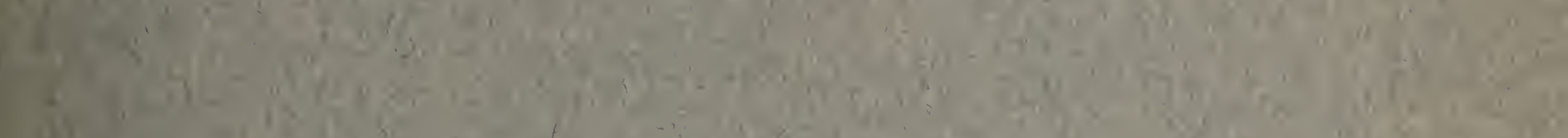
at, is

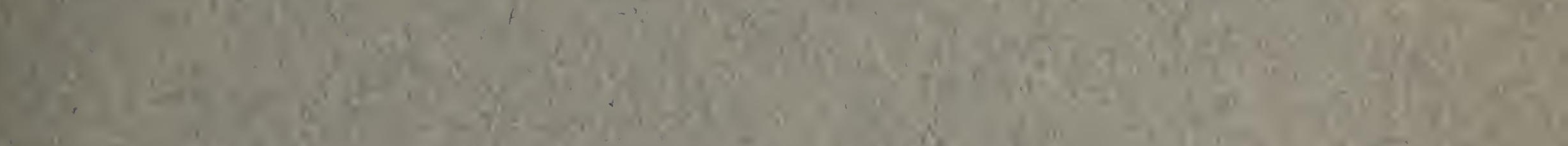

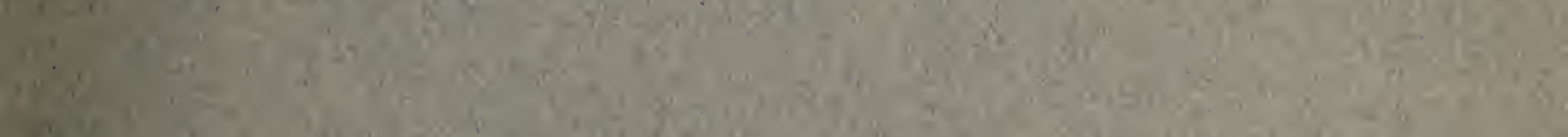

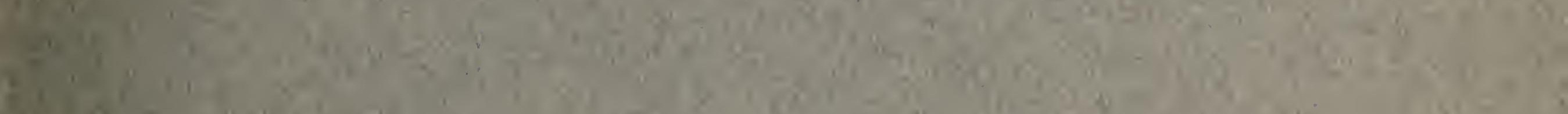

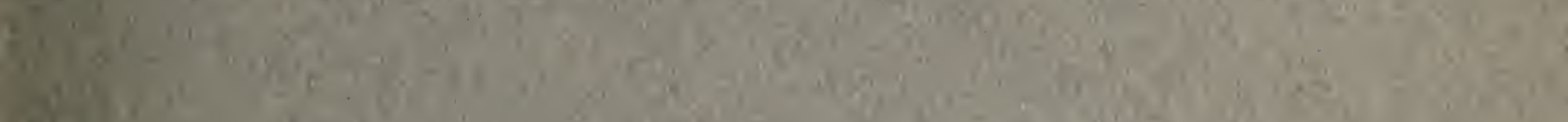
Y.

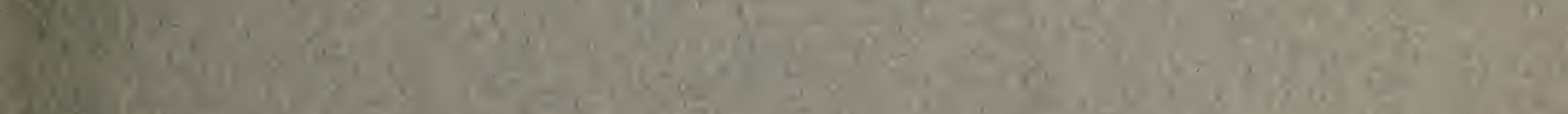
(A)

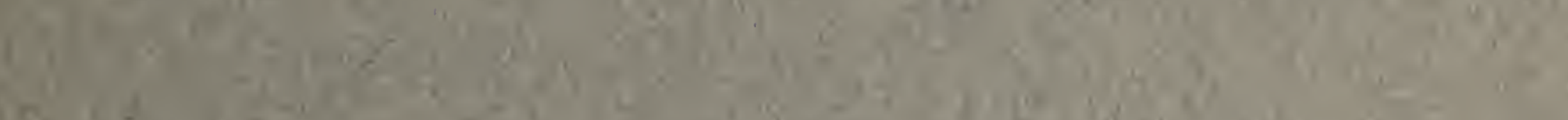

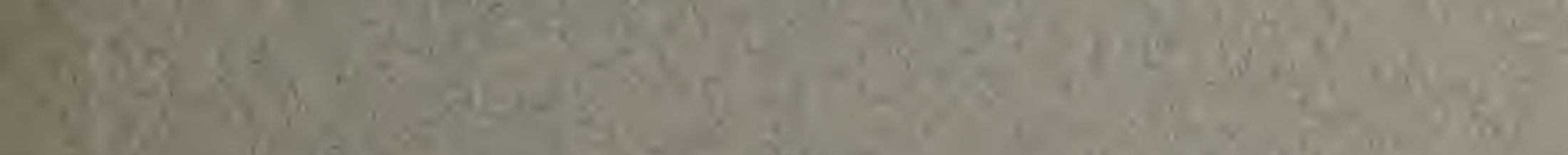

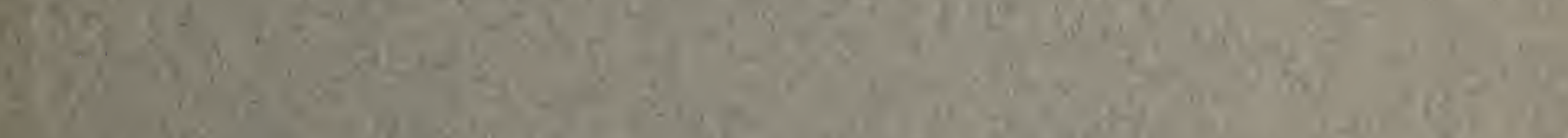

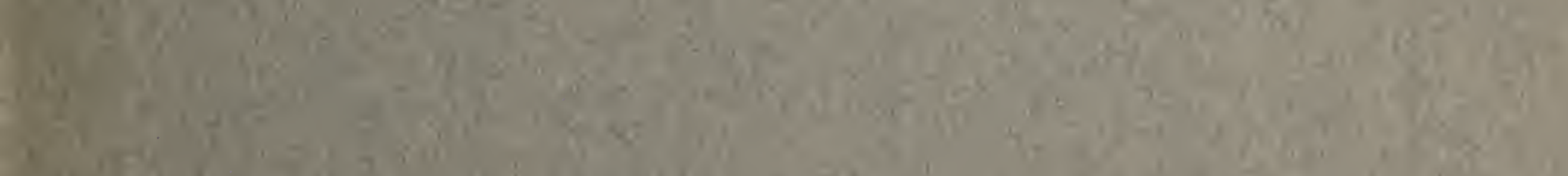

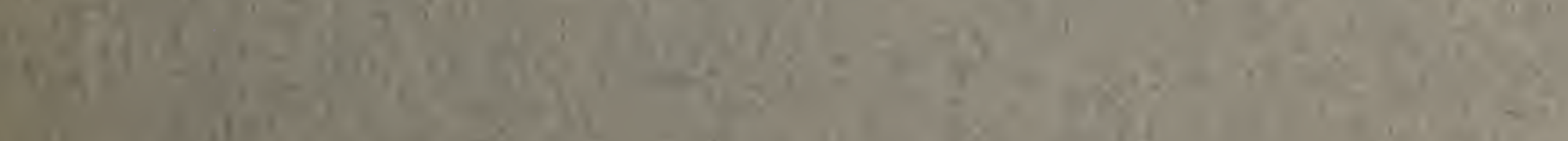

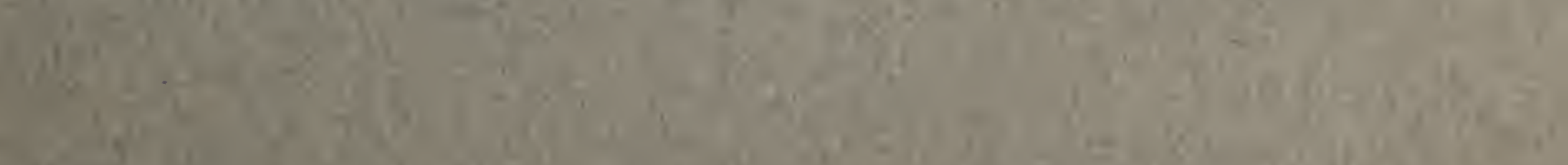




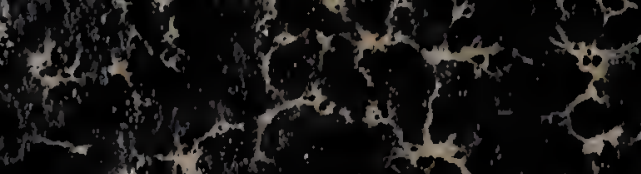

-

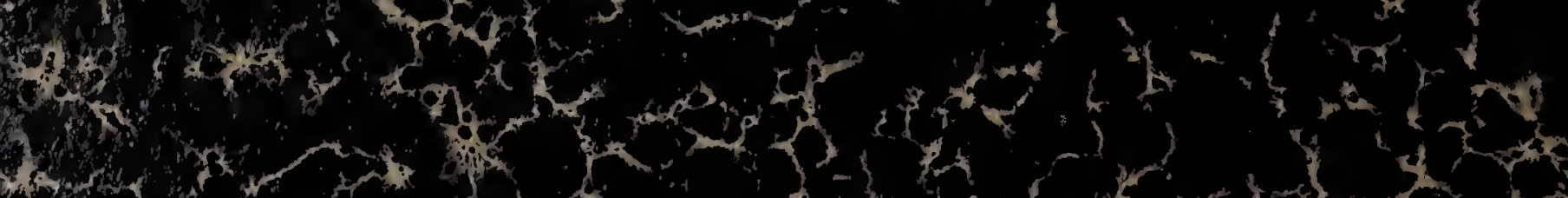

6.

(1)

$$
\text { a }
$$

a

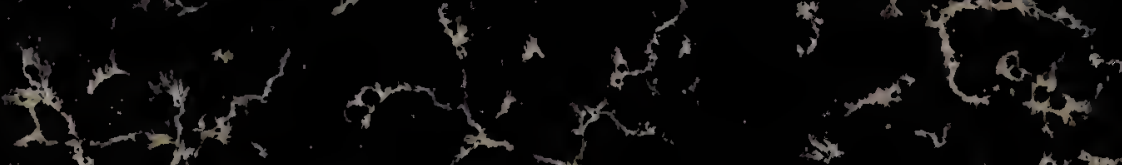

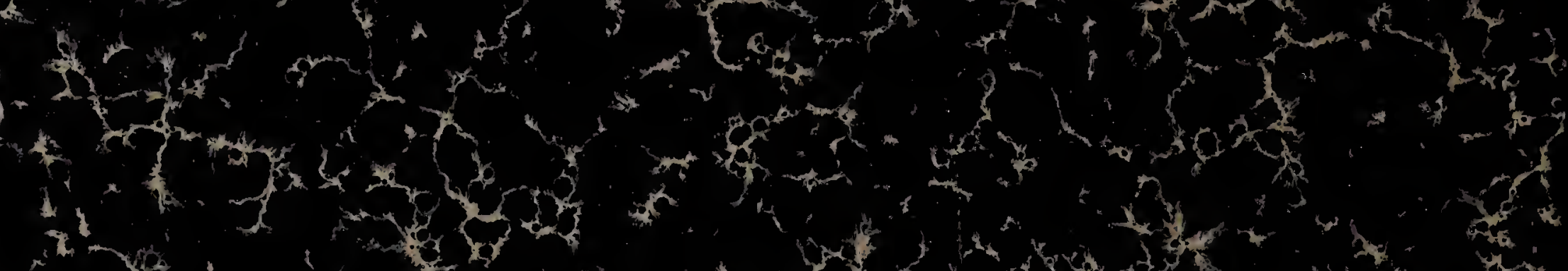

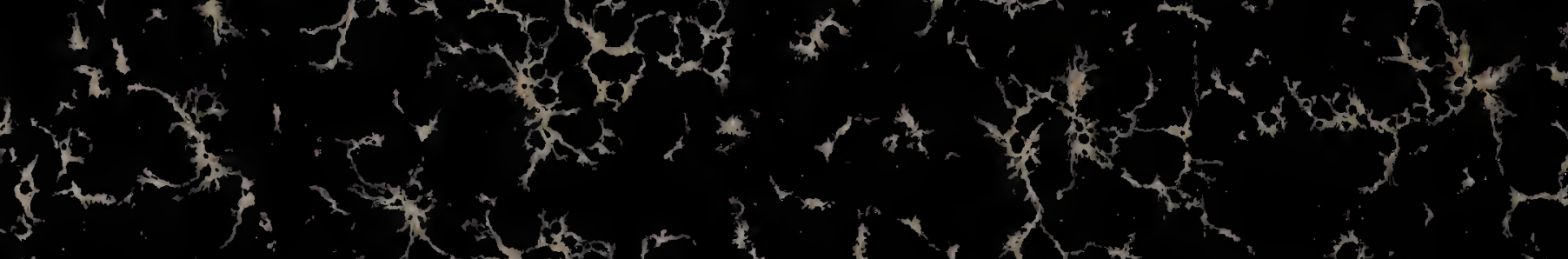

$$
\text { (1) }
$$

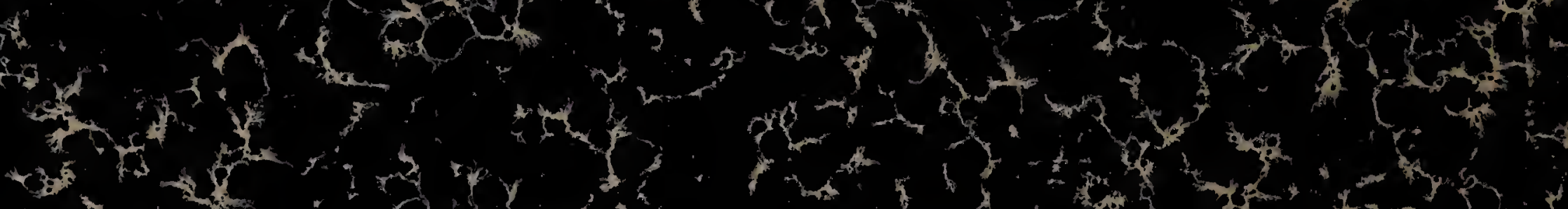

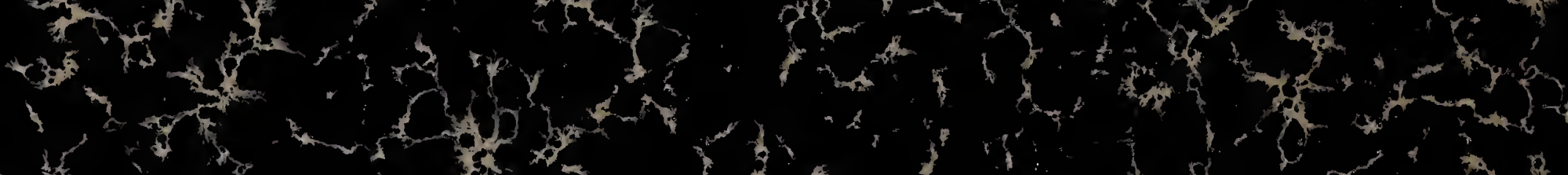

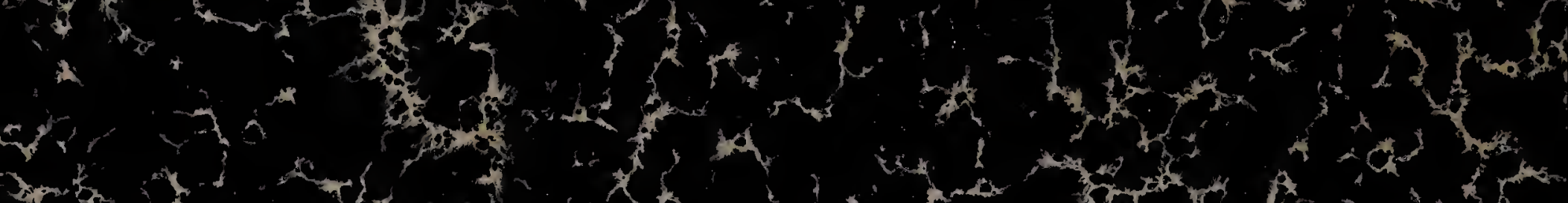

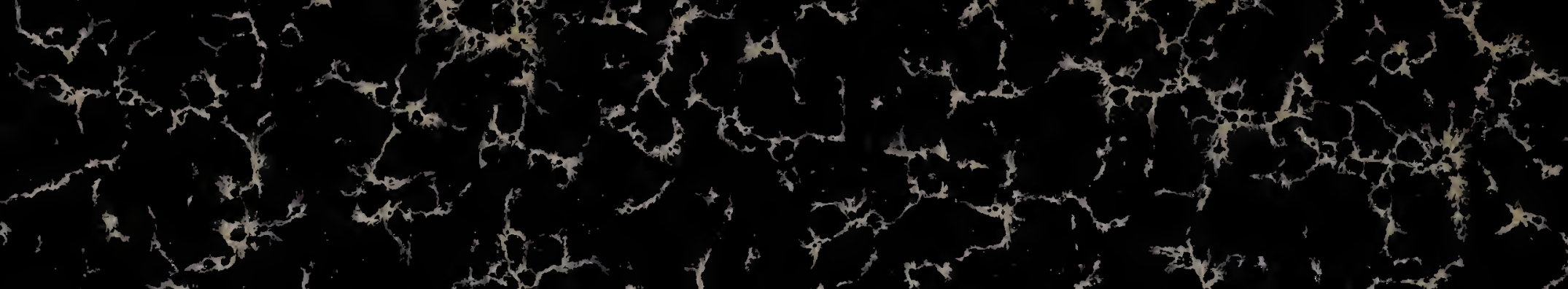

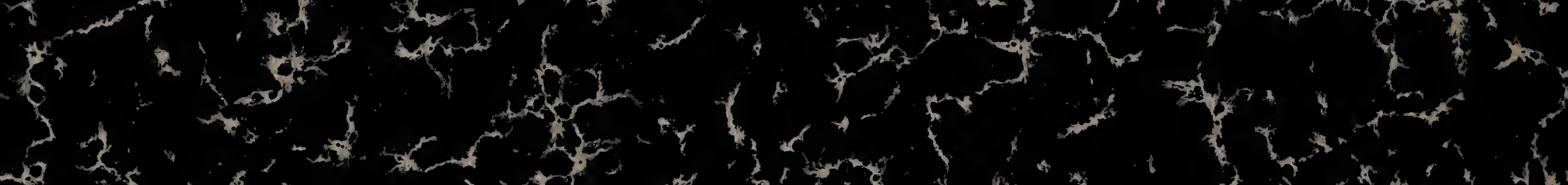
23 2. tow

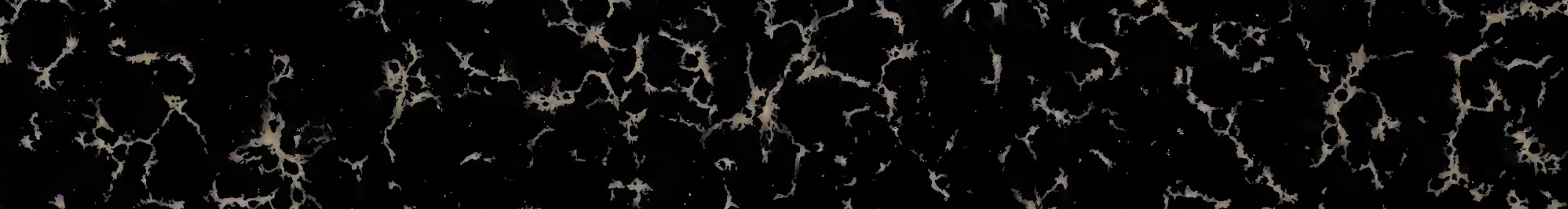

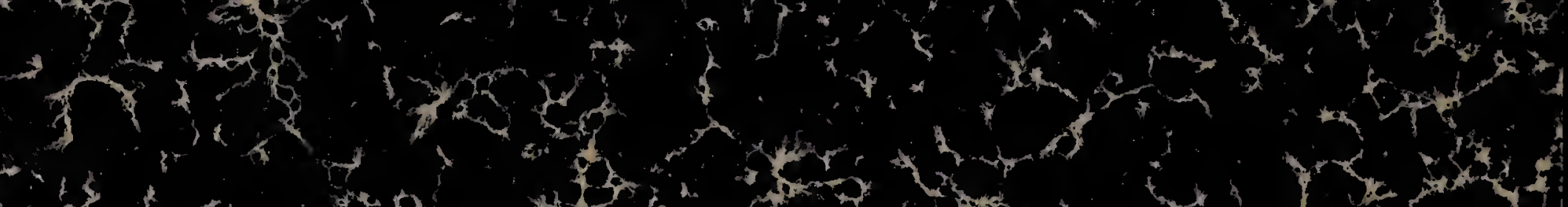
(x) 1 1.

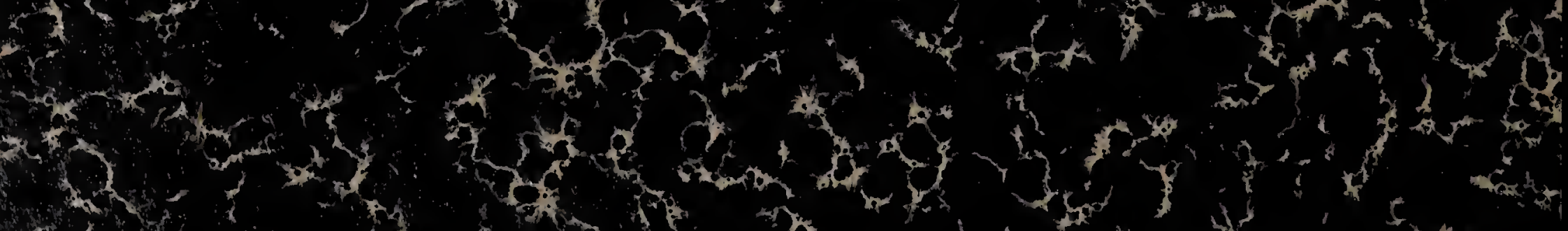

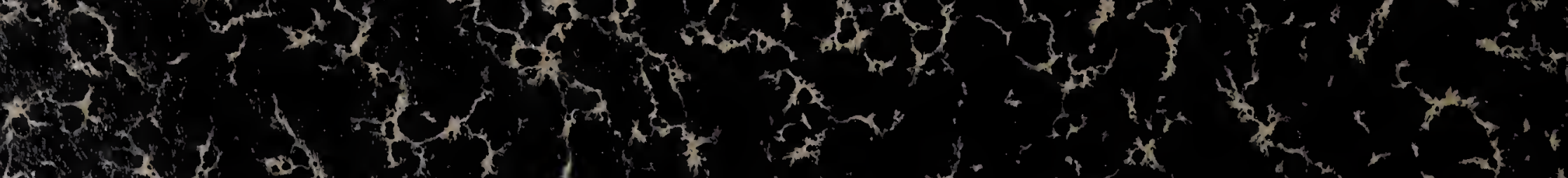

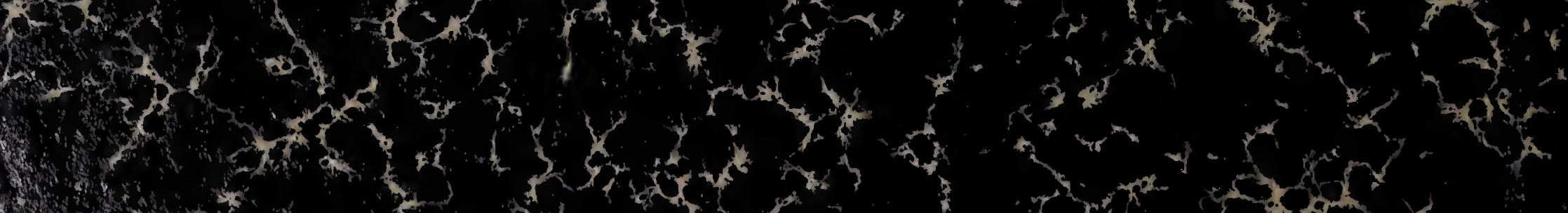

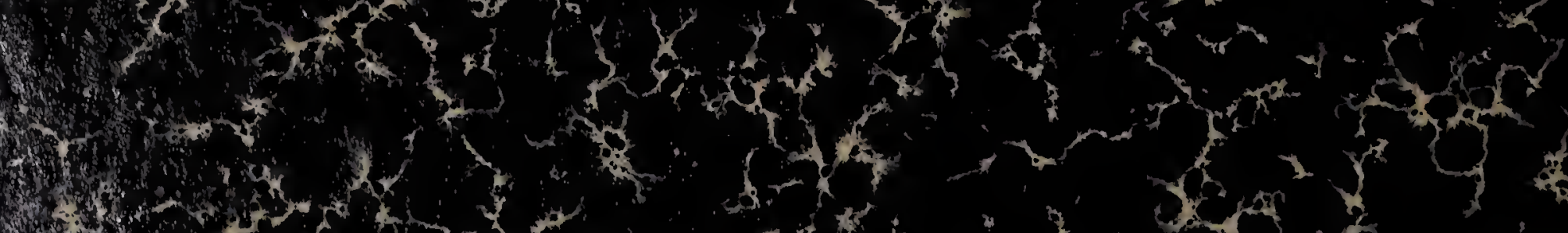

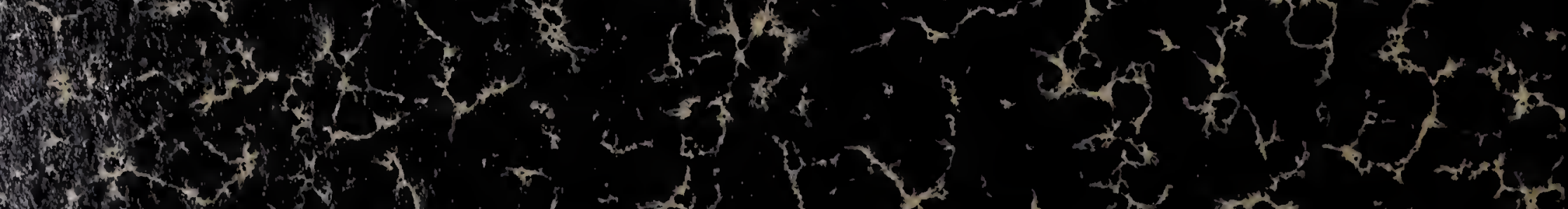

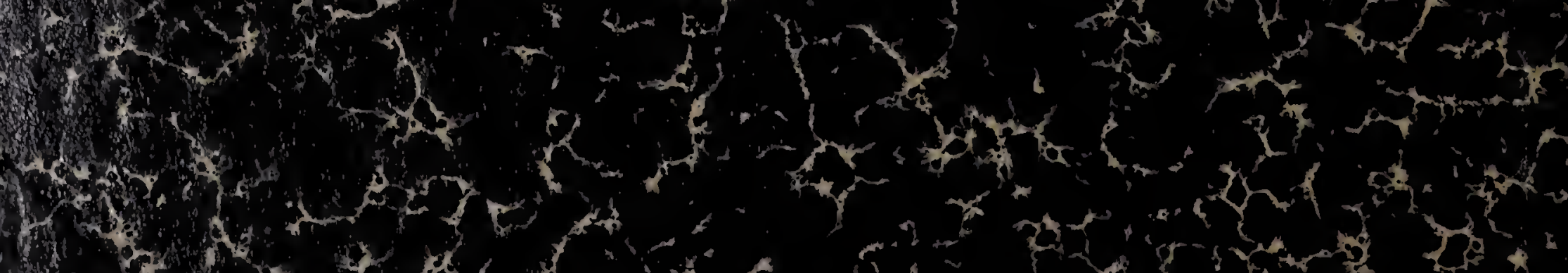

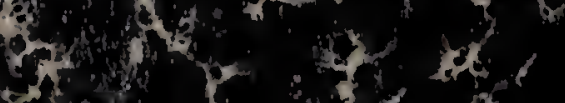

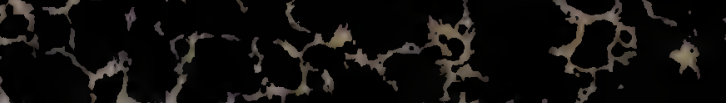

